University of Louisville

ThinkIR: The University of Louisville's Institutional Repository

Electronic Theses and Dissertations

$12-2013$

\title{
A microreactor approach for chemoselective capture and analysis of carbonyl compounds in air and exhaled breath.
}

Mingxiao Li

University of Louisville

Follow this and additional works at: https://ir.library.louisville.edu/etd

\section{Recommended Citation}

$\mathrm{Li}$, Mingxiao, "A microreactor approach for chemoselective capture and analysis of carbonyl compounds in air and exhaled breath." (2013). Electronic Theses and Dissertations. Paper 826.

https://doi.org/10.18297/etd/826

This Doctoral Dissertation is brought to you for free and open access by ThinkIR: The University of Louisville's Institutional Repository. It has been accepted for inclusion in Electronic Theses and Dissertations by an authorized administrator of ThinkIR: The University of Louisville's Institutional Repository. This title appears here courtesy of the author, who has retained all other copyrights. For more information, please contact thinkir@louisville.edu. 


\title{
A MICROREACTOR APPROACH FOR CHEMOSELECTIVE CAPTURE AND ANALYSIS OF CARBONYL COMPOUNDS IN AIR AND EXHALED BREATH
}

\author{
By \\ Mingxiao Li \\ B.E., Tsinghua University, 2008

\begin{abstract}
A Dissertation
Submitted to the Faculty of the J. B. Speed School of Engineering

University of Louisville

in Partial Fulfillment of the Requirements

for the Degree of

Doctor of Philosophy

Department of Chemical Engineering

University of Louisville

Louisville, KY
\end{abstract}

December 2013 



\title{
A MICROREACTOR APPROACH FOR CHEMOSELECTIVE CAPTURE AND ANALYSIS OF CARBONYL COMPOUNDS IN AIR AND EXHALED BREATH
}

\author{
By \\ Mingxiao Li \\ B.E., Tsinghua University, 2008
}

A Dissertation Approved On

November 13, 2013

by the Following Dissertation Committee:

Xiao-An Fu, Ph. D., Dissertation Director

Michael H. Nantz, Ph. D.

James C. Watters, Ph. D.

Gerold A. Willing, Ph. D. 


\section{ACKNOWLEDGMENTS}

I would like to express my deepest gratitude to my advisor Prof. Xiao-An Fu for his guidance, support, and encouragement during the course of my $\mathrm{PhD}$. Both the atmosphere in his group and the wide range of research topics have provided not only an ideal but also inspiring environment for my work. I also would like to thank him for giving me the chance to work on interesting projects.

I would like to thank all my dissertation committee members Prof. Michael $\mathrm{H}$. Nantz, Prof. James C. Watters, Prof. Gerold A.Willing for all the fruitful and valuable discussions we had regarding this research work. Special thanks to Dr. Michael Bousamra at Jewish Hospital, St. Mary's Healthcare and James Graham Brown Cancer Center for recruiting patients to provide exhaled breath samples and his clinical guidance.

I would like to thank Ralph Knipp and Souvik Biswas for supply of synthesized high-purity organic compounds throughout my project.

I would like to thank Prof. Richard M. Higashi for his help in the initial stage of the project and Dr. Pawel Lorkiewicz at the Center for Regulatory and Environmental Analytical Metabolomics (CREAM) for the help he offered. I would like to thank Prof. Guy Brock and his student Dake Yang for the help in statistical data analysis. 
I would also like to thank all the members and staff Dr. Julia Aebersold, Mr. Don Yeager, Mr. Michael Martin, and Mr. Curtis McKenna of the Micro/Nano Technology Center at the University of Louisville for their knowledgeable experience in microfabrication and tremendous source of support.

Finally, I would like to thank my parents for their encouragement and support, without which this dissertation and research would not have been possible. 


\section{ABSTRACT \\ A MICROREACTOR APPROACH FOR CHEMOSELECTIVE CAPTURE AND ANALYSIS OF CARBONYL COMPOUNDS IN AIR AND EXHALED BREATH}

\section{Mingxiao Li}

\section{November 13, 2013}

Detection of volatile organic compounds (VOCs) at trace level (parts per billion volume (ppbv) to parts per trillion (pptv)) has become an important research area because of demanding applications in homeland security, environmental monitoring, and noninvasive diagnosis of diseases. The analysis of trace VOCs challenges existing analytical instruments because their concentrations are beyond current instrument limits of detection.

In this dissertation, we have investigated an innovative microreactor that is suitable for quantitative analysis of volatile carbonyl compounds in ambient air as well as in human exhaled breath. The approach is based on microreactor chips fabricated from four inch silicon wafers. The chips have thousands of micropillars in the microfluidic channels for uniformly distributing gaseous samples flowing through the microreactors. The surfaces of the micropillars are functionalized with a quaternary ammonium aminooxy salt 2-(aminooxy)-N,N,N-trimethylethanammonium (ATM) iodide for trapping trace ketones and aldehydes by means of oximation reactions. 
ATM adducts and unreacted ATM are eluted from the microreactor with less than $40 \mu \mathrm{L}$ of methanol and directly analyzed by nanoelectrospray Fourier transform ion cyclotron resonance (FTICR) mass spectrometry (MS). Capture efficiencies of above $98 \%$ have been achieved for ketones and aldehydes. Carbonyl compounds at levels of 1 ppbv have been detected using the microreactor for capture.

Ambient air samples from indoor and outdoor areas were collected using Tedlar bags, and analyzed using the microreactor and FTICR-MS. The analysis of air samples provides the reference for analysis of exhaled breath samples.

Finally, exhaled breath samples from patients with untreated lung cancer (LC) patients, patients with benign pulmonary nodules and healthy volunteers (smokers and non-smokers) were collected and analyzed using the same method. The FTICR-MS spectra showed that the exhaled breath samples from LC patients have a unique pattern of VOCs, in comparison with healthy controls and patients with benign pulmonary nodules. 2-Butanone, hydroxy-acetaldehyde, 3-hydroxy-2-butanone, and 4-hydroxy-hexenal (4HHE) were found to have significant higher concentrations for LC patients. A simple diagnosis method based on four elevated VOCs could easily discriminate lung cancer patients from healthy controls and patients with pulmonary nodules with $90.6 \%$ diagnosis sensitivity and $81.3 \%$ specificity. 


\section{TABLE OF CONTENTS}

PAGE

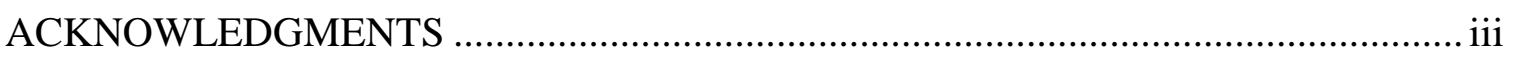

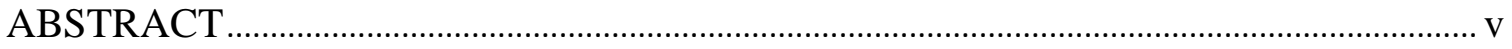

LIST OF TABLES ………………………………………………………………………......

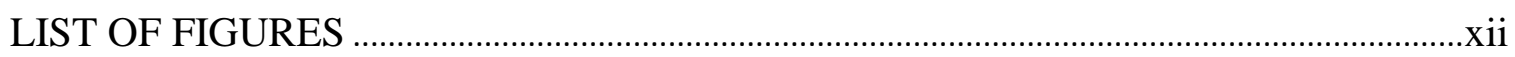

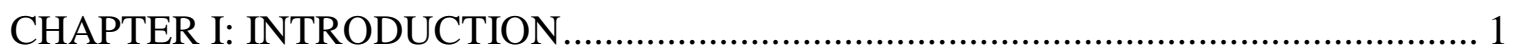

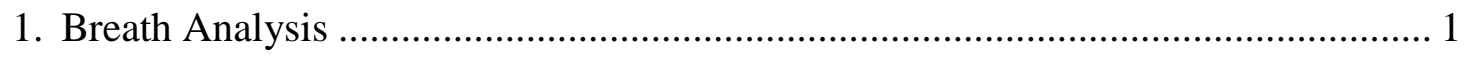

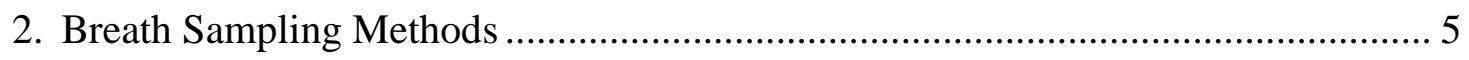

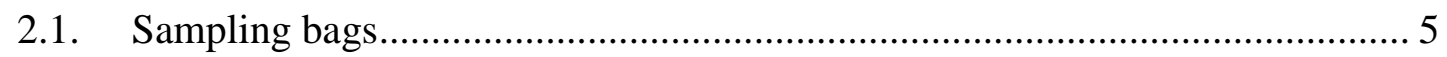

2.2. Exhaled breath condensate (EBC) ……………......................................... 5

2.3. Chemical sampling methods................................................................. 8

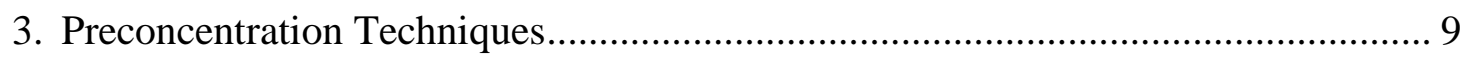

3.1. Traditional physical adsorption .............................................................. 10

3.2. Solid phase microextraction (SPME) ....................................................... 12

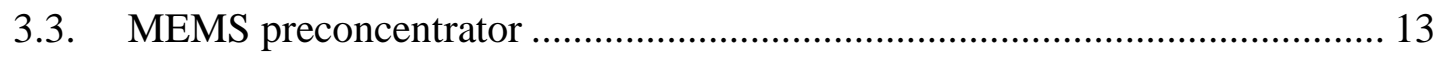

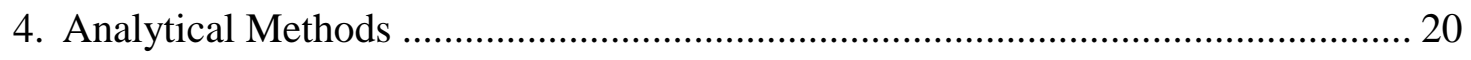

4.1. Gas chromatography combined with mass spectrometry (GC-MS).............. 21

4.2. Liquid chromatography-tandem mass spectrometry (LC-MS/MS) .............. 23

4.3. Proton transfer reaction mass spectrometry (PTR-MS) …………………..... 23 
4.4. Selected ion flow tube mass spectrometry (SIFT-MS) ............................. 24

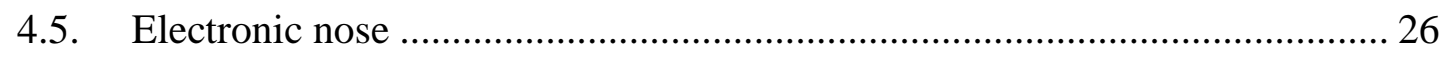

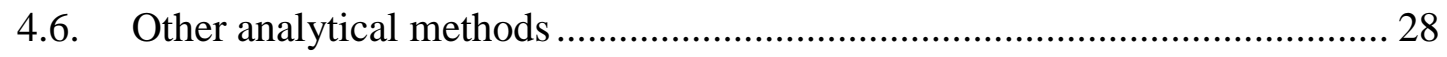

5. Carbonyl Compounds in Ambient Air and Exhaled Breath .........................................28

6. Motivation and Contributions of This Dissertation .......................................... 29

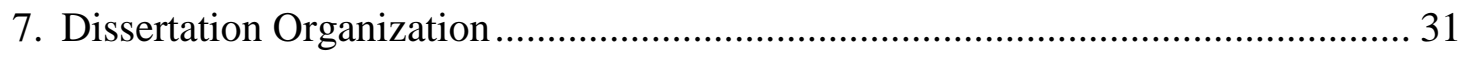

CHAPTER II: MICROREACTOR DESIGN AND FABRICATION ............................ 33

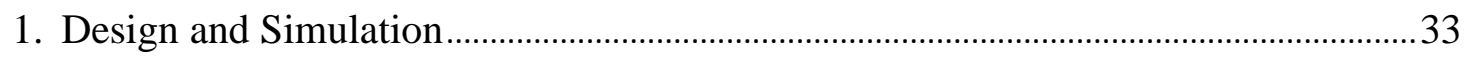

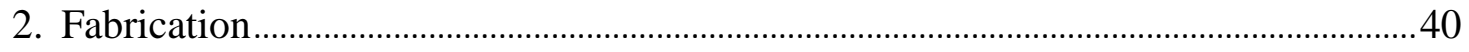

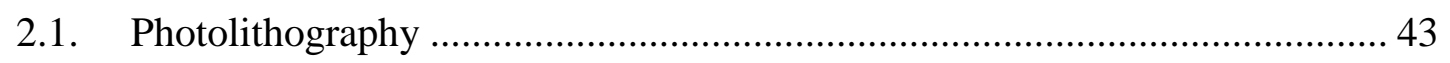

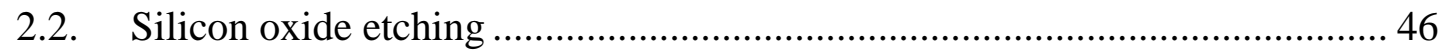

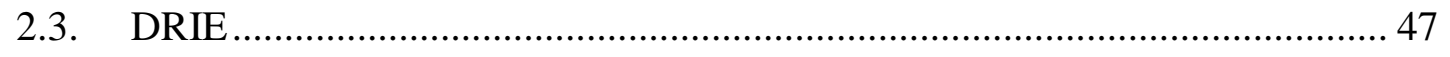

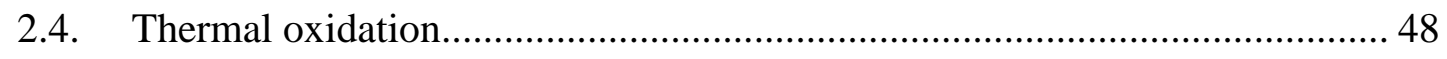

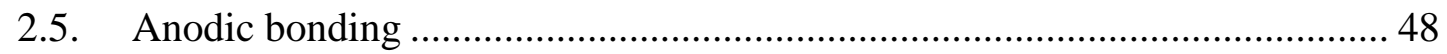

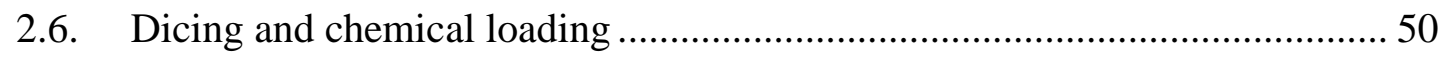

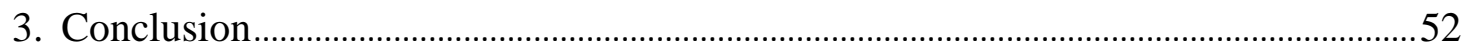

CHAPTER III: CAPTURE EFFICIENCIES OF CABONYL COMPOUNDS AT TRACE LEVELS IN MODEL GAS MIXTURES BY THE MICROREACTORS ..................... 53

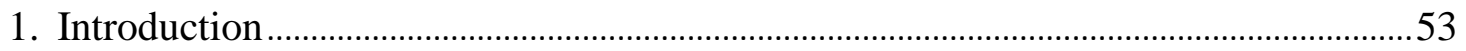

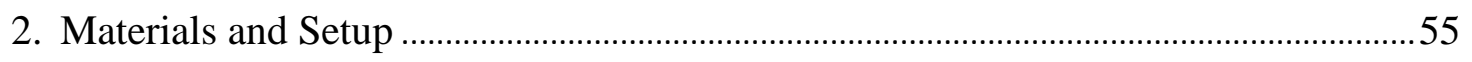

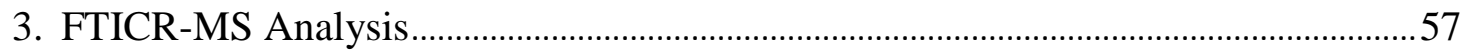

4. Initial Study of Capture of Acetone-d6 by the Microreactor...........................................58

5. Experimental Research on Capture Efficiency in Microreactor .....................................61 


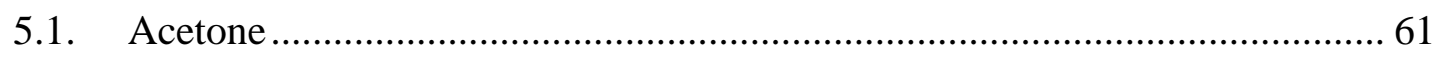

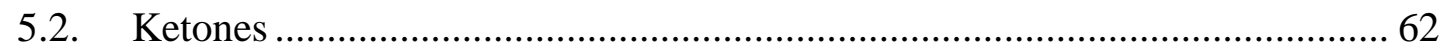

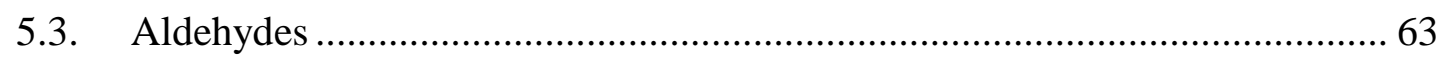

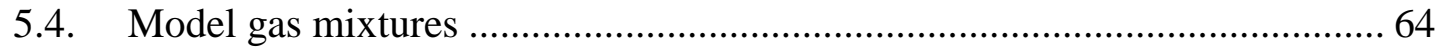

6. Kinetics Study of Oximation Reaction in Microreactor ....................................................66

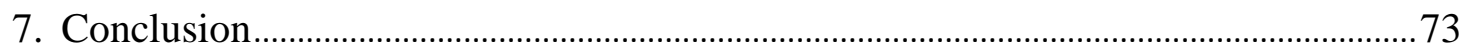

\section{CHAPTER IV: ANALYSIS OF CARBONYL COMPOUNDS IN AMBIENT AIR}

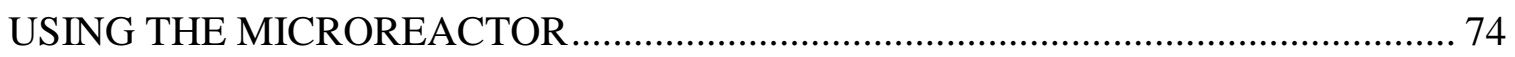

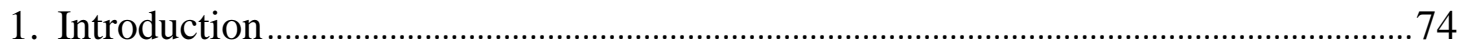

2. Materials and Sampling ………………………………………………………………....... 76

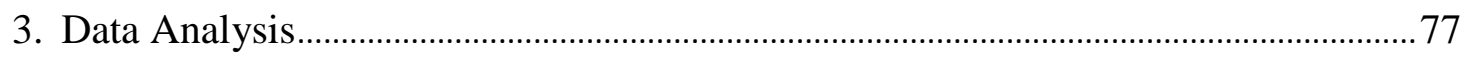

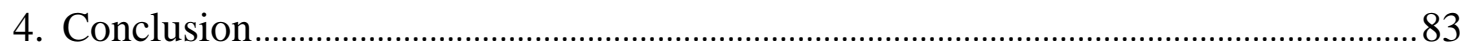

\section{CHAPTER V: DETECTION OF LUNG CANCER FROM EXHALED BREATH}

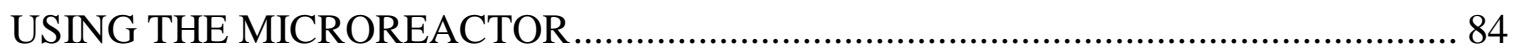

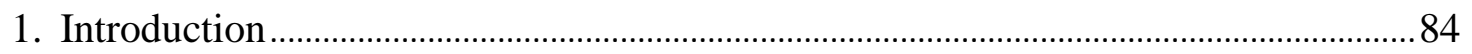

2. Breath Analysis of Smokers …………………………………………………….......

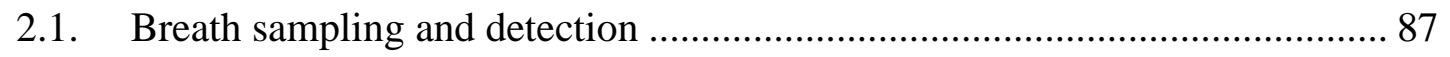

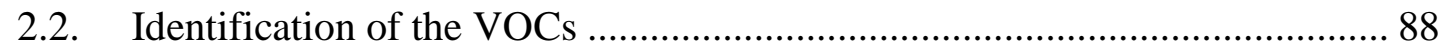

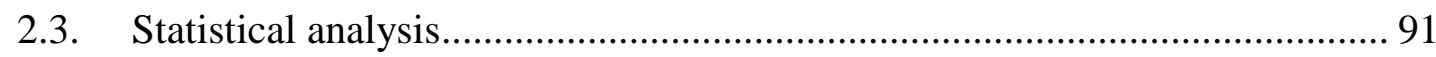

3. Breath Analysis of Lung Cancer Patient ……………………………………………......92

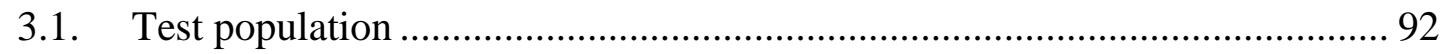

3.2. Detection of the markers............................................................................. 95

3.3. Identification of the markers....................................................................... 99 


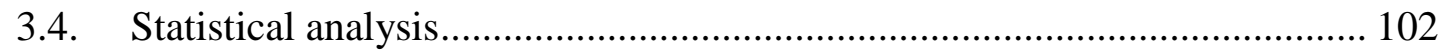

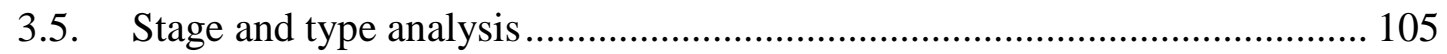

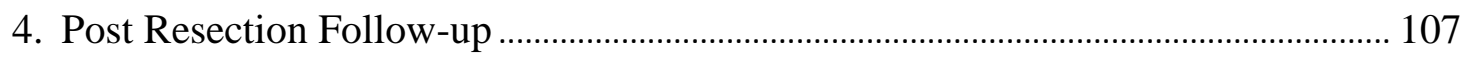

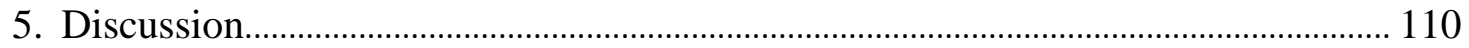

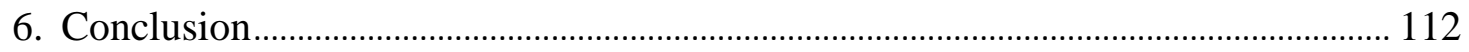

CHAPTER VI: SUMMARY AND FUTURE WORK .............................................. 113

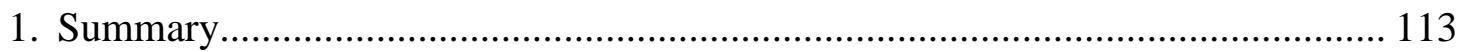

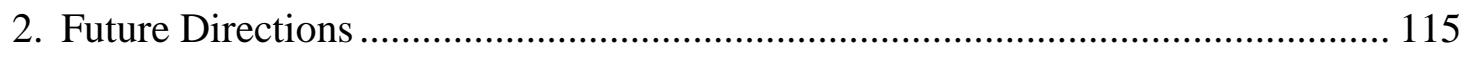

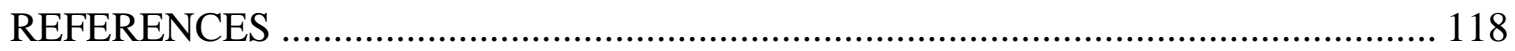

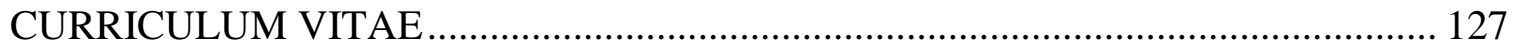




\section{LIST OF TABLES}

TABLE

PAGE

1. Physiological origins of some endogenous breath molecules ................................. 3

2. Characterization of adsorbent materials commonly used for enrichment of VOCs in

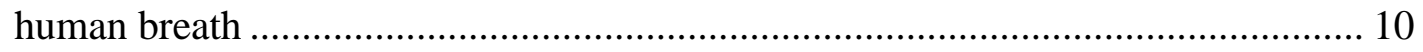

3. The details of the simulated pillar patterns ................................................... 37

4. The activation energy, frequency factor and coefficient of determination of linear

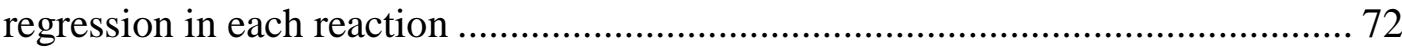

5. Average concentrations of carbonyl compounds in ambient air and detection limits

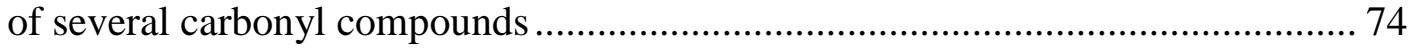

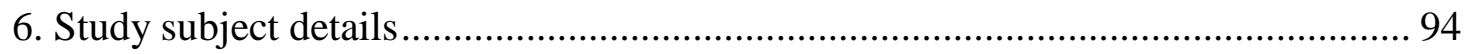

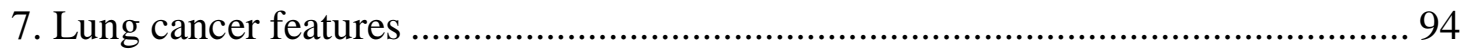

8. A comparison of identified lung cancer marker concentration range for three different groups of people and ambient air in clinic......................................... 96

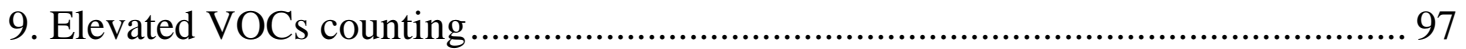




\section{LIST OF FIGURES}

FIGURE

PAGE

1. An example of a simple exhaled breath condensing device ................................. 6

2. EBC and EBV collection devices ............................................................. 8

3. Reaction scheme for the derivatization of an aldehyde with PFBHA to give cis- and

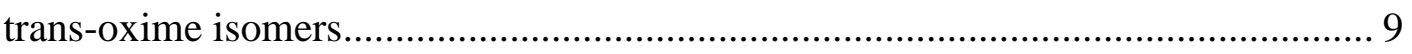

4. Illustration of particle-packed sample preparation needle ................................. 12

5. Schematic drawing of the needle transport in the autosampler............................ 13

6. Cross-section of a planar preconcentrator .................................................. 14

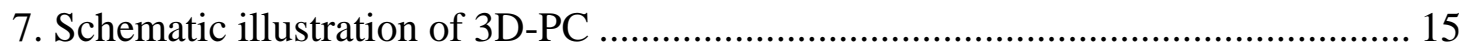

8. Schematics of process flow to fabricate the single stage PCF ............................. 16

9. Schematics for fabrication of the sealed three stages PCF ............................... 17

10.Three-stage microfabricated preconcentrator-focuser using thick microheater (upper center) packed with three carbon adsorbents to cover a wide range of

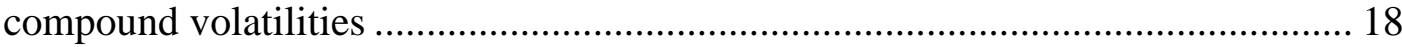

11.Image of the $\mu \mathrm{PC}$ showing the front and back sides of the device, insets are SEM monographs of the etched 3D structures and the fluidic ports ............................. 19

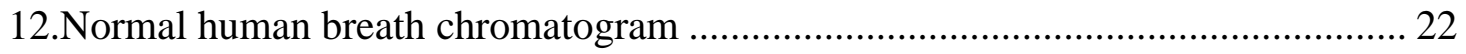

13.The simulated spectrum for the mixture of 21 compounds.................................. 24

14.Schematic representation of the FA-SIFT instrument ..................................... 25 
15.Illustration of the diagnosis of lung cancer using breath testing.

16.CFD simulations of microreactor with different pillar shapes and patterns. 36

17. Velocity distribution before the pillar arrays. 39

18.Photo mask layout of the microreactors. 41

19.Fabrication process flow of preconcentration in cross-sectional view. 42

20.Schematic illustration of glass-to-silicon anodic bonding setup...... 50

21.Schematic illustration of ATM oximation traps ketones and aldehydes in the microreactor. 51

22.Optical and SEM graphs of one microreactor 51

23. Schematic flow diagram of the preconcentration setup. 56

24.Reacted atm adducts and unreacted atm eluted from the microreactor. 56

25.FTICR-MS spectrum of methanol solution after immersing silicon micropillars cut

from the microreactor. 57

26.Typical FTICR-MS spectrum of ATM and ATM-acetone-d6 eluted from the preconcentrator. 60

27.Capturing percentage of each time after $100 \mu \mathrm{L}$ methanol flushed. 61

28.Relationship between capture efficiency and ATM/acetone molar ratio............... 62

29.Relationship between capture efficiency and ATM/ketone molar ratio. ................ 63

30.Relationship between capture efficiency and ATM/aldehyde molar ratio. 64

31.FTICR-MS spectrum of a preconcentrated TO-15 gas mixture with $1 \mathrm{ppb}$ acetone, 0.98 ppb methyl ethyl ketone, and 1.03 ppb methyl butyl ketone. 65

32.Linear regression plots of $1 / C$ vs $t$ between ATM and acetone reactions at (a) $30{ }^{\circ} \mathrm{C}$, (b) $50{ }^{\circ} \mathrm{C}$, (c) $70{ }^{\circ} \mathrm{C}$, (d) $90{ }^{\circ} \mathrm{C}$ 65 
33. Linear regression plots of $\ln (k)$ vs $1 / T$ between ATM and carbonyl compounds reactions. (a) Acetone, (b) 2-Butanone, (c) 2-Nonanone, (d) Propionaldehyde, (e) Butanal, (f) Hexanal. 69

34.The chemical structure of aminooxy salts. (a) ATM, (b) ADMB... 70

35.Linear regression plots of reactions between ADMB and carbonyl compounds .... 71

36. Schematic flow diagram of the preconcentration setup......................................... 77

37.FTICR-MS spectra of ambient air samples from a gas station and a clinic

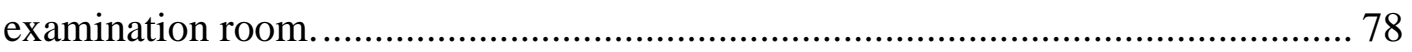

38.Average carbonyl concentrations as a function of daytime …………..................... 81

39.Schematic flow diagram of the preconcentration setup for breath anaylsis............. 88

40.Extracted ion chromatogram $(\mathrm{m} / \mathrm{z} 131)$ of breath samples from a never smoker and

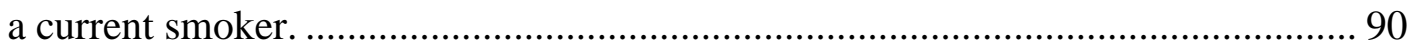

41.Normality test of acetaldehyde concentration in NS group .................................... 91

42.Comparisons of three compounds from NS group and CS group.......................... 92

43.A comparison of the FTICR-MS spectra of exhaled breath samples from a lung cancer patient, a current smoker control and a never smoker control ...................... 96

44.Comparisons of six markers from HC group, BN group and LC group .................. 97

45.FTICR-MS/MS spectra for marker identification.................................................. 89

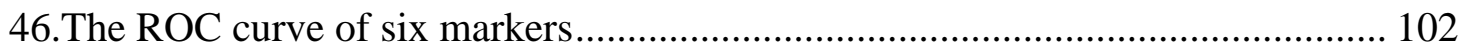

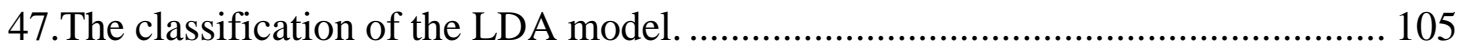

48.Comparisons of 2-butanone with different stages.................................................. 106

49. Comparisons of markers with NSCLC and SCLC ............................................. 106 
50.Comparisons of 4-HHE with adenocarcinoma NSCLC and squamous cell

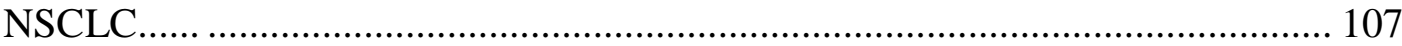

51.Comparisons of six markers before and after surgery ....................................... 109 


\section{CHAPTER I}

\section{INTRODUCTION}

\section{Breath Analysis}

Breath analysis includes both qualitative and quantitative methods for determination of chemical substances in breath. A chemical substance in exhaled breath can range from molecular hydrogen to DNA strands in size. Modern breath testing began in the 1970s when Linus Pauling detected (though without identifying) around 200 different volatile organic compounds (VOCs) in exhaled breath by gas chromatography (Pauling et al., 1971). He showed that normal human breath is a gas mixture with rather complex composition. In the last 30 years, many of these compounds have been identified. It has turned out that exhaled breath contains many VOCs, such as acetone, methanol or isoprene and even small inorganic molecules like nitric oxide, carbon monoxide or carbonyl sulfide.

Breath analysis as a diagnostic method has a number of advantages over traditional diagnostic techniques. It could potentially provide a non-invasive and painless means to assess a person's state of health, and the sampling of breath does not require skilled medical staff. Even though up to 3000 compounds may be detected in 
different person's breath, the matrix of exhaled air is less complex than that of blood or other body fluids. It can be used on people of all ages and conditions-from babies to patients on ventilators-and poses no risk to patient. However, a significant impediment to the acceptance of breath analysis as a valid diagnostic approach to detect lung cancer and other diseases is the lack of sufficiently validated data as well as standard operation procedures for sample collection, instrumental analysis, and data interpretation.

Biomarkers, which are substances that are present in an organism as a means to examine organ function or other aspects of health, are always used as the target of breath analysis.

For example, Plebani et al. (1999) determined that benzene concentration of the exhaled breath of 18 people representative of different situations: non-occupationally exposed non-smoker, non-occupationally exposed smoker, occupationally exposed nonsmoker and smoker.

Psathakis et al. found that 8-isoprostane was at a higher level in the expired breath condensate of patients with sarcoidosis (Psathakis et al., 2004). Patients with evidence of active disease seemed to be mainly responsible for this increase, as the level of 8isoprostane in patients with no active disease does not differ from that in healthy subjects.

Acetone and aldehydes are the most common chemicals detected in exhaled breath. Corradi et al. (2003) concluded that malondialdehyde (MDA), hexanal, and heptanal are increased in the EBC of patients with COPD in comparison with nonsmoking control subjects. 
Nitric oxide has also been implicated as a biomarker in various respiratory diseases including COPD. Studies have reported increased fractional exhaled nitric oxide (FENO) levels in stable COPD patients compared with healthy controls (Delen et al., 2000; Montuschi et al., 2001; Antus et al., 2010).

\section{Table 1}

Physiological origins of some endogenous breath molecules (Risby and Solga, 2006)

\begin{tabular}{|c|c|}
\hline Compound & Physiological basis \\
\hline acetaldehyde & metabolism \\
\hline acetone & decarboxylation of acetoacetate \\
\hline ammonia & protein metabolism \\
\hline carbon disulfide & gut bacteria \\
\hline carbon monoxide & production catalyzed by heme oxygenase \\
\hline carbonyl sulfide & gut bacteria \\
\hline Ethane & lipid peroxidation \\
\hline Ethanol & gut bacteria \\
\hline Ethylene & lipid peroxidation \\
\hline hydrocarbons & lipid peroxidation/metabolism \\
\hline Hydrogen & gut bacteria \\
\hline Isoprene & cholesterol biosynthesis \\
\hline Methane & gut bacteria \\
\hline
\end{tabular}




\begin{tabular}{l|c}
\hline methanethiol & methionine metabolism \\
methanol & metabolism of fruit \\
methylamine & protein metabolism \\
nitric oxide & production catalyzed by nitric oxide \\
sentane & lipid peroxidation \\
\hline
\end{tabular}

Not only were VOCs published as biomarkers of diseases, but proteins and DNA strands have also been mentioned. Researchers at the National Institutions of Health and the University of Hong Kong in China discovered that an N-terminal truncated protein variant of carboxypeptidase $\mathrm{E}(\mathrm{CPE}-\Delta \mathrm{N})$ induces tumor growth and metastasis. Patients with high levels of this protein were more likely to have their cancer spread, regardless of staging and grading; those with low levels, regardless of staging and grading, were more likely to not have their cancers spread (Lee et al., 2011). Cristofanilli et al. (2004) reported that circulating tumor cells (CTCs) have been identified in peripheral blood from cancer patients and are probably the origin of intractable metastatic disease.

However, many chemicals mentioned also have a higher level from breath samples of smoker than non-smoker. To diagnose the disease, more accurate quantification analytical methods are needed. 


\section{Breath Sampling Methods}

Superficially, sampling breath is both simple and quick, making it ideal for dealing with large numbers of patients. The sampling 'apparatus' must be comfortable and safe for the patient, and easy to breathe into.

\subsection{Sampling bags}

Breath can be collected into various sampling canisters, gas sampling bags, syringes, and sorbent tubes containing multiple beds or analyzed directly in analytical systems. Tedlar® sampling bags are widely used in breath sampling. They are made from polyvinyl fluoride (PVF), which is tough, durable, and considered chemically inert to a wide range of compounds. Polypropylene, stainless steel, and teflon can also be fitted in the bags. Tedlar® bags can be reused for most applications. Prior to reuse, the bags must be evacuated and thoroughly cleaned and flushed with purified air or nitrogen. It is recommended that an analysis is performed after the final flush to ensure that the background levels of gases in the bag are acceptable for its intended use. Canisters and bags are used for a single alveolar breath sampling. Though useful in many respects, Tedlar® bags release, for example, N,N-dimethylacetamide and phenol in relatively high concentrations.

\subsection{Exhaled breath condensate (EBC)}

EBC, the vapor and aerosol matrix captured by cooling or freezing the breath as it leaves the mouth/nose, is a source of low molecular weight volatile compounds and potentially larger biomolecules, which may be associated with some types of (e.g., lung) 
cancer cells; in contrast to genomic changes which are not always reliable predictors of the clinical course of disease in a cancer patient, protein expression may provide a more reliable detection and monitoring tool (Conrad et al., 2007). Mass Spectrometry in combination with newly emerging tools for proteomics and the analysis of EBC may lead to discovery of biomarkers useful in early detection of cancer. Figure 1 shows a one-way valve that allows air to be inspired and the exhaled breath to be cooled using ice or another cooling system, e.g., dry ice or a refrigerated circuit. The conditions (e.g., temperature) and types of materials used in EBC collection can influence the amounts and types of captured markers.

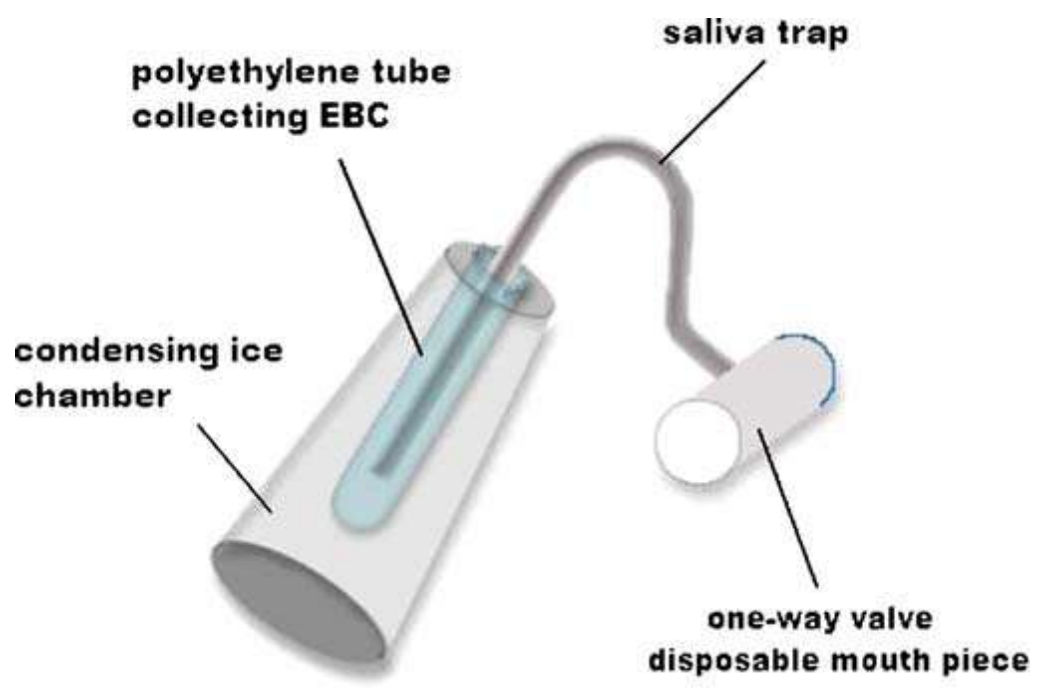

Figure 1. An example of a simple exhaled breath condensing device (Conrad et al., 2007)

Methods used in collection and detection of EBC play significant roles in the accuracy and reliability of biomarker characterization. Variables such as collection device type and temperature can significantly impact experimental reproducibility and ideally these methods should be standardized. For example, a number of articles report on 
the merits of various procedures used to collect EBC samples from human and animal subjects. Czebe et al (2008) compared EBC pH and protein concentrations obtained by three types of commercially available exhaled EBC collection devices (EcoScreen, RTube, Anacon). They hypothesized that surface adherence properties toward proteins are an important factor affecting efficiency of protein collection from EBC samples.

A new procedure, exhaled breath vapor (EBV) collection, involving the active sampling and preconcentration of a breath sample with a solid-phase microextraction (SPME) fiber fitted inside a modified commercial breath collection device was also reported in Martin et al., 2010's work. 


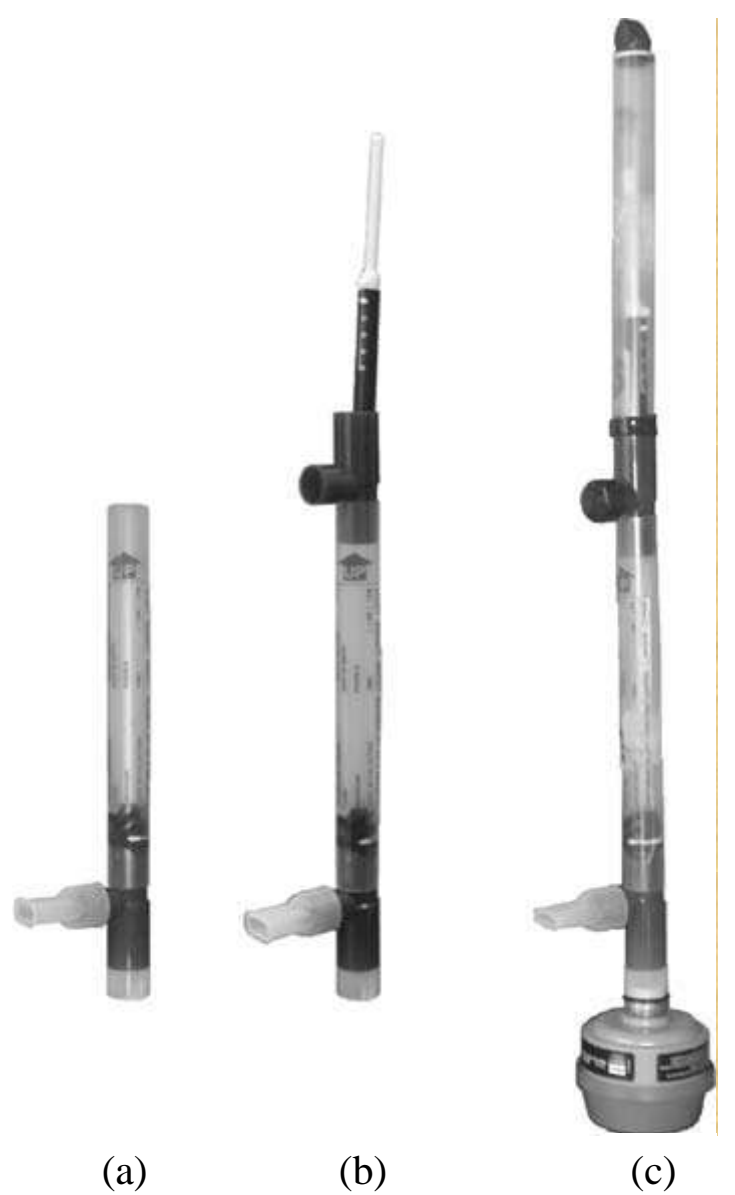

Figure 2. EBC and EBV collection devices: a) The commercially available RTube ${ }^{\mathrm{TM}}$; b) The RTube ${ }^{\mathrm{TM}}$ was modified for EBV collection by the addition of a plastic fitting to hold a SPME fiber for active sampling; c) The additional modification of the RTube ${ }^{\mathrm{TM}}$ to provide an enclosed environment for SPME sampling as well as the addition of a respirator to purify inhaled air (Martin et al., 2010)

\subsection{Chemical sampling methods}

Chemical sampling methods were sometimes used to sample breath. Using chemical derivatization to capture VOCs in breath was reported in Svensson et al., 2007's research, however, it has not been widely used. 


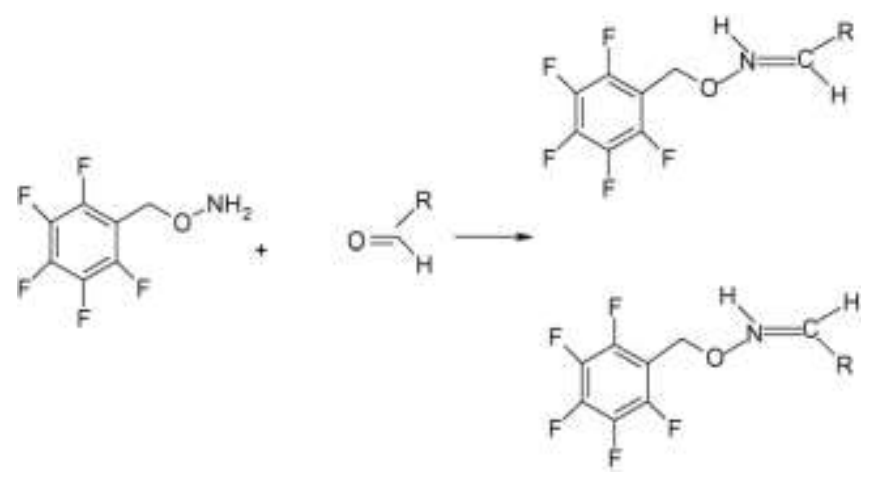

Figure 3. Reaction scheme for the derivatization of an aldehyde with PFBHA to give cisand trans-oxime isomers (Svensson et al., 2007)

\section{Preconcentration Techniques}

Detection of volatile organic compounds (VOCs) at trace level (ppbv to pptv) has become an important research area because of demanding applications in homeland security, environmental monitoring, and noninvasive health diagnosis (Tian et al., 2005; Agah et al., 2006) The analysis of trace VOCs challenges existing analytical methods because their concentrations are beyond instrument limits of detection. This problem is further exacerbated by other interfering gases that are mixed in large concentration with the VOCs.

Because of the very low concentrations of components in breath, preconcentration techniques are sometimes required prior to analysis, e.g. adsorption or cryotrapping, to increase the amount of collected VOCs. However, high humidity of breath gas and the presence of certain endogenous organic vapors make the collection of breath samples 
difficult to perform. Improvements in sampling and analytical techniques have partly solved these methodological problems.

\subsection{Traditional physical adsorption}

There are varieties of preconcentration techniques for breath analysis such as adsorptions of analytes, followed by their thermal desorption and determination by gas chromatography combined with mass spectrometry (GC/MS). Adsorbents in collection traps have to be selected carefully to avoid both breakthrough and carryover effects. Organic polymers, activated charcoal, different types of graphitized carbon and carbon molecular sieves have been used for enrichment of VOCs in human breath.

\section{Table 2}

Characterization of adsorbent materials commonly used for preconcentration of VOCs in human breath (Dettmer and Engewald, 2002)

\begin{tabular}{|c|c|c|c|c|c|c|}
\hline Absorbent & $\begin{array}{l}\text { Particle } \\
\text { size }\end{array}$ & $\begin{array}{l}\text { Sampling } \\
\text { range }\end{array}$ & $\begin{array}{l}\mathbf{T}_{\max } \\
\left({ }^{\circ} \mathrm{C}\right)\end{array}$ & $\begin{array}{l}\text { Spec. } \\
\text { Surface } \\
\operatorname{area}\left(\mathrm{m}^{2} / \mathrm{g}\right)\end{array}$ & $\begin{array}{l}\mathbf{V}_{\mathbf{g}} \\
(\mathrm{ml} / \mathrm{g})\end{array}$ & $\begin{array}{l}\text { Desity } \\
(\mathrm{g} / \mathrm{ml})\end{array}$ \\
\hline \multicolumn{7}{|c|}{ Carbon molecuar sieves } \\
\hline Carboxen 563 & $20 / 45$ & C2-C5 & $>400$ & 510 & 778 & 0.53 \\
\hline Carboxen 564 & $20 / 45$ & C2-C5 & $>400$ & 400 & 276 & 0.60 \\
\hline Carboxen 569 & $20 / 45$ & $\mathrm{C} 2-\mathrm{C} 5$ & $>400$ & 485 & 257 & 0.58 \\
\hline
\end{tabular}




\begin{tabular}{|c|c|c|c|c|c|c|}
\hline Carboxen 1000 & $60 / 80$ & $\mathrm{C} 2-\mathrm{C} 5$ & $>400$ & 1200 & 418 & 0.44 \\
\hline Carboxen 1001 & $60 / 80$ & $\mathrm{C} 2-\mathrm{C} 5$ & $>400$ & 500 & 234 & 0.61 \\
\hline Carboxen 1003 & $40 / 60$ & $\mathrm{C} 2-\mathrm{C} 5$ & $>400$ & 1000 & 79 & 0.46 \\
\hline Carbosieve SIII & $60 / 80$ & $\mathrm{C} 2-\mathrm{C} 5$ & $>400$ & 820 & 387 & 0.61 \\
\hline Carbospher & $60 / 80$ & $\mathrm{C} 2-\mathrm{C} 5$ & 400 & 1000 & 779 & -- \\
\hline \multicolumn{7}{|l|}{ Graphitized carbon } \\
\hline Carbotrap F & $20 / 40$ & $>\mathrm{C} 20$ & $>400$ & 5 & -- & 0.66 \\
\hline Carbotrap C & $20 / 40$ & $\mathrm{C} 12-\mathrm{C} 20$ & $>400$ & 10 & -- & 0.72 \\
\hline $\begin{array}{l}\text { Carbotrap Y 20/40 C12- } \\
\text { C20>400 } 25-0.42\end{array}$ & $20 / 40$ & $\mathrm{C} 12-\mathrm{C} 20$ & $>400$ & 25 & -- & 0.42 \\
\hline $\begin{array}{l}\text { Carbotrap X 20/40 C3- } \\
\text { C5 >400 250-0.41 }\end{array}$ & $20 / 40$ & $\mathrm{C} 3-\mathrm{C} 5$ & $>400$ & 250 & -- & 0.41 \\
\hline $\begin{array}{l}\text { Carbograph } 5 \text { 20/40 C3- } \\
\text { C5 >400 } 560-\end{array}$ & $20 / 40$ & $\mathrm{C} 3-\mathrm{C} 5$ & $>400$ & 560 & -- & -- \\
\hline $\begin{array}{l}\text { Porous organic } \\
\text { polymers }\end{array}$ & & & & & & \\
\hline $\begin{array}{l}\text { Chromosorb } 106 \\
\text { (styrene/divinylbenzene) }\end{array}$ & $60 / 80$ & $\begin{array}{l}\text { Small } \\
\text { molecules }\end{array}$ & 250 & 750 & 173 & -- \\
\hline Tenax TA & $60 / 80$ & C7-C26 & 350 & 35 & 39 & 0.25 \\
\hline poly-(2,6-diphenyl-)- & & & & & & \\
\hline p-phenylenoxide & & & & & & \\
\hline
\end{tabular}




\subsection{Solid phase microextraction (SPME)}

Preconcentration of some volatile substances has already been simplified by the introduction of SPME. SPME was introduced two decades ago by Arthur and Pawliszyn (1990) as a rapid extraction technique for the analysis of volatile and semi-volatile compounds from a variety of matrices. Choosing a proper SPME fiber coating is crucial to the effectiveness of the analytical method to a particular analyte types. Before a selection can be made, several determining factors of the analyte should be taken into consideration, i.e. polarity, molecular weight, sample matrix, expected concentration range, sampling temperature and detector type. Non-polar fiber coatings such as PDMS should be used for hydrocarbons with low polarity. Carboxen and divinylbenzene fibers are preferred for polar compounds, such as alcohols, organic acids and others. Figure 4 and Figure 5 show a kind of extraction needle which was often reported.

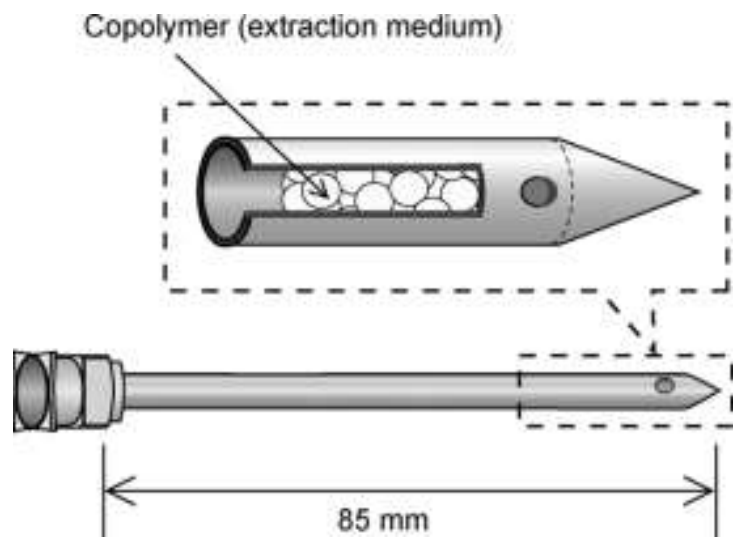

Figure 4. Illustration of particle-packed sample preparation needle (Ueta et al., 2009) 

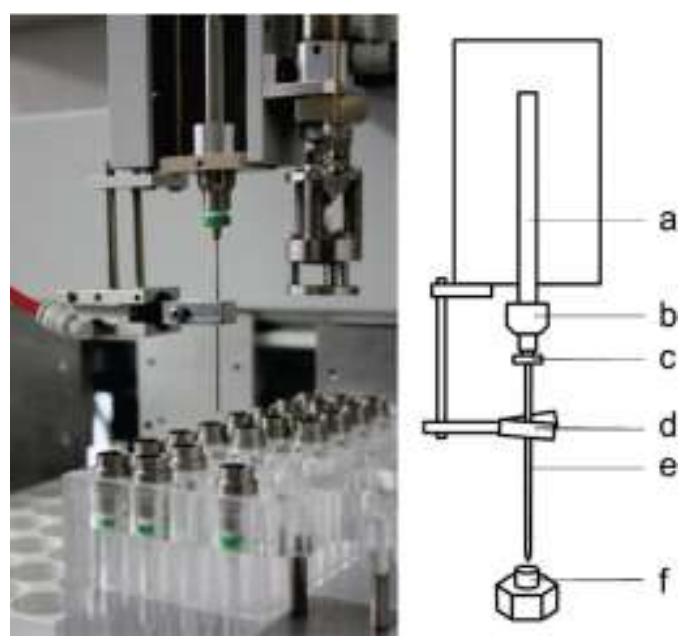

Figure 5. Schematic drawing of the needle transport in the autosampler: (a) solenoid; (b) magnetic cap with Teflon inlay; (c) Luer-lock connection of the needle; (d) pneumatic claw; (e) needle trap; (f) injector nut with a bigger cone (Mieth et al., 2010)

\subsection{MEMS preconcentrator}

In recent years, microfabricated gas preconcentrators and gas chromatography columns have demonstrated the potential for real-time, low-power, and hand-held gas detection (Tian et al., 2005; Agah et al., 2006). Preconcentrators fabricated from silicon wafers using microelectromechanical system (MEMS) technology typically consist of a microhot plate and an adsorption material placed adjacent to the heating element (Voiculescu et al., 2008; Alfeeli and Agah, 2009).

Manginell et al (2003) fabricated planar preconcentrator (PC) to meet the need for a low-power, chemical preconcentrator and chromatographic injector. First, a Si wafer was bonded to a resultant free-standing silicon nitride $\left(\mathrm{Si}_{2} \mathrm{~N}_{3}\right)$ membrane which was typically $2.2 \mu \mathrm{m}$ on a side. A thin-film heater was deposited on the silicon nitride 
membrane layer prior to the etching. It consisted of a platinum layer, $180-\mathrm{nm}$-thick, ebeam evaporated onto a titanium adhesion layer, 15-nm thick. Then the wafer was etched with $\mathrm{KOH}$ etching or DRIE. Following device processing, the microhotplate was coated with an adsorbent layer to complete the preconcentrator. Spray coating through a mask was used to apply the adsorbent in a fairly uniform circular patch. They used microporous hydrophobic surfactant-templated sol-gel layer as the absorbent coating.

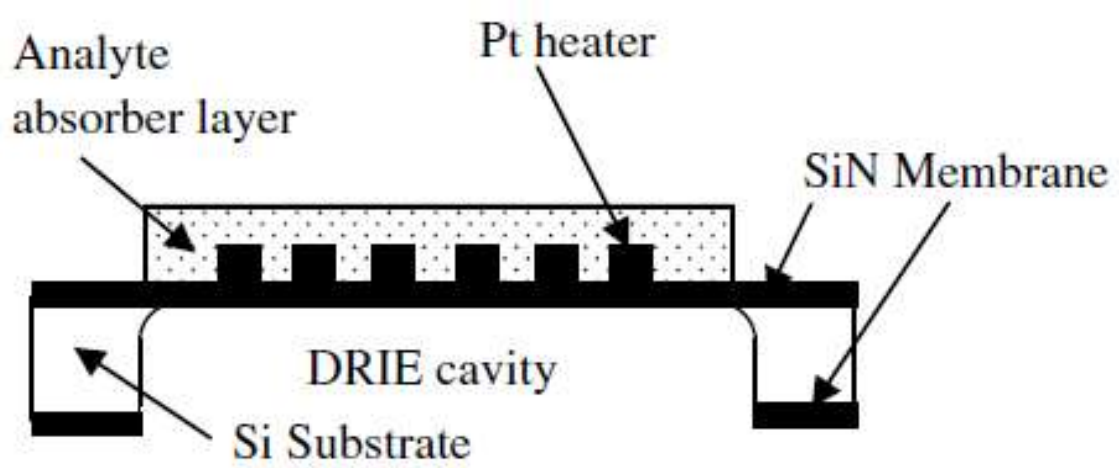

Figure 6. Cross-section of a planar preconcentrator (Casalnuovo et al., 1999)

To increase collection area, while minimizing power consumption, Lewis et al. (2006) had independently implemented the three-dimensional preconcentrator(3D-PC) designs. Bosch etching through the wafer thickness to a silicon nitride thermal isolation membrane is used to construct the 3D-PC. This process was similar to that used for the planar device except that some silicon structures remain suspended on the central portion of the membrane to provide additional adsorbent support area. Because sample gas flow is perpendicular to the device surface, the 3D-PC of Fig. 7(a) is deemed a "perpendicular flow" device; in contrast, the flow through the device showed in Fig. 7(b) is parallel to the wafer surface and is thus a "parallel flow" preconcentrator. Nanoporous carbon, sol gels, and commercial packing materials have been tested with the 3D-PC devices used to impart selectivity to semi-volatile polar analytes relative to hydrocarbons. Heat 
conduction through the silicon nitride suspensions is comparable to that of the planar device. However, the available surface area for depositing or packing in coatings has increased in 3D-PC, up to a factor of 20 , depending on the particular design, via the use of the wafer-thickness silicon structures as adsorbent supports.

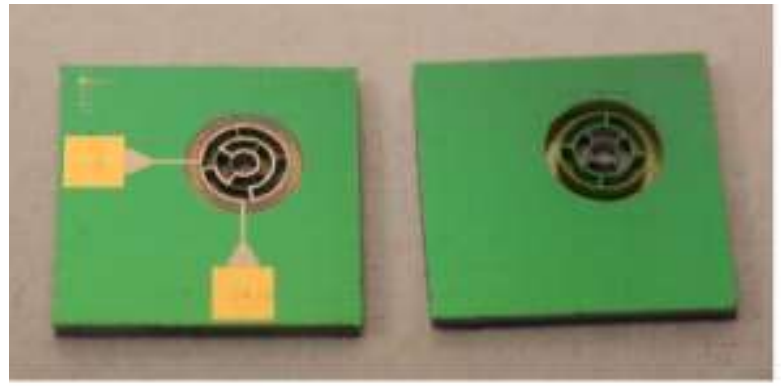

(a)

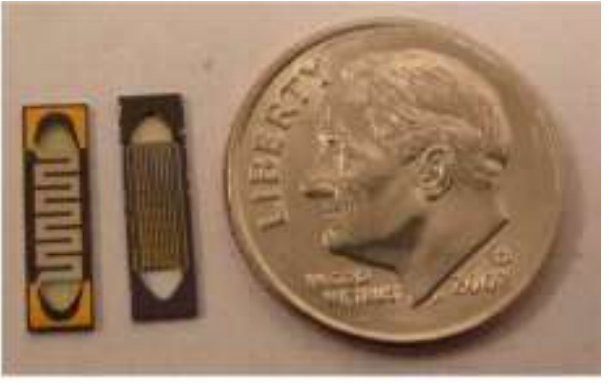

(b)

Figure 7. Schematic illustration of 3D-PC. (a) Perpendicular flow 3D-PC, (b) Parallel flow 3D-PC (Lewis et al., 2006)

Tian et al (2005) fabricated a kind of single-stage preconcentrator (SPC) based on a hotplate for single stage shown in Figure 8. The adsorbent material, Carbopack X was a graphitized carbon having a specific surface area of $250 \mathrm{~m}^{2} / \mathrm{g}$. This material is suitable for capturing (and releasing) compounds with vapor pressures in the range of 5 to 95 torr. 


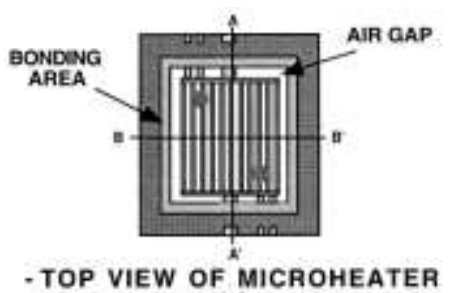

(a)

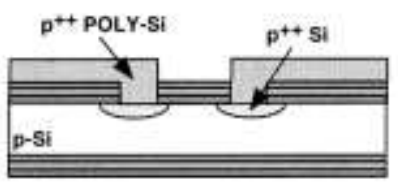

- PATTERN POLY-Si INTERCONNECTS AND TEMPERATURE SENSORS

(d)

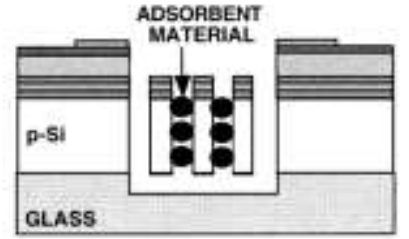

- FILL HEATER WITH CARBON ADSORBENT MATERIAL

(g-BB')

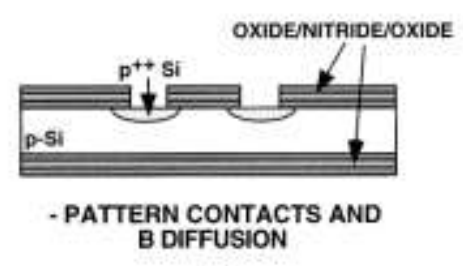

(b)
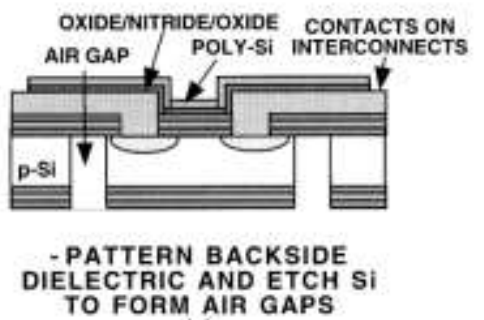

(e)

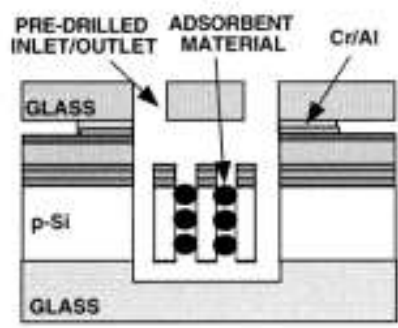

- SEAL HEATER WITH GLASS/AI/SI SOLDER BONDING

(h-BB')

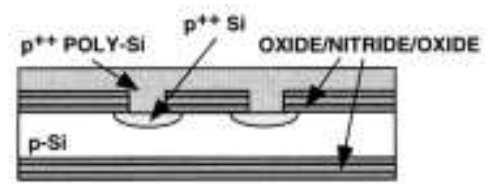

-DEPOSIT POLY-SI AND $2^{\text {nd }}$ B DIFFUSION

(c)

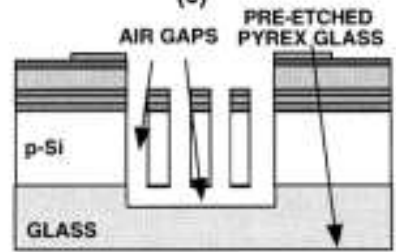

- SI ANODICALLY BONDED TO GLASS AND DEEP SI ETCH

TO FORM HEATERS

(f)

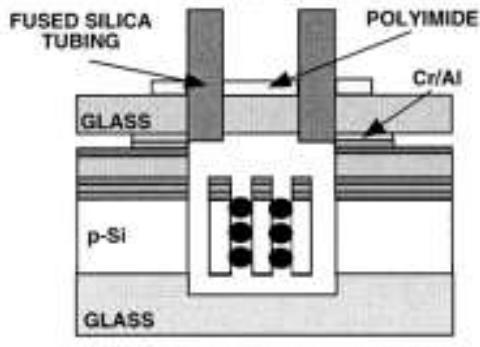

-INSERT FUSED SILICA TUBING AS INLET/OUTLET AND SEAL WITH POL YIMIDE

(i-BB')

Figure 8. Schematics of process flow to fabricate the SPC (Tian et al., 2005)

During the testing, a preconcentration factor in range of 1260-5200 was achieved by using a stop-flow time of $25 \mathrm{~s}$ at $2.25 \mathrm{~W}$ with detecting the signal of benzene. They also fabricated a kind of multi-stage preconcentrator based on a hotplate for multiple stages shown in Figure 9. 


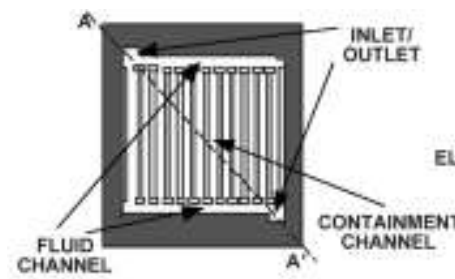

TOP VIEW OF $\mu$ PCF

(a-1)

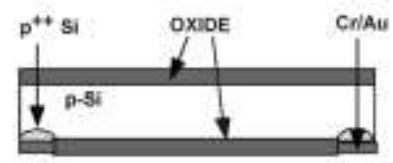

B DIFFUSION AND METALIZATION TO FORA CONTACTS

(c)

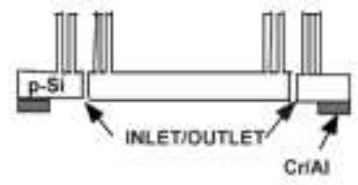

- DRY ETCH TO OPEN INLET/OUTLET TUBING STANDS ON FRONTSIDE OF SI COVER

(1)

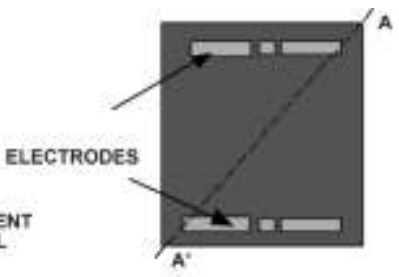

- BACK VIEW OF $\mu$ PCF (a-2)

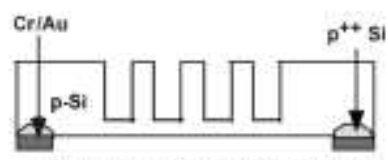

- DEEP SI ETCHING TO DEFINE HEATING ELEMENTS ON FRONTSIDE

(d)

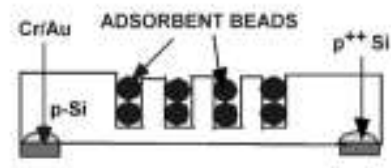

- INSERT ADSORBENT GRANULES IN BETWEEN HEATING ELEMENTS

(g)

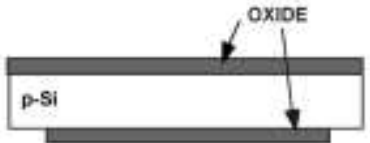

- GROW OXIDE AND OPEN CONTACT AREA ON BACKSIDE

(b)

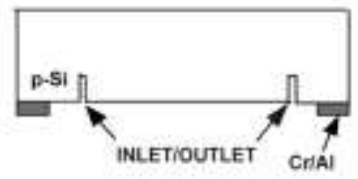

- DEPOSIT BONDING MATERIAL AND ETCH TO FORM INLETIOUTLET ON BACKSIDE OF SI COVER

(e)

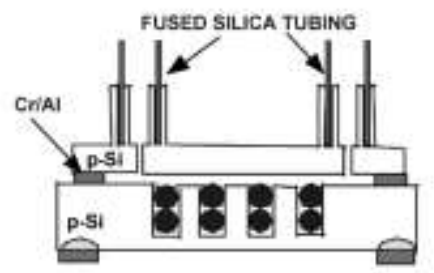

- SEAL SI HEATER TO SI COVER WITH SOLDER BONDING AND INSERT FUSED SILICA TUBING

(h)

Figure 9. Schematics for fabrication of sealed three stages PC (Tian et al., 2005)

Instead of using one adsorbent material as in the single-stage, three different adsorbent materials, Carbopack B, Carbopack X, and Carboxen 1000 were chosen in the three stages because each adsorbent has its specific surface area, pore morphology, and pore size distribution which enabled it to handle compounds with a particular range of vapor pressures shown in Figure 10. The 3 adsorbents had different surface areas (100 for Carbopack B, 250 for Carbopack X, and 1200 for Carboxen 1000) and were used to trap compounds with different volatilities. 


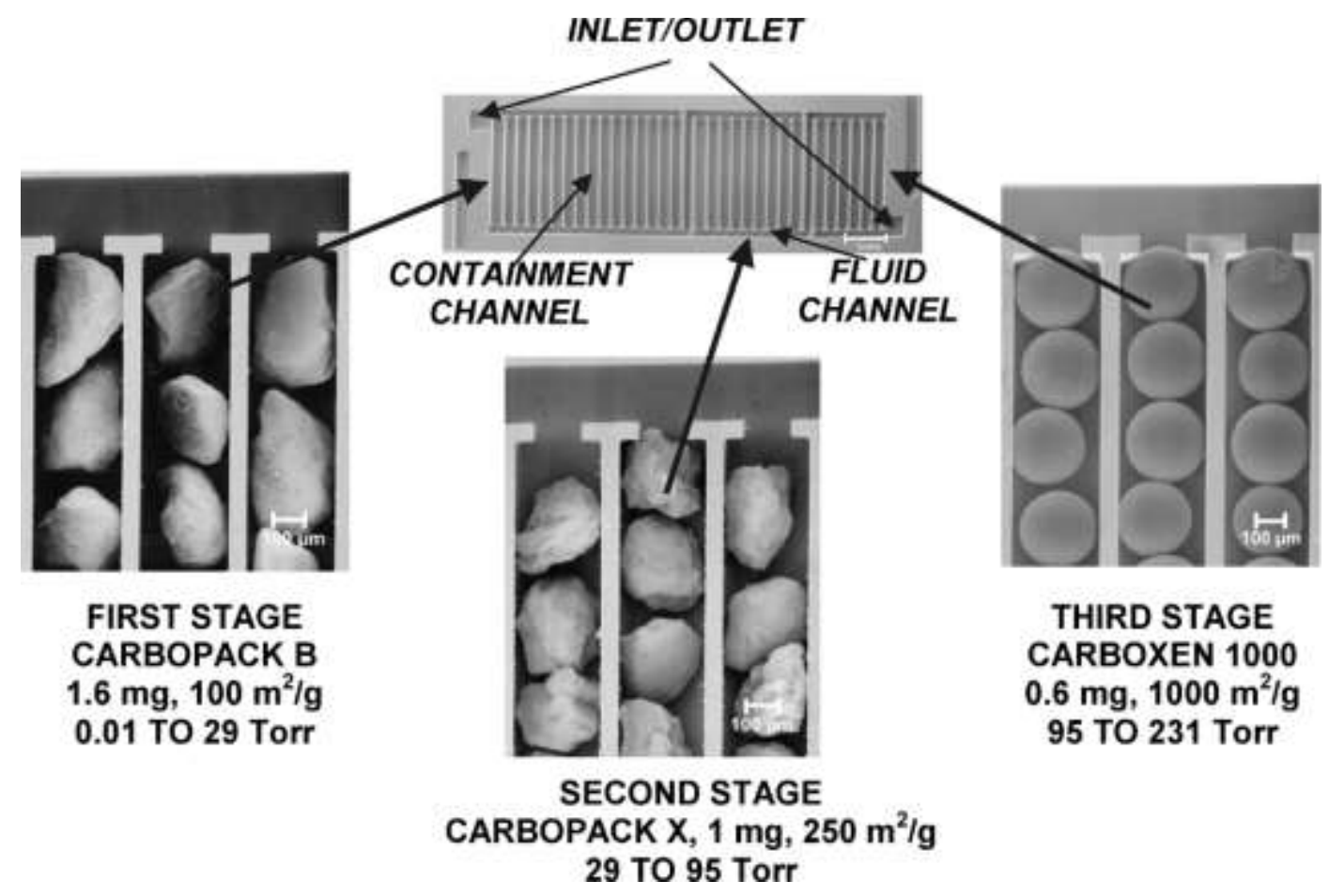

Figure 10. Three-stage microfabricated preconcentrator-focuser using thick microheater (upper center) packed with three carbon adsorbents to cover a wide range of compound volatilities. (Tian et al., 2005)

The preconcentration factor was $>5600$ during the testing, and a sample with 30 VOCs preconcentrated by this three stages micropreconcentrator ( $\mu \mathrm{PC})$ was successfully separated according to the chromatogram using HP-GC 6890 and FID detector.

Alfeeli and Agah (2008) developed a kind of $\mu$ PC with 3D micropillars. The fabrication required only two masks, one for patterning the microstructures and one for patterning on-board heaters and sensors. Using high resolution, superior aspect ratio thick film photoresist (PR9260), the micropillars and the fluidic ports were patterned on a 4-in. silicon wafer. The pattern was then etched using deep reactive ion etching (DRIE) to form $240-\mu \mathrm{m}$ deep 3D structures. To seal the structure, the etched wafer was bonded to a 
Pyrex glass wafer. Anodic bonding which is more stable than a polymer adhesive has been used to make the bond. PECVD oxide was deposited on the backside of the wafer and then $20 / 40 \mathrm{~nm} \mathrm{Ti} / \mathrm{Pt}$ was evaporated and patterned by the lift-off technique to form heat sensors and pressure sensors. The wafer containing 130 chips was diced into individual devices. Each device was connected on both sides with $240-\mu \mathrm{m}$ outside diameter, $100-\mu \mathrm{m}$ inside diameter, deactivated fused silica tubing using a high temperature silica-based bonding agent shown in Figure 11.

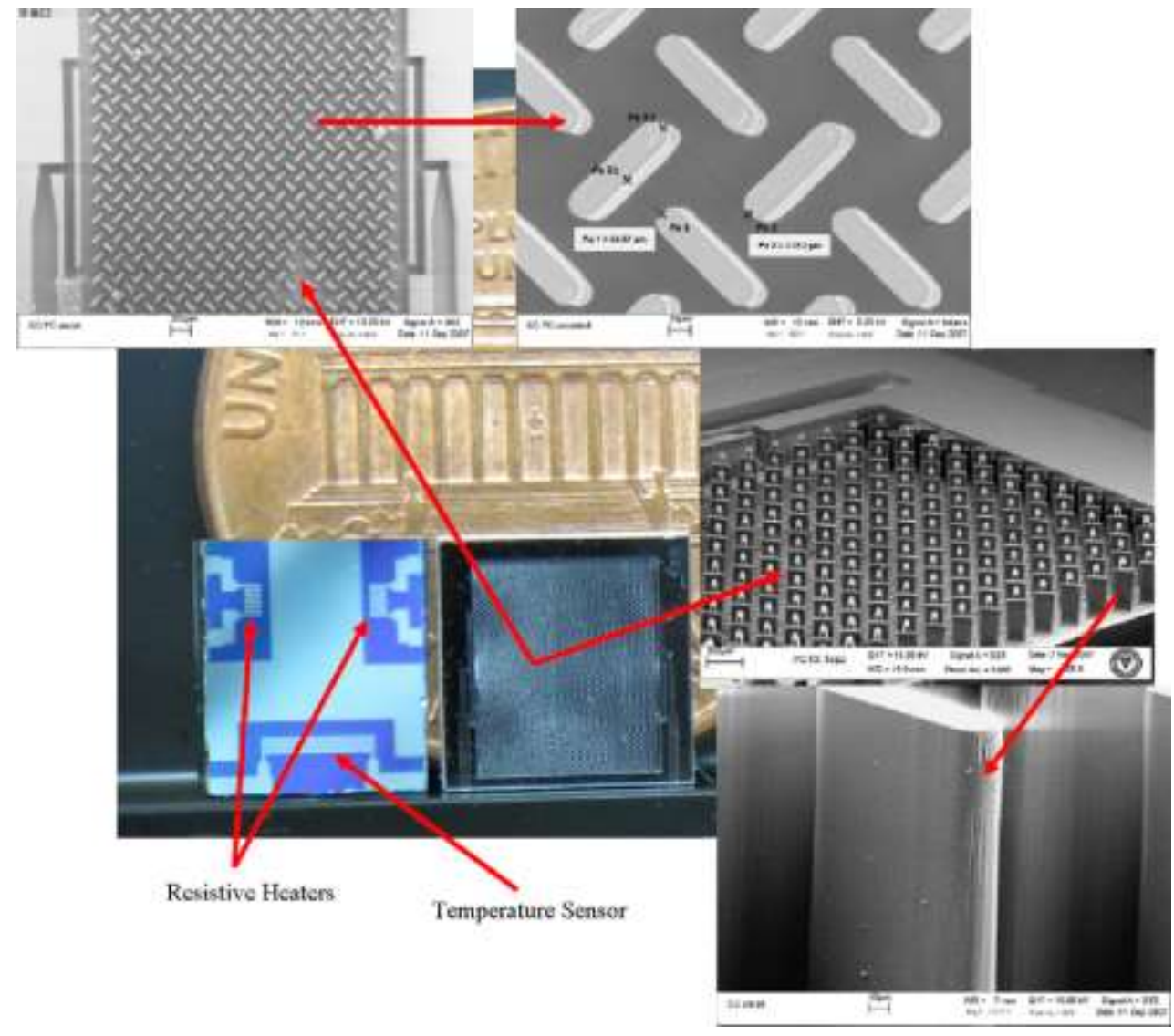

Figure 11. Image of the $\mu \mathrm{PC}$ showing the front and back sides of the device, insets are SEM monographs of the etched 3D structures and the fluidic ports. (Alfeeli and Agah, 2009) 
They used Tenax TA dissolved in dichloromethane to coat the 3D structures with film adsorbent. At a constant concentration of pure isopropanol vapor, the preconcentration factor can achieve more than 10,000. A mixture of five hydrocarbon compounds: $\mathrm{C} 8, \mathrm{C} 9, \mathrm{C} 10, \mathrm{C} 12$, and $\mathrm{C} 14$ preconcentrated by this $3 \mathrm{D}$ pillar $\mu \mathrm{PC}$ was successfully separated according to the chromatogram using HP-GC 6890 and FID detector.

\section{Analytical Methods}

Photonic and spectroscopic techniques such as infrared (IR) and fluorescent spectroscopy should provide sufficient sensitivity to analyze chemical components of human exhaled breath. However, they are limited either in terms of achievable resolving power (hence specificity) or their inability to detect many classes of compounds (e.g., the need for derivatization in fluorescent studies). Conventional nuclear magnetic resonance (NMR) is a powerful technique for analyte characterization but suffers from poor sensitivity and is not suitable for analysis of complex mixtures. Spectrometric methods such as ion mobility spectrometry (IMS) and mass spectrometry (MS) offer high sensitivity, specificity, and mass resolving power and are commonly used for complex mixture analysis and unknown compounds identification. However, most modern and high resolution mass spectrometers are expensive. Conversely, hand-held, portable, and small devices can be less expensive but their uses are often limited to detecting identified compounds. Addition of multiple detection systems for tandem analyses improves data quality and reliability. 


\subsection{Gas chromatography combined with mass spectrometry (GC-MS)}

Spectrometric analysis of volatile compounds is mostly done by gas chromatography. Hydrocarbons in the nanomolar to picomolar per liter (ppbv-pptv) range, such as ethane, pentane or isoprene, are usually determined using gas chromatography coupled to flame ionization detector (FID) or a mass selective detector. Nowadays gas chromatography-flame ionization detector (GC-FID) and GC-MS are two crucial GC techniques used for analysis of biological VOCs. Especially, GC-MS is a powerful analytical technique in the study of biological VOCs owing to the strong identification function of mass spectrometry. Mass spectrometric analysis has to be applied for the identification of unknown substances. GC- MS has been applied to the identification of pathogens from cultures and diagnosing illness from breath samples (Riemer et al., 1998; Phillips et al., 1999; Apel et al., 2003). GC-MS has been also used for the identification of metabolic end products including pentane, acetone, ethanol, isoprene and other VOCs in normal human breath shown in Figure 12. 


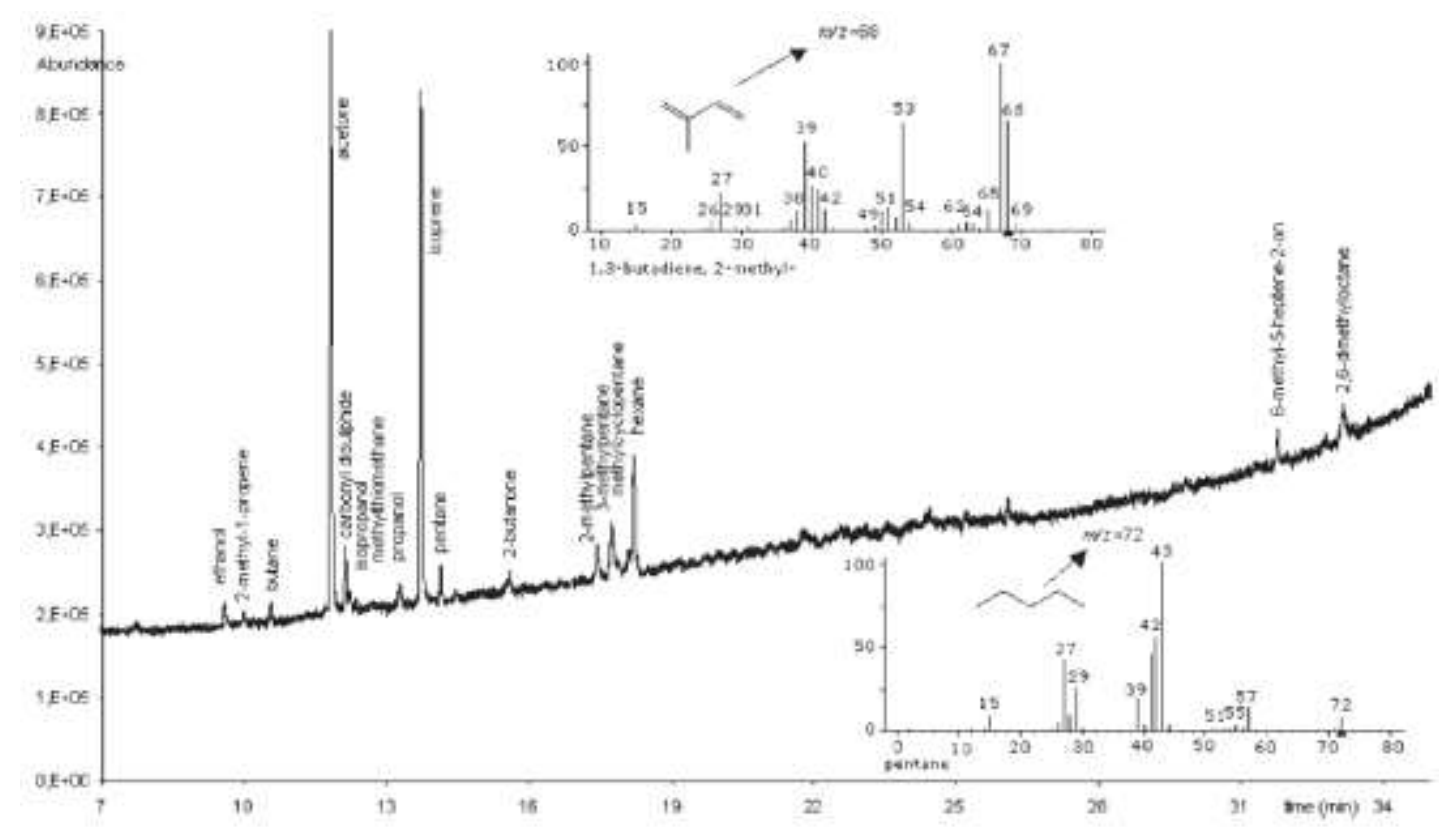

Figure 12. Normal human breath chromatogram (Phillips et al., 1999)

Two dimensional GC is also used in breath analysis (Mieth et al., 2008). High peak capacity is achieved from chromatograms defined on a two-dimensional retention time plane rather than on a single retention-time axis. Another important advantage of the $\mathrm{GC} \times \mathrm{GC}$ system is that it greatly reduces resource requirements relative to systems requiring cryogenic materials and compressed gases for modulator heating and cooling. With the present system, only carrier gas, flame gas and electric power are required.

Preconcentrating breath gas by various means and subsequent analysis by means of gas chromatography combined with mass spectrometry (GC-MS) constitute a reliable and sensitive set of methods for VOCs analysis. Initial results suggest that the GC-MS technique will be able to assist in the diagnosis of diseases in the near future. Despite its high sensitivity, there are a number of limitations associated with its use. This method generally involves both sampling and preconcentration steps prior to the introduction of 
the collected sample into a gas chromatographic column, which can lead to contamination problems and losses of analyses.

\subsection{Liquid chromatography-tandem mass spectrometry (LC-MS/MS)}

LC-MS/MS has been demonstrated to be a powerful technique for the quantitative determination of biomarkers in complex biological fluids, like blood and urine, without requiring extensive sample manipulation. Nevertheless, it is well known that precision and accuracy of LC-MS/MS quantitative bioanalysis could be affected by matrix effects, especially at very low concentration levels of analytes, and derivatization of analytes with 2, 4-dinitrophenylhydrazine (DNPH) is needed. Manini et al (2010) detected malondialdehyde (MDA), acrolein, 4-hydroxyhexenal (4-HHE), 4hydroxynonenal (4-HNE), and saturated aldehydes (n-hexanal, n-heptanal and n-nonanal) were detected from EBC using LC-MS/MS technique.

\subsection{Proton transfer reaction mass spectrometry (PTR-MS)}

PTR-MS is a very sensitive technique for online monitoring of VOCs developed by Hansel et al. (1995), which allows on-line monitoring of VOCs with volume mixing ratios as low as a few parts per trillion (pptv). Chemical ionization, based on proton transfer reactions with $\mathrm{H}_{3} \mathrm{O}^{+}$as the primary reactant ion, is used before mass spectrometry. Even though fragmentation is not desirable for quick visual interpretation, it can be an advantage when using more sophisticated mathematical techniques. If the fragmentation patterns of the compounds in a sample are known, and if the spectra of the pure compounds do not completely overlap, it is possible to recalculate the true 
concentrations. Figure 13 shows one simulated PTR-MS spectrum for the mixture of 21 compounds.

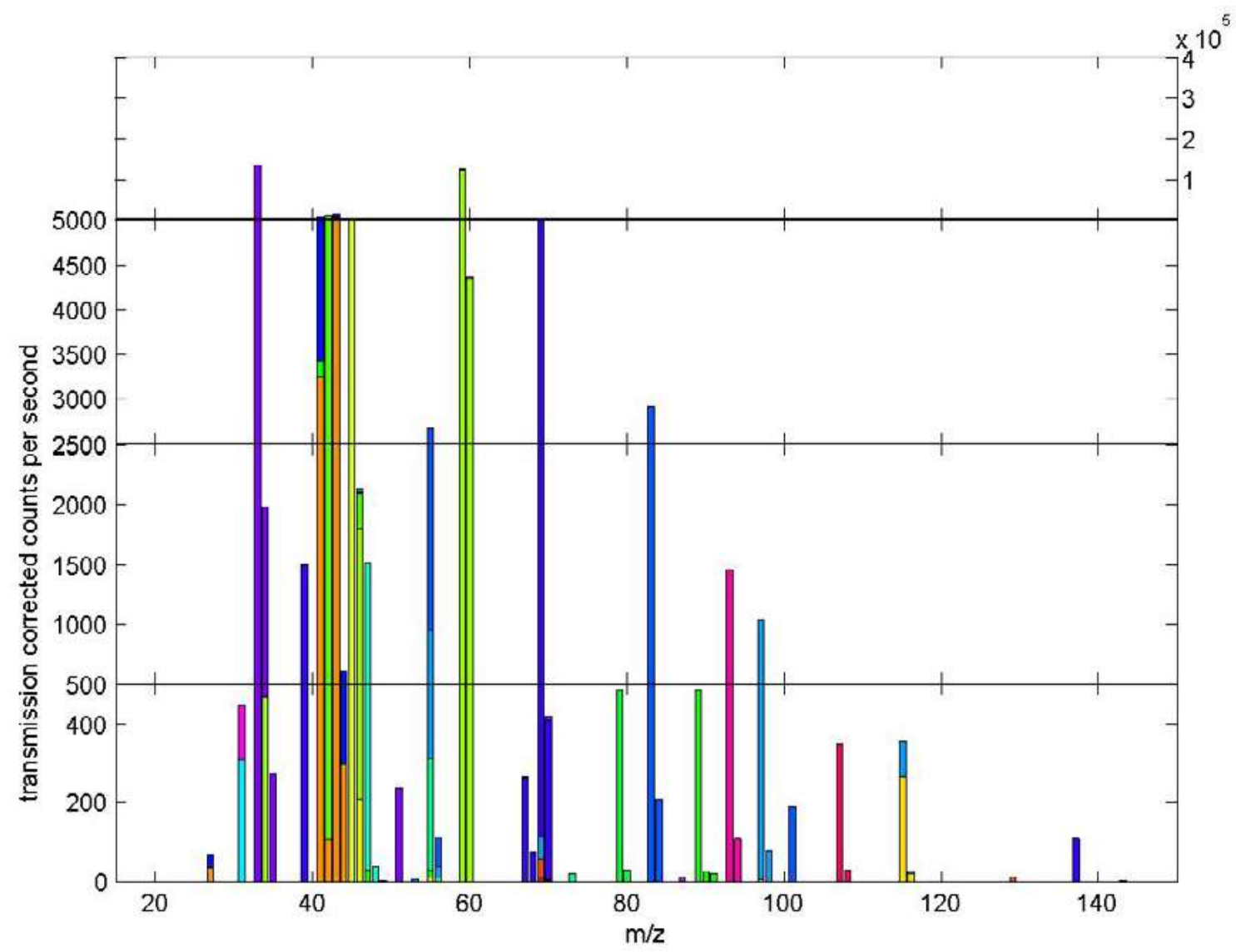

Figure 13. The simulated spectrum for the mixture of 21 compounds. (Schwarz et al., 2009)

\subsection{Selected ion flow tube mass spectrometry (SIFT-MS)}

SIFT-MS emerged as a new technology for detection of exhaled breath gases in humans (Spanel et al., 2006; Pysanenko et al., 2008; Hryniuk and Ross, 2009). SIFT-MS can analyze complex mixtures regardless of the water vapor content in real time without sample preparation. Figure 14 shows the schematic representation of the flowing after 
glow-selected ion flow tube (FA-SIFT) instrument. Acetone, acetaldehyde, ammonia, ethanol and water vapor were measured by SIFT-MS at ppbv level in a single-breath exhalation in real time (Scotter et al., 2005; Hryniuk and Ross, 2009). In the SIFT instrument reactant ions (precursors) are formed by electron ionization (EI) or microwavedischarge in a carrier gas in a separate ionization region. The trace gases in the sample react with quadrupole mass-selected $\mathrm{H}_{3} \mathrm{O}^{+}, \mathrm{NO}^{+}$or $\mathrm{O}_{2}^{+}$primary positive ions in the sample injection region. The resulting productions are mass selected by a second downstream quadrupole and detected using a particle multiplier producing the resulting mass spectrum. Thus, quantification of particular trace gases in the air sample is achieved. Nevertheless, the most commonly used precursor ion is water proton because this reacts with a wide range of non-dissociative organic species.

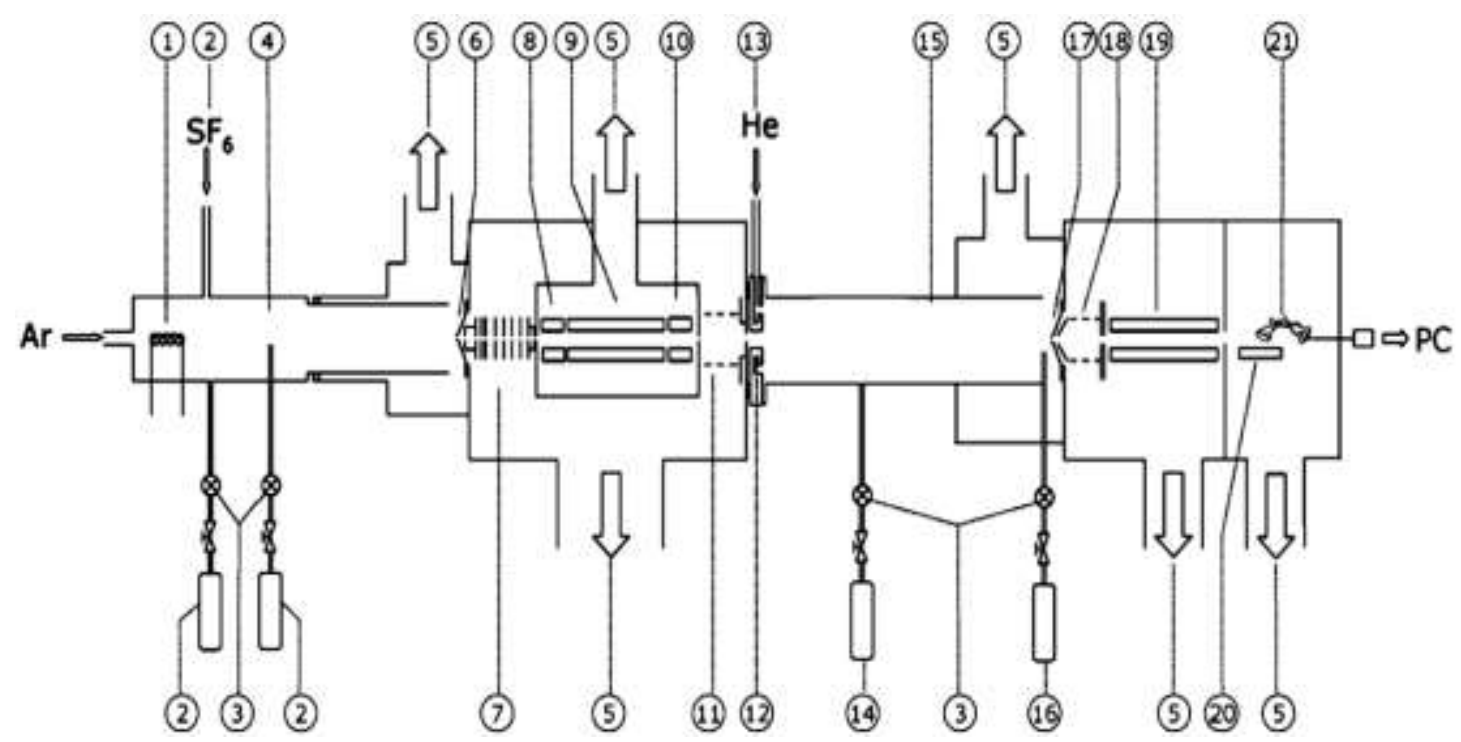

Figure 14. Schematic representation of the FA-SIFT instrument. (Dhooghe et al., 2009) 


\subsection{Electronic nose}

Apart from classical chemical analytical techniques, electronic nose has been proposed as a new analytical technique in the study of biological VOCs based on the bionic and electronic theory. Electronic nose consists of an array of nonspecific, gas sensitive, chemical sensors as artificial odor receptors. The sensor system in electronic nose contains quartz microbalance (Fleischer et al., 2002), carbon-polymer array (Chapman et al., 2012), colorimetric sensor array (Mazzone et al., 2007), gold nanoparticles (Peng et al., 2009; Peng et al., 2010), and so on. As an electronic simulation system of biological nose, it has been developed rapidly in the recent years and widely used to analyze volatile organic compounds in food, cosmetic, essential oil and so on. Mazzone et al. (2007) used colorimetric sensor array which consists of 36 chemically sensitive dots impregnated on a disposable cartridge to diagnose lung cancer. Figure 15 shows the process of breath analysis using the array of gold nanoparticle sensors. 
a

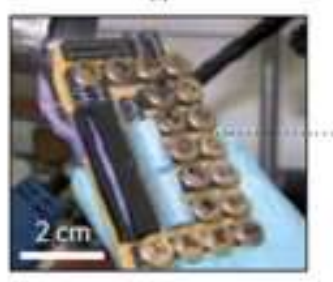

(ii)

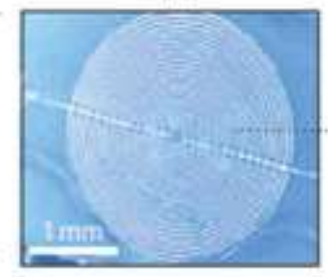

(iii)
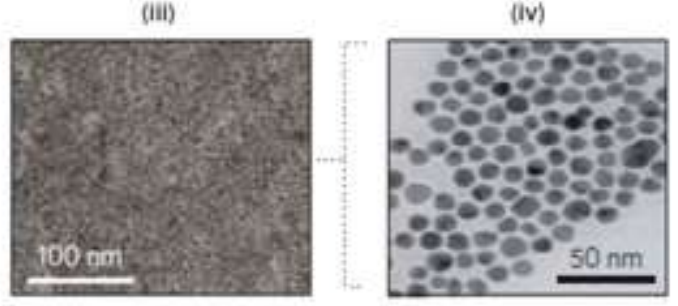

b

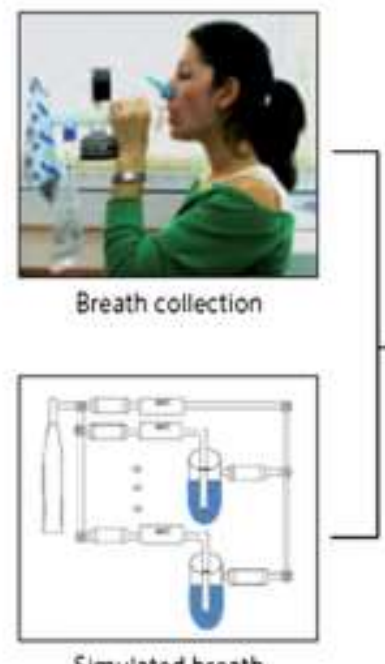

Simulated breath

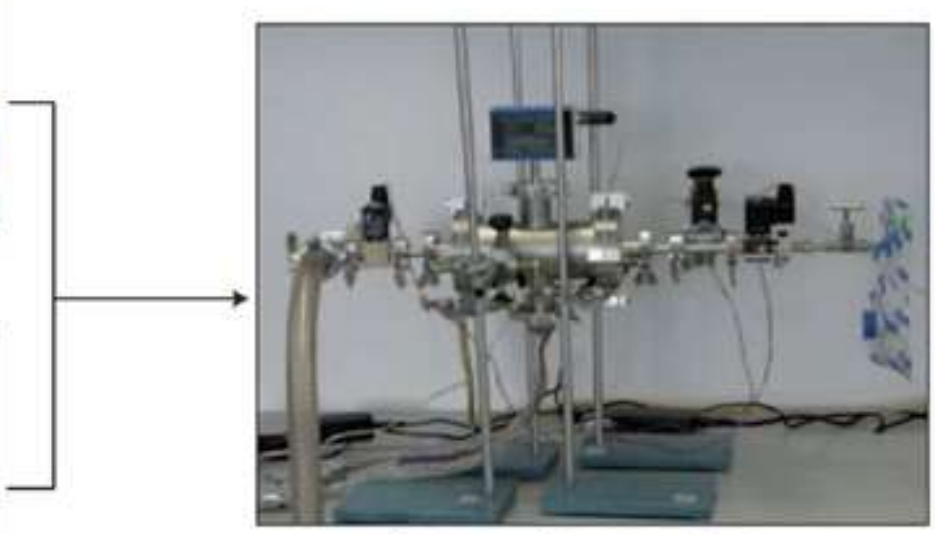

Application of the collected breath to the sensors array

Figure 15. Illustration of the diagnosis of lung cancer using breath testing. (a) A photograph of the array of sensors; (b) testing the exhaled breath collected from patients and simulated breath using the array of gold nanoparticle sensors (Peng et al., 2009).

Electronic nose can respond to the entire biological volatile profile, but cannot give the signal for every individual VOC component. Moreover, owing to the limitation of sensing material, manufacture technique and data-processing method, electronic nose cannot completely satisfy the requirement of analysis of complicated biological VOCs (Roeck et al., 2008)). For the determination of typical biological VOC or analysis of complicated real biological VOC system, GC-MS is still a preferred method. 


\subsection{Other analytical methods}

Moreover, analytical instruments have been used either as stand alone or in tandem with novel gas prefiltration systems to identify chemical components present in human exhaled breath. Schumann et al. (2006) used spectroscopic tools to find higher erythropoietin (EPO) levels in COPD patients. Laarkso et al. (2000) used low-resolution FT-IR spectrometry providing accurate measurement of ethanol in human breath.

\section{Carbonyl Compounds in Ambient Air and Exhaled Breath}

Carbonyl compounds are common atmospheric pollutants of direct emissions from motor vehicles (Schauer et al., 1999; Grosjean et al., 2001; Jakober et al., 2008; Zhao et al., 2010) and other combustion sources (Schauer et al., 2001; Kabir et al., 2010), produced by oxidation of virtually all hydrocarbons and photochemical reaction of precursors with free radicals and ozone (Baez et al., 2000; Cheng et al., 2010; Yuan et al., 2012; Guo et al., 2013). Carbonyl compound concentrations in ambient air of urban and rural areas and in emission gases form vehicles have been widely measured (Grosjean and Fung, 1982; Kuwata et al., 1983; Levin et al., 1985; Uchiyama et al., 2003; Uebori and Imamura, 2004) Several carbonyl compounds, such as formaldehyde, acetaldehyde, and propionaldehyde, are included in the results of 2005 national-scale assessment (NATA) of air toxics (http://www.epa.gov/nata2005/). Acrolein is a severe lung irritant that, at high acute exposures, can induce oxidative stress, decrease pulmonary function and cause lung injury, including asthma and lung cancer.

In recent years, several investigators have suggested that certain ketones and aldehydes in exhaled breath could be used as metabolic markers of lung cancer for 
noninvasive diagnosis of lung cancer in its early stages (Phillips et al., 2008; Bajtarevic et al., 2009; Fuchs et al., 2010; Poli et al., 2010) and chronic obstructive pulmonary disease (COPD) (Corradi et al., 2003). The reported concentrations of these ketones and aldehydes in breath are in the ppbv to pptv range. Ketones and aldehydes are produced in biochemical pathways as intermediates, and many are unique to a given pathway. Ketones and aldehydes are also generated from oxidative reactions, such as lipid peroxidation (Esterbauer et al., 1991; Pryor et al., 1991).

Most recently, SPME with adsorbed O-(2,3,4,5,6-pentafluorobenzyl) hydroxylamine hydrochloride (PFBHA) (Fuchs et al., 2010; Poli et al., 2010) and 2, 4dinitrophenylhydrazine (DNPH) (Grosjean et al., 2002; Fusaya et al., 2004; Wang et al., 2007) as sampling media has been used for analysis of aldehydes in exhaled breath. SPME is a popular preconcentration method introduced two decades ago as a rapid extraction technique for analysis of volatile organic compounds from a variety of matrixes (Arthur and Pawliszyn 1990). However, SPME is only a semiquantitative method due to competitive adsorption on the SPME fiber. It is also difficult to determine the actual volume of air that is sampled by the SPME fiber. The derivatives were subsequently eluted and analyzed by either high-performance liquid chromatography (HPLC) with an ultraviolet (UV) detector (Fusaya et al., 2004; Wang et al., 2007) or GC/MS (Fuchs et al., 2010; Poli et al., 2010).

\section{Motivation and Contributions of This Dissertation}

Detection of VOCs, at trace level (ppbv to pptv) has become an important research area because of demanding applications in homeland security, environmental 
monitoring, and noninvasive health diagnosis. (Tian et al., 2005; Agah et al., 2006) The analysis of trace VOCs challenges existing analytical methods because their concentrations are beyond current instrument limits of detection. This problem is further exacerbated by other interfering gases that are mixed in large concentration with the VOCs. Gas chromatography coupled with a mass spectrometry detector (GC/MS) is currently a dominant technique for analysis of trace VOCs in air (Riemer et al., 1998; Phillips et al., 1999; Apel et al., 2003). A complex preconcentration process consisting of cryogenic adsorption and thermal desorption typically is required before trace VOC samples can enter into a GC column (Gilpin et al., 1997; Agah et al., 2006; Alfeeli et al., 2008; Apel et al., 2010). In recent years, microfabricated gas preconcentrators and gas chromatography columns have demonstrated the potential for real-time, low-power, and hand-held gas detection. These MEMS preconcentrators have common issues of inefficient physical adsorption and thermal desorption (Alfeeli et al., 2008; Voiculescu et al., 2008; Alfeeli and Agah, 2009). So the idea of chemical adsorption MEMS preconcentrator for rapid analysis and identification of VOC adducts on a microliter sample size was emerged.

This dissertation presents four inter-connected research objectives: 1) design, fabricate MEMS microreactors; 2) fundamentally understand the relationship between the chemoselective capture efficiency and microfabricated microreactor structure and surface functionality; 3) utilize the developed microreactor and analysis technique to analyze carbonyl compound concentrations in ambient air; 4) analyze exhaled breath samples from patients with pulmonary nodules for identification of lung cancer biomarker.

The contributions in this dissertation are summarized as follows: 
1. A novel microreactor using MEMS technology with high chemoselective capture efficiency for analysis of trace carbonyl compounds has been developed.

2. The novel microreactor has been used for preconcentration of carbonyl VOCs in ambient air.

3. Six carbonyl VOCs in exhaled breath have been identified to distinguish lung cancer from healthy controls and patients with benign pulmonary nodules using the microreactor approach. Two VOCs can be further used to discriminate small cell lung cancer (SCLC) from non-small cell lung cancer (NSCLC), and one VOC to discern squamous cell from adenocarcinoma lung cancer.

4. In the double-blind study, lung cancer patients were identified with $90.6 \%$ sensitivity and $81.3 \%$ specificity using uncomplicated statistics model.

\section{Dissertation Organization}

The dissertation consists of six chapters including present chapter. The following summary presents the scope of each chapter.

Chapter II introduces the design and fabrication process of the microreactor. The flow patterns of the microreactor were simulated using MEMS simulation software (CoventorWare). Microreactors with structures optimized by CoventorWare simulation were fabricated using MEMS technique.

Chapter III shows the characterization of microreactors capturing carbonyl compounds at a trace level in model gas mixtures, presents the relationship between the capturing efficiency and surface functionality, and provides kinetics study of the oximation reaction in the microreactor. 
Chapter IV demonstrates the application of the microreactor for capturing carbonyl compounds in ambient air. This application presents the ability of the microreactor to capture VOCs at 100 pptv level. In this chapter, carbonyl compounds from indoor and outdoor air samples were compared, and the change of the concentration of carbonyls in one day was monitored. The results of this chapter led to the analysis of the exhaled breath samples, and provide the background data of breath samples in the next chapter.

Chapter V presents the use of the microreactor for capturing carbonyl VOCs in human exhaled breath. The markers of lung cancer were found by statistical data analysis of the concentrations between the healthy controls and lung cancer patients. Lung cancer patients were identified based on simple statistics models with $90.6 \%$ sensitivity and $81.3 \%$ specificity.

Chapter VI concludes the dissertation and outlines the future work. 


\section{CHAPTER II}

\section{MICROREACTOR DESIGN AND FABRICATION}

\section{Design and Simulation}

The microreactor was analyzed using finite element method via computational fluid dynamics (CFD) software. CFD software package in Commercial CoventorWare is a powerful tool to simulate gas flow and provides guideline for the design of microfabricated microreactor. The CFD module of CoventorWare has been widely used for design of microfludic devices. CFD simulation can aid to predict the performance of microreactors, thus save a large amount of time and resource for fabrication and testing devices.

A $1.5 \mathrm{~mm} \times 2.5 \mathrm{~mm}$ rectangular area channel was defined for simulation in order to save computer memory. There were thousands of square pillars $(50 \mu \mathrm{m} \times 50 \mu \mathrm{m})$ or cylindrical pillars $(\mathrm{d}=50 \mu \mathrm{m})$ with $250 \mu \mathrm{m}$ high in the channel in order to distribute gas flow and increase the adsorption surface area.

The microfluids in the channel area are assumed to follow the fundamental governing equations of fluid dynamics. The continuity equation is: 


$$
\frac{\partial \rho}{\partial \mathrm{t}}+\nabla \cdot(\rho \vec{v})=0
$$

The momentum equation follows the Navier-Stokes equation, which is:

$$
\rho\left(\frac{\partial \vec{v}}{\partial \mathrm{t}}+\vec{v} \cdot \nabla \vec{v}\right)=-\nabla p+\nabla \cdot \boldsymbol{T}+f
$$

where $\rho$ is the fluid density, $\vec{v}$ is the flow velocity, $\mathrm{p}$ is the pressure, $\mathbf{T}$ is the component of the total stress tensor and $f$ represents body forces acting the fluid.

Eight different kinds of layouts were simulated. The microreactor performance was simulated in terms of flow velocity profile. The channel area of the microreactor was meshed into linear extruded bricks by split \& merge algorithm. Boundary conditions were assigned as follow: all the fluid velocities on the surface of the wall and micropillars in the microreactor were considered as 0 . The pressure difference between entrance and exit area is $1 \times 10^{5}$ pa. A simulated $2 \times 10^{6} \mu \mathrm{m} / \mathrm{s}$ in $\mathrm{x}$ direction, steady state, and compressible, finite volume gas flow through the different channel designs was simulated as shown in Figure 16. 


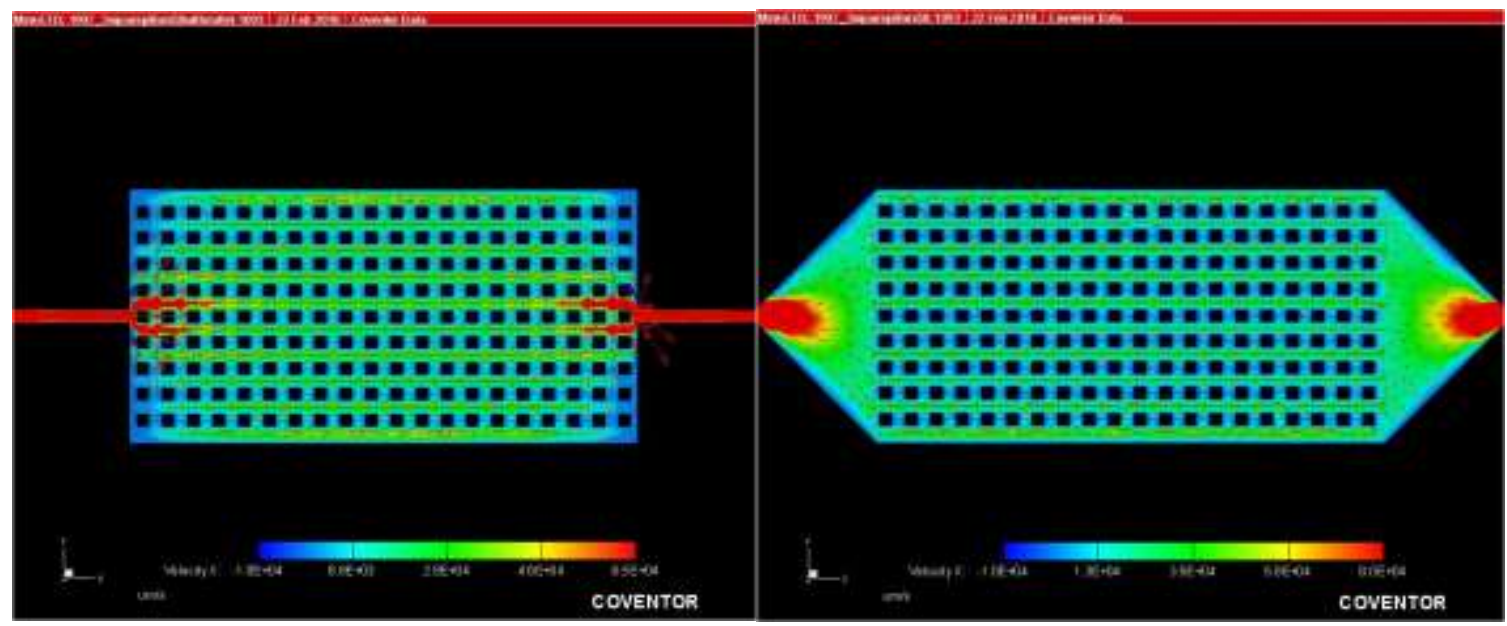

(a)

(b)

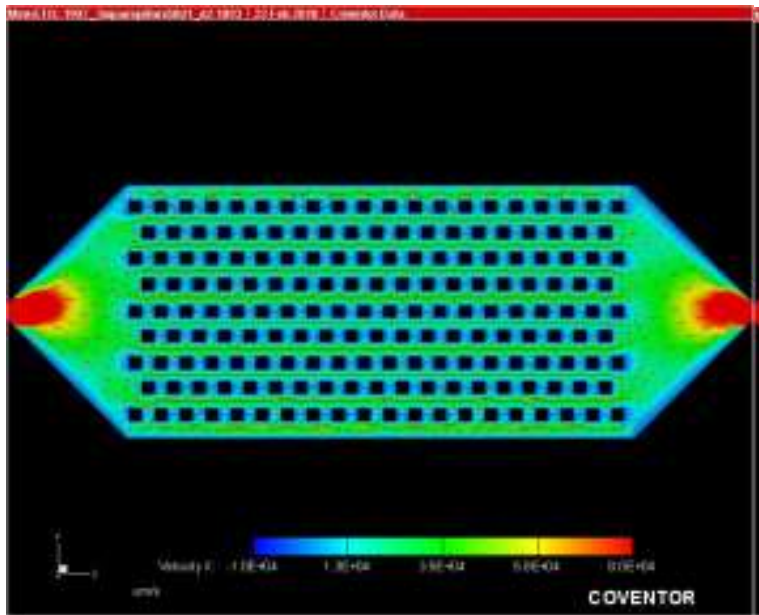

(1)

(2)

(c)

(d)

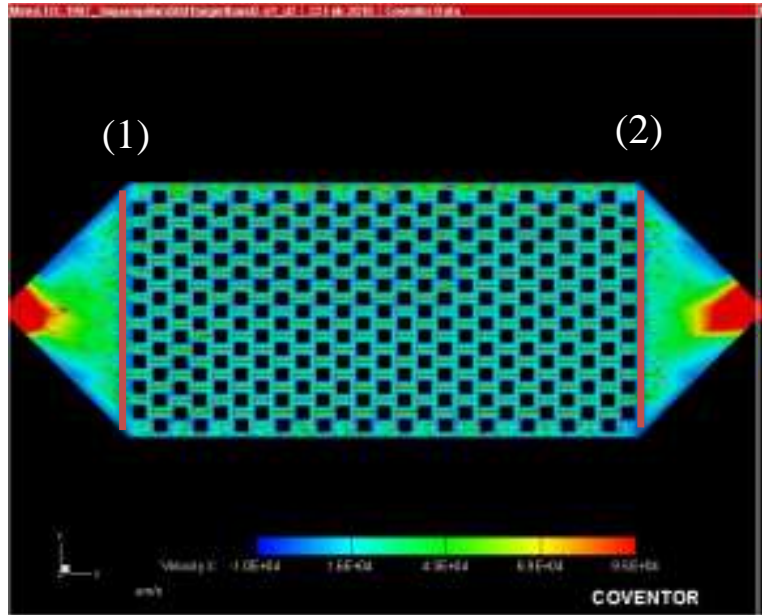

(e)
(1)

(2)

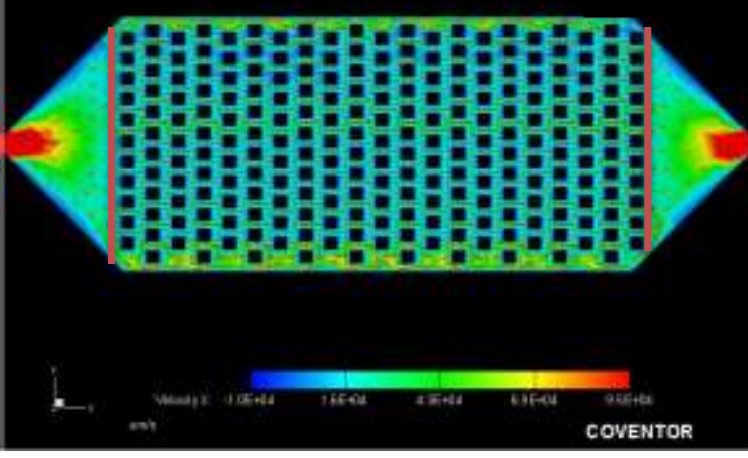

(f) 


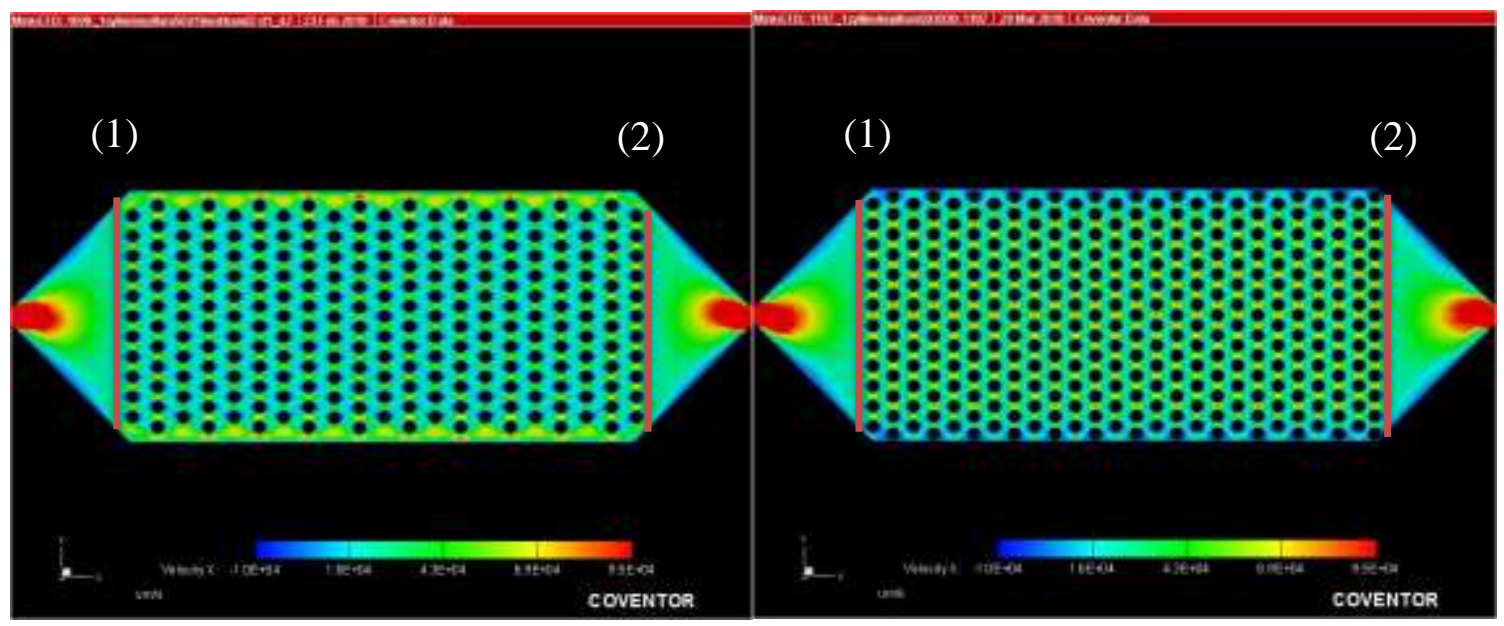

(g)

(h)

Figure 16. CFD simulations of microreactor with different pillar shapes and patterns. (a) Square pillar arrays without inlet/outlet, (b) Ordered square pillar arrays, (c) Square pillars parallel in alternate rows moved in x-axis, (d) Square pillars in alternate columns vertically shifted in $y$-axis $\left(d_{1}=50 \mu \mathrm{m}, d_{2}=50 \mu \mathrm{m}\right)$, (e) Square pillars in alternate columns vertically shifted in $y$-axis $\left(d_{1}=50 \mu \mathrm{m}, d_{2}=30 \mu \mathrm{m}\right)$, (f) Square pillars in alternate columns vertically shifted in y-axis $\left(\mathrm{d}_{1}=30 \mu \mathrm{m}, \mathrm{d}_{2}=50 \mu \mathrm{m}\right),(\mathrm{g})$ Cylindrical pillars in alternate columns vertically shifted in $\mathrm{y}$-axis $\left(\left(\mathrm{d}_{1}=30 \mu \mathrm{m}, \mathrm{d}_{2}=50 \mu \mathrm{m}\right)\right.$, (h) Cylindrical pillars in alternate columns vertically shifted in y-axis $\left(\left(d_{1}=30 \mu \mathrm{m}, d_{2}=50 \mu \mathrm{m}\right)\right.$.

The microreactor without inlet/outlet structures was designed first shown in Fig. 16(a), and the distances between adjacent pillars in $\mathrm{x}$-axis and $\mathrm{y}$-axis are both $50 \mu \mathrm{m}$. A large area of dead space (blue area) was found near the inlet/outlet area. The design was changed by adding isosceles right triangle shape inlet and outlet structures shown in Fig. 16(b) without changing the patterns of pillar arrays, however, the dead space area can still be found around the square pillars because of the ordered pillar arrays. The dead space decreased when the pillar arrays were parallel moved in x-axis (Fig. 16(c)). And it further reduced when the pillar in alternate columns were vertically shifted in y-axis (Fig. 16(d)). 
The distance between the pillar columns $\left(\mathrm{d}_{1}\right)$ (Fig. 16(e)) and the distance between adjacent pillars in each column $\left(\mathrm{d}_{2}\right)$ (Fig. 16(f)) were adjusted, and the pillar shape was changed to cylinder to achieve further less dead space (Fig. 16(g) and (h)). The details of the patterns of the pillar arrays were presented in Table 3.

\section{Table 3}

The details of the simulation pillar patterns

Pattern ID Pillar Pillar size $\quad \mathrm{d}_{1}(\mu \mathrm{m}) / \mathrm{d}_{2}(\mu \mathrm{m}) \quad$ Surface $\quad$ No. of

(Shown in shape $\quad \operatorname{area}\left(\mathrm{mm}^{2}\right) \quad$ pillars

Fig. 16)

\begin{tabular}{|c|c|c|c|c|c|}
\hline $\mathrm{a}$ & Square & $50 \mu \mathrm{m} \times 50 \mu \mathrm{m}$ & $50 / 50$ & 9 & 180 \\
\hline b & Square & $50 \mu \mathrm{m} \times 50 \mu \mathrm{m}$ & $50 / 50$ & 9.95 & 180 \\
\hline $\mathrm{c}$ & Square & $50 \mu \mathrm{m} \times 50 \mu \mathrm{m}$ & $50 * / 50 *$ & 9.95 & 176 \\
\hline d & Square & $50 \mu \mathrm{m} \times 50 \mu \mathrm{m}$ & $50 / 50$ & 9.95 & 199 \\
\hline e & Square & $50 \mu \mathrm{m} \times 50 \mu \mathrm{m}$ & $50 / 30$ & 11.85 & 237 \\
\hline $\mathrm{f}$ & Square & $50 \mu \mathrm{m} \times 50 \mu \mathrm{m}$ & $30 / 50$ & 12.05 & 241 \\
\hline$g$ & Cylinder & $\mathrm{d}=50 \mu \mathrm{m}$ & $30 / 50$ & 9.45 & 241 \\
\hline h & Cylinder & $\mathrm{d}=50 \mu \mathrm{m}$ & $30 / 30$ & 13.25 & 325 \\
\hline
\end{tabular}

*In pattern $\mathrm{c}, \mathrm{d}_{1}$ equals distance between the pillar rows; $\mathrm{d}_{2}$ equals distance between adjacent pillars in each column. 
Since uniform velocity distribution can promote better mixing of the compounds in fluid and the coating materials on the surface of the microreactor, the pillar arrays not only reduce dead space, but also contribute to uniform velocity distribution. Two planes which are before (Plane 1) and after pillar arrays (Plane 2) (Positions shown in Fig. 16(d), (e), (f), (g) and (h)) were monitored from Pattern d to Pattern h shown in Figure 16.

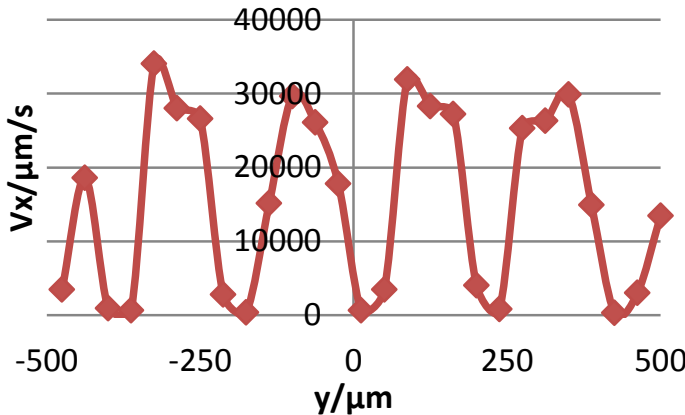

(a)

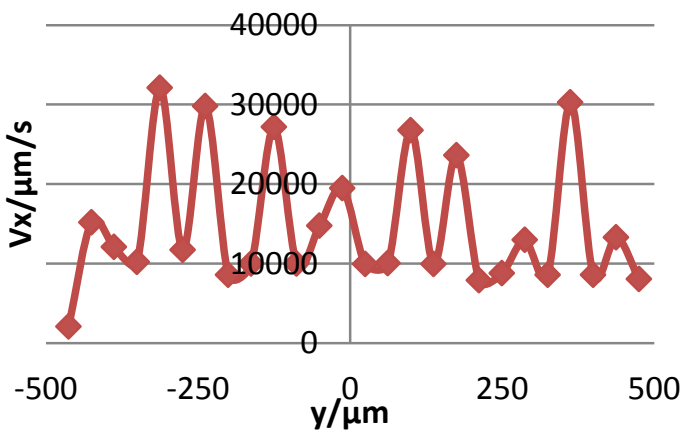

(c)

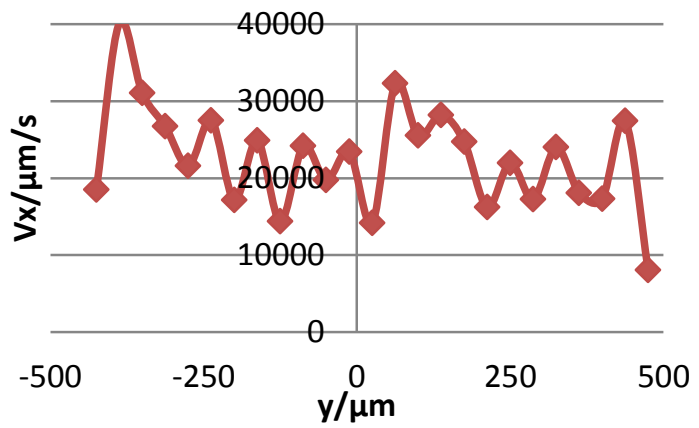

(e)

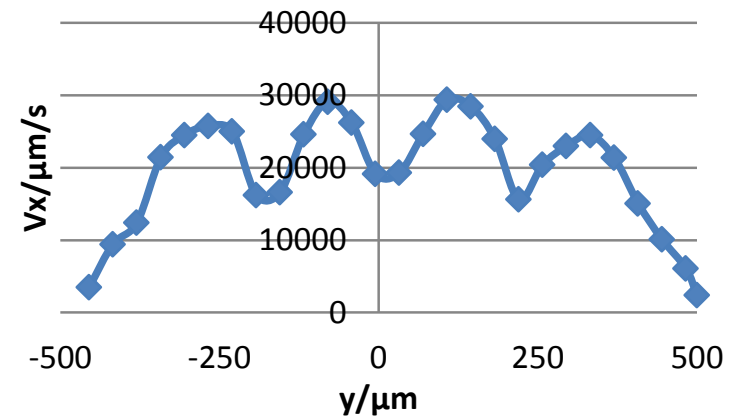

(b)

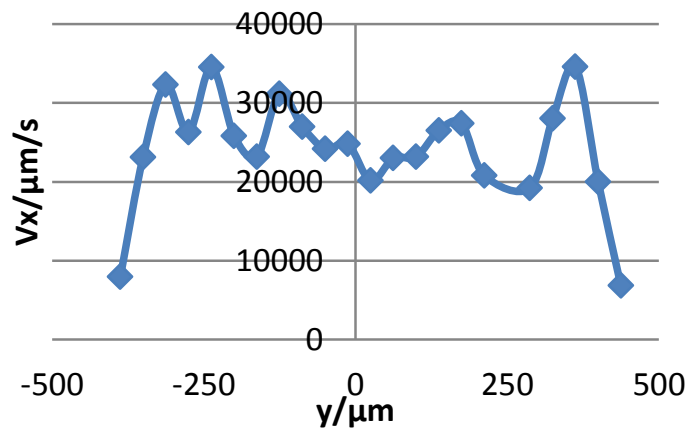

(d)

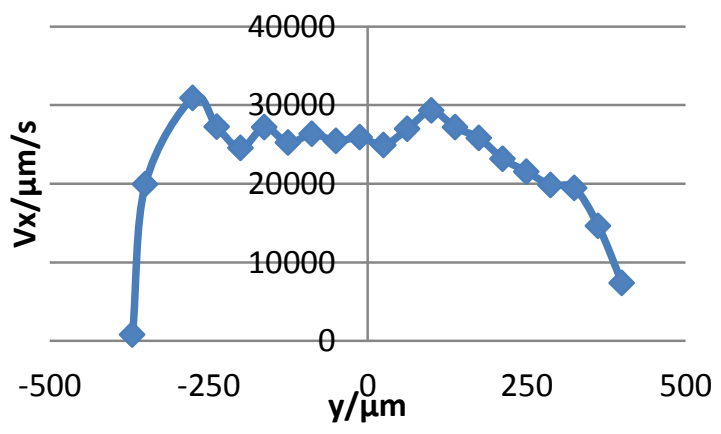

(f) 


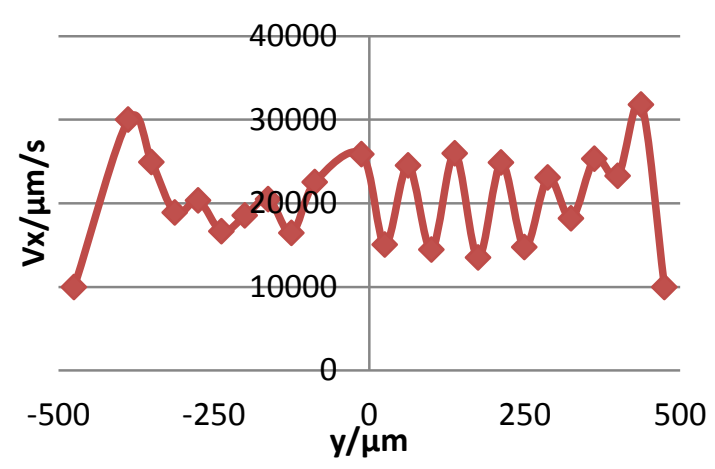

(g)

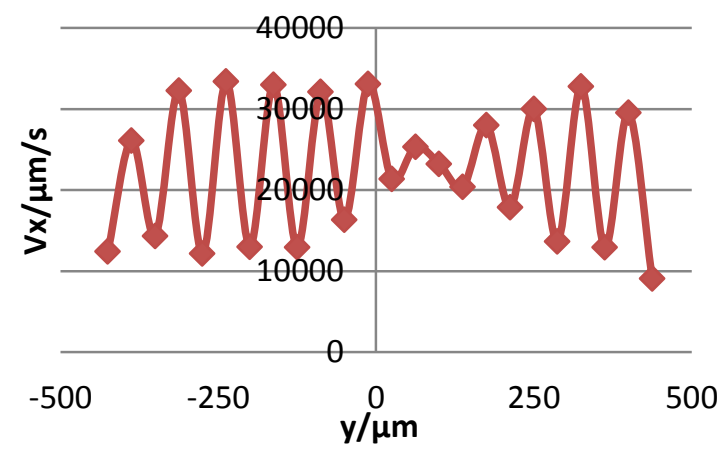

(i)

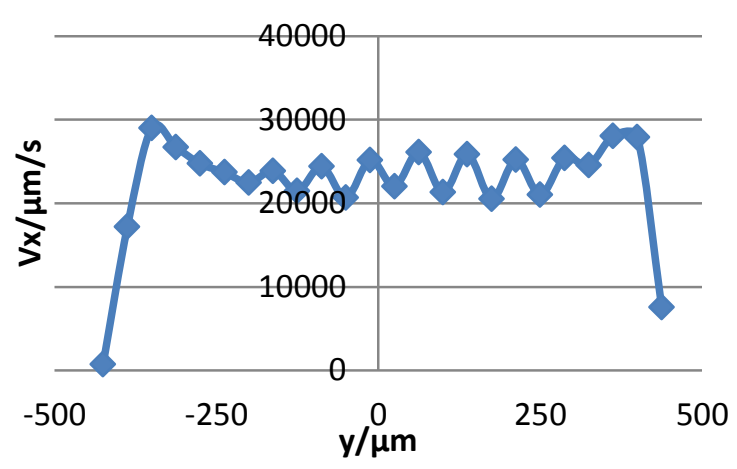

(h)

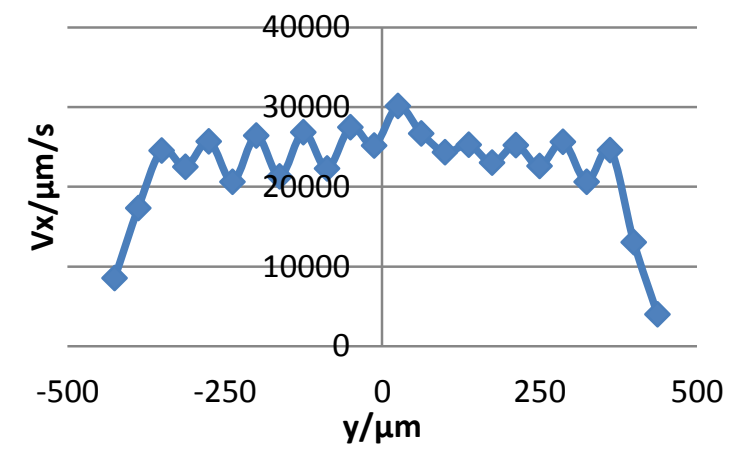

(j)

Figure 17. Velocity distribution before the pillar arrays: (a) Pattern d, (c) Pattern e, (e) Pattern f, (g) Pattern g, (i) Pattern h; velocity distribution after pillar arrays: (b) Pattern d, (d) Pattern e, (f) Pattern f, (h) Pattern g, (j) Pattern h shown in Figure 16.

Velocity distributions were more uniform after flowing through the pillar patterns than before entering into the pillar patterns shown in Figure 17. In square pillar arrays, distribution of Pattern f (Fig. 17(f)) was more uniform than Pattern d (Fig. 17(b)) and Pattern e (Fig. 17(f)). Compared velocity distributions after square pillar arrays (Fig. 17(f)) with cylindrical pillar arrays (Fig. 17(h)), although Pattern $f$ had more uniform distribution in the middle, the right part of it decreases continuously, and there are two obvious peaks at each end. However, the distribution of Pattern g maintained the level 
between 20,000 and $25,000 \mu \mathrm{m} / \mathrm{s}$. The dead space also decreased in the cylindrical pillar arrays. When $d_{2}$ decreased to $30 \mu \mathrm{m}$ (Pattern $\mathrm{h}$ ), there was one peak in the middle of $y$ direction and the velocity distribution was less uniform in Pattern g shown in Figure 16. Therefore, the distance between the pillars affects the gas flow velocity distribution. The pillar arrays of Pattern $\mathrm{g}$ was chosen as the design base of the microreactor.

\section{Fabrication}

A selection of CoventorWare simulated microreactor microstructures including inlet and outlet, micro pillar shape, size, and distances among micropillars have been fabricated on the same wafer for measuring preconcentrating efficiencies and correlated with the CoventorWare simulation results. The microreactors are designed with hundreds of micropillars for increasing surface area for deposition. MEMS design software L-edit was used to generate $\mu \mathrm{PC}$ microstructures and the masks for microfabrication at the University of Louisville. A total of sixteen microreactors can be fabricated on the same 4" in diameter silicon wafers which is the significant advantage of microfabrication. Figure 18 shows 16 microreactors designed on one photo mask. The entire fabrication processes are simple and routinely used for MEMS device fabrication. Figure 19 shows the fabrication process flow schematics. 


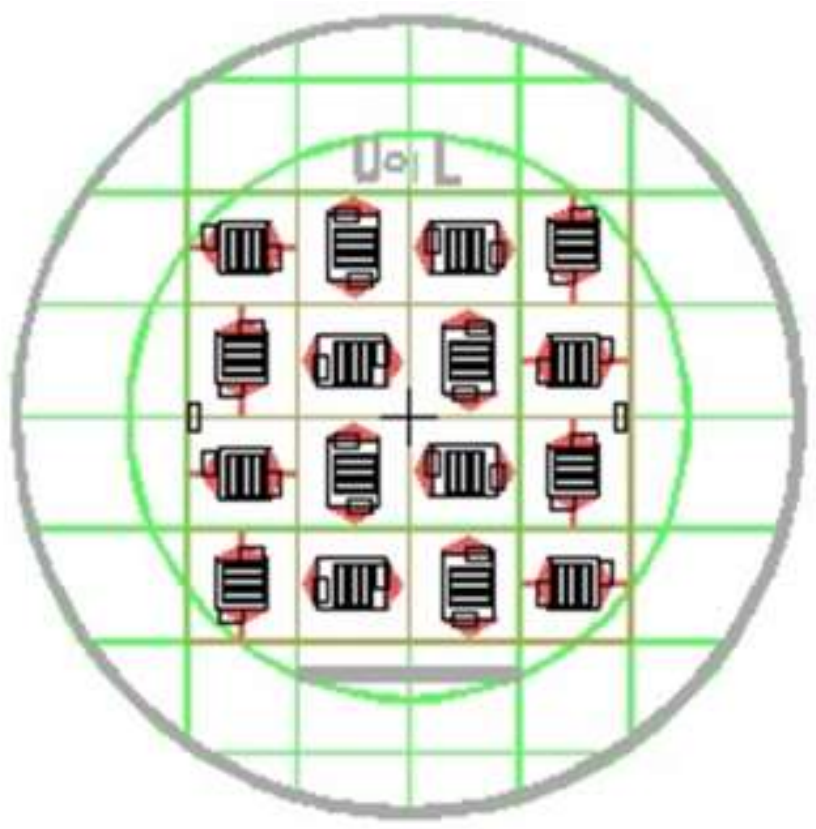

Figure 18. Photo mask layout of the microreactors. 


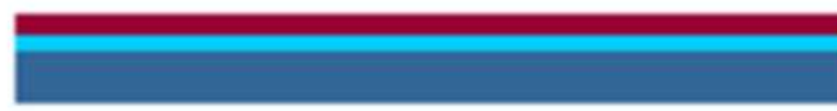

(a)

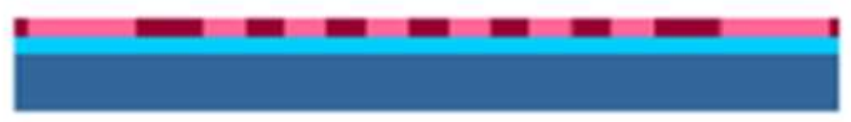

(b)

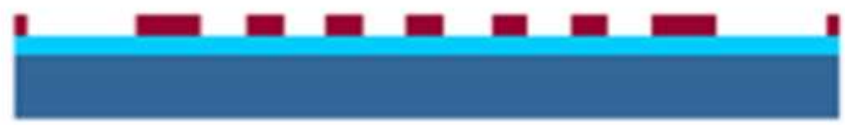

(c)

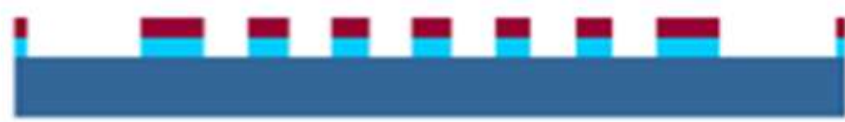

(d)

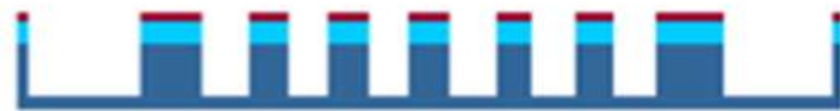

(e)

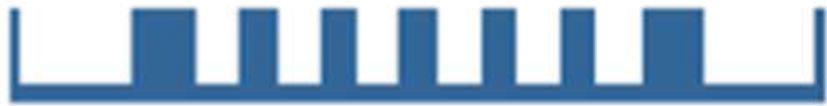

(f)

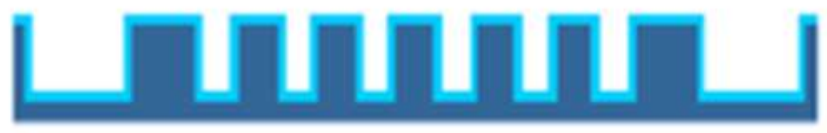

(g)

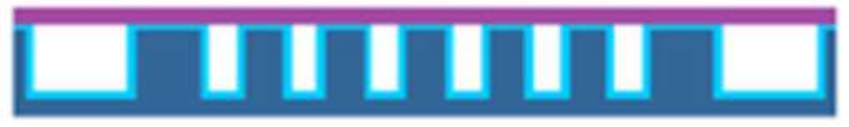

(h)

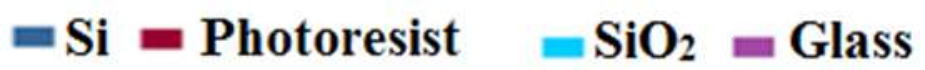

Figure 19. Fabrication process flow of preconcentration in cross-sectional view. (a) Photoresist coating, (b) UV light exposure, (c) Development, (d) Buffered oxide etching (BOE), (e) Deep reactive ion etching (DRIE), (f) Photoresist removing and BOE, (g) Oxidation, (h) Anodic bonding.

The detailed processes shown in Figure 19 are described in the following paragraphs. 


\subsection{Photolithography}

Photolithography, literally meaning light-stone-writing in Greek, is a process used in microfabrication by which patterns transferred on a substrate. It uses ultraviolet (UV) light to transfer a geometric pattern from a photo mask to a light-sensitive chemical "photoresist". A photoresist is a light-sensitive polymer material used in photolithography. The UV light causes the photoresist to degrade in the exposed region. Photoresists are classified into two groups: positive resists and negative resists. The action of light on a positive resist causes photoresist exposed area to decompose and washed away by developer solution in the areas exposed to the light. A negative resist has the reverse property. Exposure to UV-light causes the exposed photoresist to decompose.

Before the photoresist was applied to the silicon wafer, the wafer was cleaned to remove any trace contaminations on the surface of the wafer such as dust, organic, ionic and metallic compounds, and then a $500 \mathrm{~nm}$ layer of silicon dioxide was formed by a wet oxidation process as DRIE mask. The cleaned wafer is crucial to aid the adhesion of the photoresist to the surface of the substrate. Hexamethyldisilazane (HMDS) adhesion promoter was applied to the surface of the wafer using Headway Spinner machine. This tool holds the wafer using vacuum. The surface layer of silicon dioxide on the wafer reacts with HMDS to form tri-methylated silicon-dioxide. The hydrophobic layer prevents the aqueous developer from penetrating between the photoresist layer and the wafer surface. A S1827 photoresist was then applied until it covered approximately half the substrate. The spinner spread the photoresist at low-speed (500 rpm) for 1 second and spun it at high-speed (4000 rpm) for 10 seconds. The rotation caused the photoresist to be spread uniformly across the surface of the wafer with excess being spun off. The 
thickness of photoresist was around $2700 \mathrm{~nm}$ (Fig. 19(a)). S1827 photoresist is a kind of positive resists that mixed cresol novolak resin is dissolved in electronic grade propylene glycol monomethyl ether acetate. Novolaks are phenol formaldehyde (PF) type polymers, generally synthesized using cresol rather than phenol, with the polycondensation reaction halted before the polymer becomes crosslinked. Being phenols, these polymers are soluble in aqueous base, although the rate of dissolution is quite slow. However, in the presence of suitable additives, the dissolution process can be greatly enhanced. The additives can be produced photochemically, leading to a useful photoresist system.

Preparation of the photoresist was concluded by softbake, where the wafer is gently heated on a hotplate to evaporate the resist solvent and to partially solidify the photoresist. After coating, the photoresist film contains a remaining solvent concentration depending on the resist, the solvent, the thickness of the resist film and coating technique. The softbake reduces the remaining solvent content in order to improve resist adhesion to the substrate. Softbake plays a critical role in photolithography. The photoresist coatings become photosensitive, or imageable, only after softbake. So the silicon wafer was soft baked for 75 seconds at $115^{\circ} \mathrm{C}$ using the hotplate after coating process.

One of the most important steps in the photolithography process is mask alignment. A photomask is a square glass plate with a patterned chromium film on one side. The mask is aligned with the wafer, so that the pattern can be transferred onto the wafer surface. Once the mask has been accurately aligned with the pattern on the wafer's surface, the photoresist is exposed through the pattern on the mask with a high intensity ultraviolet light. There are three primary exposure methods: contact, proximity, and projection. The Karl Suss Mask Aligner MA6/BA6 used in the experiment provided 
contact exposure method. In contact printing, the resist-coated silicon wafer is brought into physical contact with the glass photomask. The wafer is held on a vacuum chuck, and the whole assembly rises until the wafer and mask contact each other. The photoresist is exposed with UV light while the wafer is in contact position with the mask (Fig. 19(b)). Because of the contact between the resist and mask, very high resolution is possible in contact printing. The minimum feature size of the patterns can be approximately defined by:

$$
C D=k_{1} \cdot \frac{\lambda}{N A}
$$

where $C D$ is the minimum feature size, $k_{l}$ is a coefficient that encapsulates processrelated factors, and typically equals 0.4 for production, $\lambda$ is the wavelength of light used, and $N A$ is the numerical aperture of the lens as seen from the wafer. In the experiment, Iline $(365 \mathrm{~nm})$ light wavelength was used. The contact method provided low value of $N A$. $1 \mu \mathrm{m}$ feature size can be achieved in the UV lithography. The wafer was exposed for 3555 seconds depending on the UV light resource power in the process.

One of the last steps in the photolithographic process is development. The unexposed areas of negative resist remains completely soluble in the developer solution. As the exposure energy is increased above a threshold value, more of the resist film remains after development. For positive resists (S1827) used in this experiment, the resist solubility in its developer is finite. The solubility of the exposed areas gradually increases until, at some threshold, it becomes completely soluble. These curves are affected by all the resist processing variables: initial resist thickness, prebake conditions, developer chemistry, developing time, and others. Microposit ${ }^{\circledR}$ MF 319 developer was used in the 
process, which is tetramethylammonium hydroxide dissolved in water. The wafer was immersed into the beaker contained MF 319 developer to develop for 60-80 seconds, rinsed under running deionized water, and dried by $\mathrm{N}_{2}$. The developed wafer was observed using optical microscope (Fig. 19(c)). The spin, exposure and development processes would be redone until the whole micropillars were patterned.

To remove the solvent content in photoresist thereby increasing adhesion, hardening the photoresist and making it etch resistant, hardbake process is required. The wafer was finally hardbaked for 75 seconds using the hotplate at $115^{\circ} \mathrm{C}$.

\subsection{Silicon oxide etching}

The thermal oxide in the microreactor area is patterned by buffered oxide etching (BOE) solution. BOE solution is a wet etchant used in microfabrication, which comprises a 6:1 volume ratio of $40 \%$ ammonium fluoride $\left(\mathrm{NH}_{4} \mathrm{~F}\right)$ in water to hydrofluoric Acid (HF). Its use is in etching thin film of $\mathrm{SiO}_{2}$. Overall reaction for etching $\mathrm{SiO}_{2}$ with $\mathrm{BOE}$ solution is as follows:

$$
\mathrm{SiO}_{2}+4 \mathrm{HF} \rightarrow \mathrm{SiF}_{4}+2 \mathrm{H}_{2} \mathrm{O}
$$

where a buffering agent, $\mathrm{NH}_{4} \mathrm{~F}$ is added to maintain $\mathrm{HF}$ concentration and to control $\mathrm{pH}$ (to minimize attack of photoresist). Buffering reaction is shown in Equ. (5):

$$
\mathrm{NH}_{4} \mathrm{~F} \leftrightarrows \mathrm{NH}_{3}+\mathrm{HF}
$$

The etch rate of $\mathrm{BOE}$ at $22{ }^{\circ} \mathrm{C}$ is $120 \mathrm{~nm} / \mathrm{min}$. The thickness of $\mathrm{SiO}_{2}$ is $500 \mathrm{~nm}$, so the wafer was immersed into BOE solution for 5 minutes to make sure that the $\mathrm{SiO}_{2}$ layer 
in the microreactor area was etched completely (Fig. 19(d)). After BOE, the wafer was rinsed for 2 minutes in running DI water, and dried by $\mathrm{N}_{2}$ gun.

\subsection{DRIE}

DRIE is a common tool for the microfabrication of MEMS devices requiring controllable anisotropic etching to form high aspect ratio features. The Bosch process version of this technique when used on silicon consists of alternating sulfur hexafluoride $\left(\mathrm{SF}_{6}\right)$ isotropic plasma etching and polymer (such as octafluorocyclobutane, $\mathrm{C}_{4} \mathrm{~F}_{8}$ ) deposition passivation steps. During the etching process, the plasma contains some ions, which attack the wafer from a nearly vertical direction. The main reactions for etching $\mathrm{Si}$ with $\mathrm{SF}_{6}$ and $\mathrm{O}_{2}$ plasma:

$$
\begin{gathered}
\mathrm{SF}_{6}+4 e \rightarrow \mathrm{SF}_{2}+4 \mathrm{~F}+4 e \\
\mathrm{O}_{2}+e \rightarrow 2 \mathrm{O}+e \\
\mathrm{Si}+4 \mathrm{~F} \rightarrow \mathrm{SiF}_{4} \\
\mathrm{Si}+2 \mathrm{O} \rightarrow \mathrm{SiO}_{2} \\
\mathrm{SiO}_{2}+4 \mathrm{~F} \rightarrow \mathrm{SiF}_{4}+\mathrm{O}_{2}
\end{gathered}
$$

The passivation layer protects the entire substrate from further chemical attack and prevents further etching.

An STS MESC Multiplex ICP machine was used for DRIE etching silicon wafers. During etching step, $160 \mathrm{sccm} \mathrm{SF}_{6}$ and $13 \mathrm{sccm} \mathrm{O} \mathrm{O}_{2}$ gas were purged into the chamber of the machine and the wafer was etched for 9.5 seconds. Then $75 \mathrm{sccm} \mathrm{C}_{4} \mathrm{~F}_{8}$ gas was 
substituted for 7 seconds in passivation step. The etching rate was $1.67 \mu \mathrm{m} / \mathrm{min}$ under this recipe. The wafer was etched for 2.5 hours (Fig. 19(e)).

\subsection{Thermal oxidation}

After DRIE, the residual photoresist and $\mathrm{SiO}_{2}$ layer was removed by acetone and BOE, respectively (Fig. 19(f)). The wafer will be oxidized to form a $50 \mathrm{~nm} \mathrm{SiO}$ layer. The surface of the $\mathrm{SiO}_{2}$ layer has weak negative charge caused by radiation (Deal, 1974) which contributes to adsorption of aminooxy compounds loading into the microreactor. It also helps the formation of bonding between silicon wafer and glass wafer (Xiong et al., 2010).

In the experiment, the post DRIE silicon wafer was "wet" oxidized in a quartz thermal oxidation furnace in $\mathrm{O}_{2}$ and $\mathrm{H}_{2} \mathrm{O}$ atmosphere at $1000^{\circ} \mathrm{C}$. The reactions are:

$$
\begin{gathered}
\mathrm{Si}+\mathrm{H}_{2} \mathrm{O} \stackrel{1000^{\circ} \mathrm{C}}{\longrightarrow} \mathrm{SiO}_{2}+\mathrm{H}_{2}(\mathrm{~g}) \\
\mathrm{Si}+\mathrm{O}_{2} \stackrel{1000^{\circ} \mathrm{C}}{\longrightarrow} \mathrm{SiO}_{2}
\end{gathered}
$$

The wet thermal oxidation rate at $1000{ }^{\circ} \mathrm{C}$ is about $5 \mathrm{~nm} / \mathrm{min}$, so the wafer was oxidized for 10 minutes (Fig. 19(g)).

\subsection{Anodic bonding}

The wafer was sealed by anodic bonding a glass wafer on the top of the microreactor wafer. Anodic bonding is popular in MEMS packaging due to the simple set-up with inexpensive equipment required. Anodic bonding provides reliable hermetic sealing that is important for applications in microchannels in microfluidic devices. 
Another advantage of this bonding technique is that anodic bonding can take place at relatively low temperatures in the range of 250 to $500{ }^{\circ} \mathrm{C}$, which results in low risk of residual stress and strain in the materials after the bonding. Figure 20 illustrates the set-up for anodic bonding of a glass wafer to silicon wafer. Both silicon and glass surface protect from environmental effects, e.g. humidity or contamination. A modest weight is normally placed on the top of the glass wafer to ensure good contacting pressure. An electric field with a 500-1500 DC voltage is applied to the system. The silicon and glass wafer between the two electrodes form a parallel plate capacitor. Consequently, the voltage applied to the electrodes pulls the two wafers into intimate contact with induced electrostatic force. Under the influence of the applied electric field, the sodium ions $\left(\mathrm{Na}^{+}\right)$ in glass wafer are attracted towards the negatively charged cathode. The left $\mathrm{O}_{2}{ }^{-}$ions near the contact surface can be chemically bonded to the contacting $\mathrm{Si}^{+}$ions with the supplied heating of the system, and can form a very thin film layer of $\mathrm{SiO}_{2}$. This thin film of $\mathrm{SiO}_{2}$ serves as the bond between silicon and glass wafers. Pyrex 7740 glass is a popular choice for anodic bonding because it is rich in sodium ions. Suss SB6e Bonder was used in the experiment. The wafers were applied with $1200 \mathrm{DC}$ voltage at $450^{\circ} \mathrm{C}$ (Fig. 19(h)). 


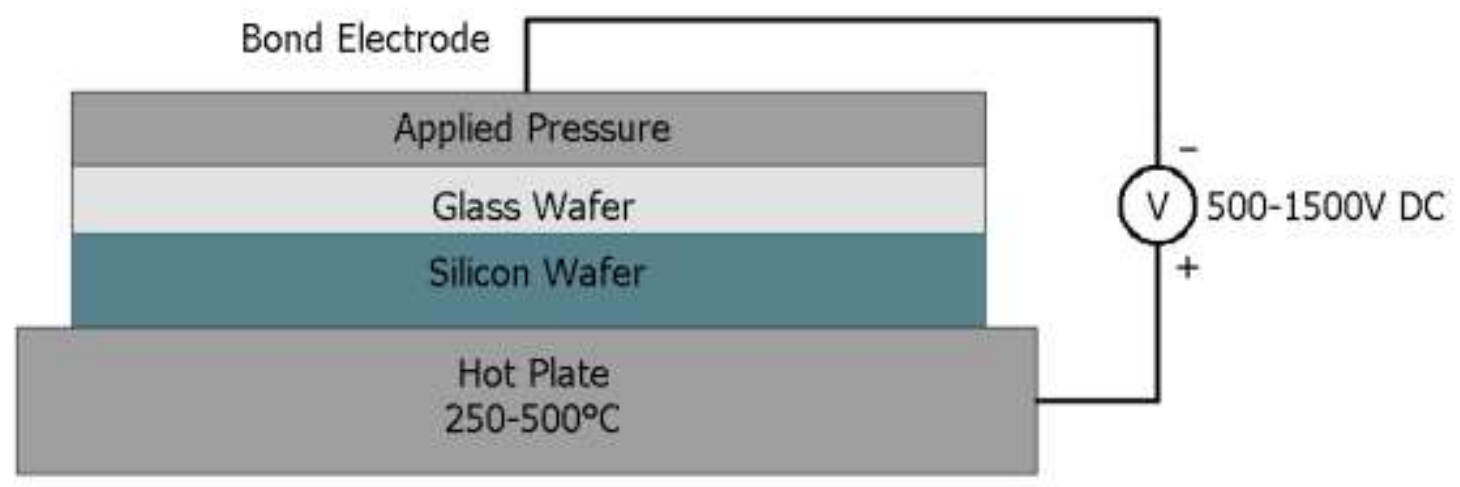

Figure 20. Schematic illustration of glass-to-silicon anodic bonding setup.

\subsection{Dicing and chemical loading}

The wafer was diced and the connection ports were opened. Then, the microreactor was loaded with aminooxy compounds by infusion of aminooxy compound in methanol solution and evaporate methanol in a vacuum oven. Figure 21 shows the schematic illustration of [2-(aminooxy)-ethyl]-N, N, N-trimethylammonium (ATM) iodide, which was synthesized according to a published method and provided by Professor Nantz (Biswas et al., 2010), adsorbed on micropillars and oximation reaction with carbonyl compounds. Finally, the inlet and outlet of the preconcentrator were connected with $190 \mu \mathrm{m}$ O.D., $100 \mu \mathrm{m}$ I.D. deactivated fused silica tubes using a silicabased bonding agent. The optical picture and SEM picture of a fabricated microreactor is shown in Figure 22. 


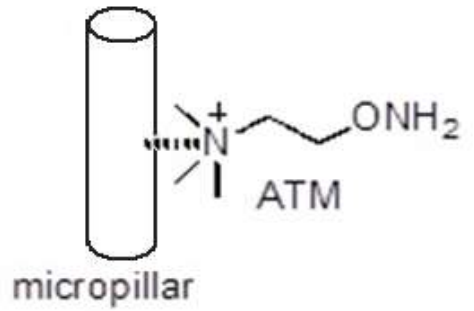

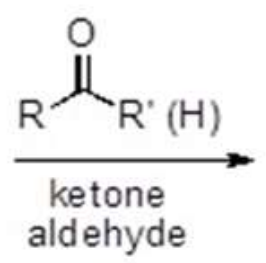

aldehyde

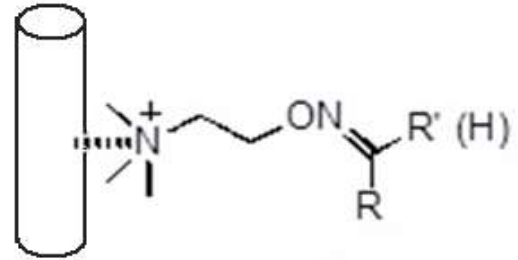

oxime ether

Figure 21. Schematic illustration of ATM oximation to capture ketones and aldehydes in the microreactor.

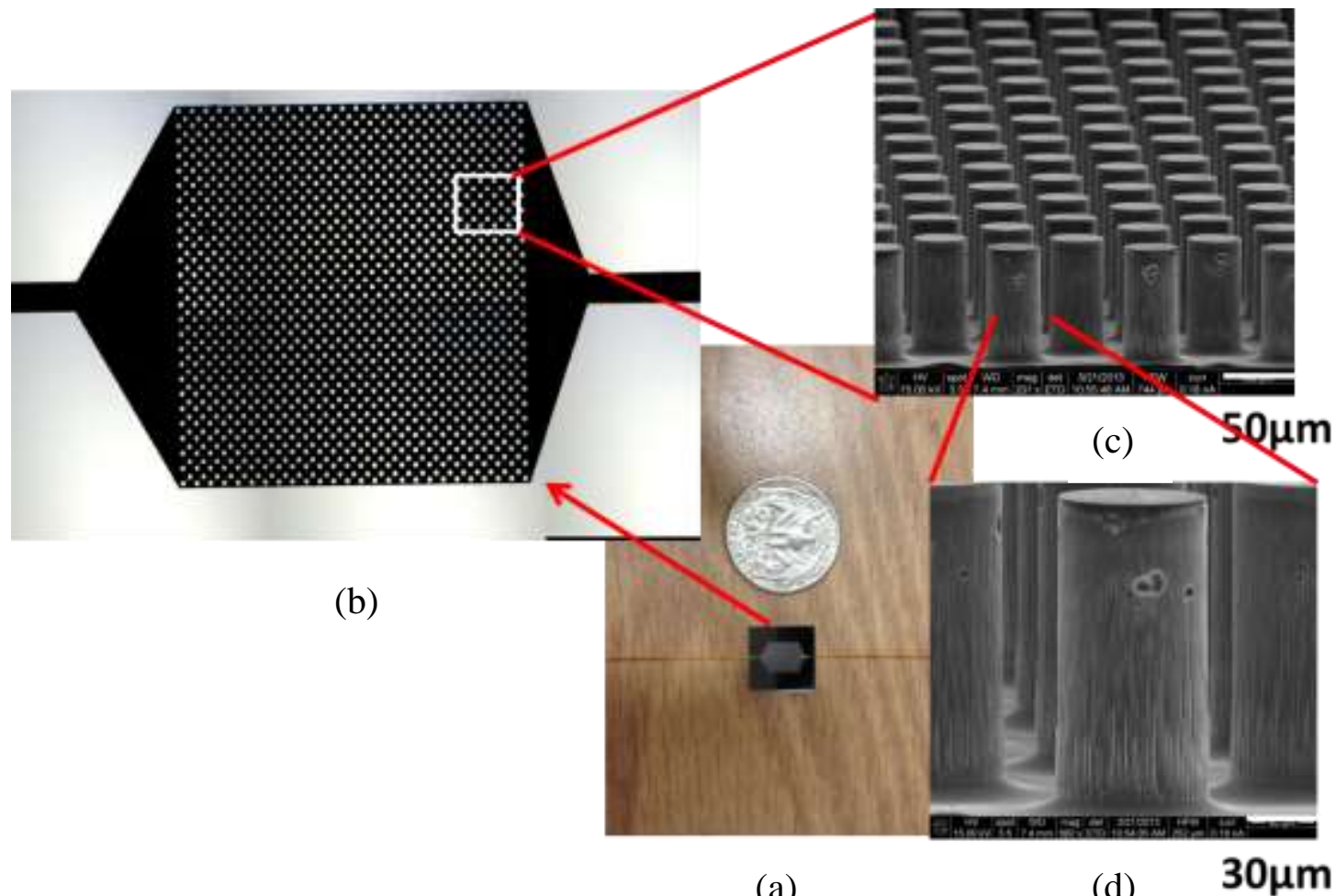

Figure 22. Optical and SEM graphs of one microreactor. (a) Schematic illustration of one microreactor compared with a quarter coin, (b) Optical micrograph of a fabricated microreactor with thousands of internal micropillars, (c) SEM micrographs of the micropillar arrays, (d) SEM micrographs of one micropillar. 


\section{Conclusion}

A microreactor device with thousands of micropillars was designed and simulated using CFD software package in CoventorWare. Cylindrical micropillar arrays have less dead space and contribute more uniform flow velocity than square micropillar arrays. The

chosen microreactor chip with cylindrical micropillar patterns was fabricated from a silicon wafer using microfabrication process. The micropillar surfaces were functionalized with a quaternary ammonium aminooxy salt, ATM, for capturing trace carbonyl compounds flowing through the preconcentrator by means of an oximation reaction. The unique microstructure of the microreactor provides uniform gas flow and high probability of oximation reaction between ATM on the surfaces of micropillars and carbonyl compounds in gas flow. The combination of microreactor design and cationic aminooxy chemistry make the approach attractive for analysis of ketones and aldehydes in air and exhaled breath. 


\section{CHAPTER III}

\section{CAPTURE EFFICIENCIES OF CABONYL COMPOUNDS AT TRACE LEVELS IN MODEL GAS MIXTURES BY THE MICROREACTORS}

\section{Introduction}

Detection of volatile VOCs at trace level (ppbv to pptv) has become an important research area because of demanding applications in homeland security, environmental monitoring, and noninvasive health diagnosis (Tian et al., 2005; Agah et al., 2006). The analysis of trace VOCs challenges existing analytical methods because their concentrations are beyond instrument limits of detection. This problem is further exacerbated by other interfering gases in high concentrations that are mixed with the carbonyl VOCs. GC-MS is currently the dominant technique for analysis of trace VOCs in air (Cao et al., 2007; Phillips et al., 1999; Apel et al., 2003). A complex preconcentration process consisting of cryogenic adsorption and thermal desorption is typically required before trace VOC samples can enter into a GC column (Apel et al., 2010; Sive et al., 2005). In recent years, microfabricated gas preconcentrators and gas chromatography columns have demonstrated the potential for real-time, low-power, and hand-held gas detection (Tian et al., 2005; Agah et al., 2006). Preconcentrators fabricated 
from silicon wafers using MEMS technology typically consist of a micro hot plate and an adsorption material placed adjacent to the heating element (Alfeeli et al., 2008; Alfeeli and Agah, 2009). These MEMS preconcentrators have common issues of inefficient physical adsorption and thermal desorption (Alfeeli et al., 2008; Alfeeli and Agah, 2009; Voiculescu et al., 2008 ).

In this chapter, we describe a novel preconcentration approach for analysis of trace ketones and aldehydes. We designed and fabricated a microreactor using MEMS technology. The benefits of the MEMS approach are advantages in microstructure flexibility and microliter sample size in comparison to conventional DNPH-based packed cartridges (Levin et al., 1985; Kuwata et al., 1983; Uchiyama et al., 2003). Thousands of micropillars in the microreactors distribute gas flow and provide large surface areas for trapping target gases. The surfaces of the micropillars are functionalized by a quaternary ammonium aminooxy salt, ATM, as a "capture phase" via oximation reactions with ketones and aldehydes. This approach is suitable for quantitative analysis of ketones and aldehydes in exhaled breath. For rapid analysis and identification of VOC adducts on a microliter sample size, we use nanoelectrospray FTICR-MS, which is benefited by the permanent positive charge of ATM. The complete elution of the capture phase and its adducts avoids the current problems of sample transfer from a preconcentrator to an analytical instrument. In addition to the aminooxy group for oximation of the carbonyl VOCs, the ATM molecule was designed with a positively charged group (quaternary ammonium ion) for enhancing detection by nanoelectrospray FTICR-MS. Combining the strategies of (i) efficient oximation chemistry for trapping carbonyl compounds, (ii) analysis by FTICR-MS provides an innovative approach for analysis of trace carbonyl 
compounds in gas mixtures, and (iii) kinetics study of oximation reaction in microreactor, have provided high capture efficiencies of carbonyl compounds in air and exhaled breath.

\section{Materials and Setup}

All reagents and solvents, including deuterated acetone (acetone-d6) (99.9\%), acetone (99\%), 2-butanone (99\%), 2-pentanone, propanal, n-butanal (99\%), n-hexanal (98\%), and methanol (99.9\%), were purchased from Sigma-Aldrich. The quaternary ammonium aminooxy compound ATM was synthesized according to a published method (Biswas et al., 2010). The toxic organic gas mixture TO-15 standard was purchased from the Spectra Gases Co., Branchburg, NJ.

The quaternary ammonium aminooxy salt, ATM was used as a "capture phase" via oximation reactions to trap ketones and aldehydes. This approach is suitable for quantitative analysis of ketones and aldehydes in exhaled breath. For rapid analysis and identification of trace VOC adducts in a microliter volume sample, FTICR-MS was used in the experiment, which is benefited by the permanent positive charge of ATM. Figure 23 shows schematically the test setup for preconcentration of ketones and aldehydes in a carrier gas $(\mathrm{He})$. 


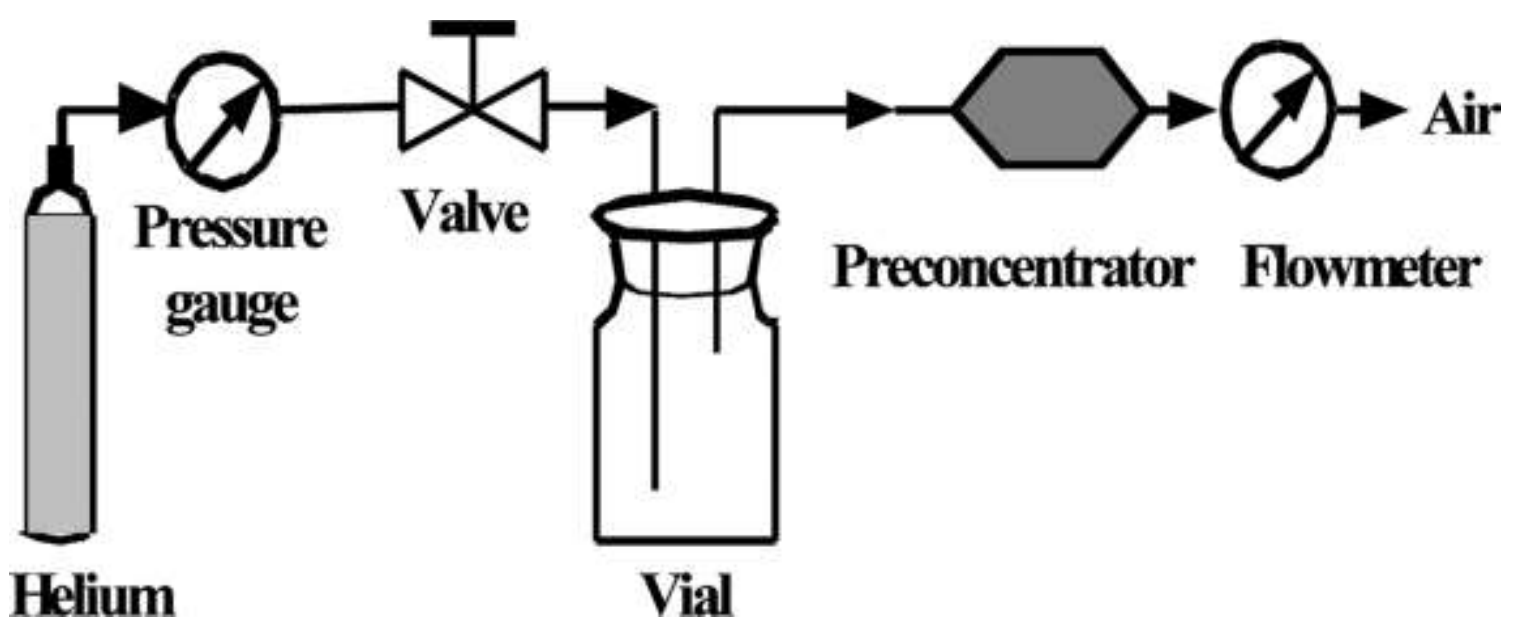

Figure 23. Schematic flow diagram of the preconcentration setup.

A microreactor is connected to an ultra-high-purity $\mathrm{He}$ gas cylinder by the attached fused silica tubes. A mechanical needle valve made by Hoke Co. is used to adjust the He flow rate, while a flow meter is used to measure the He flow rate. There is no detectable leakage of He in the setup verified by a He gas leakage detector. After the He flow rate is stabilized and the setup is flushed for at least 10 min, a known amount of acetone-d6 diluted in methanol is injected into the vial with He flowing through the microreactor as indicated in Figure 23. After flowing continuously for $20 \mathrm{~min}$, the flow is then stopped. The flow rate and flow time are recorded after the injection of ketone(s) and/or aldehyde(s), and the microreactor is then disconnected from the setup. The reacted ATM adduct and unreacted ATM are eluted from the microreactor by flowing methanol from one slightly pressurized vial through the microreactor and then into an empty collecting sample vial. Figure 24 shows the elution process. The eluted solutions were directly used for FTICR-MS analysis without any further process. 


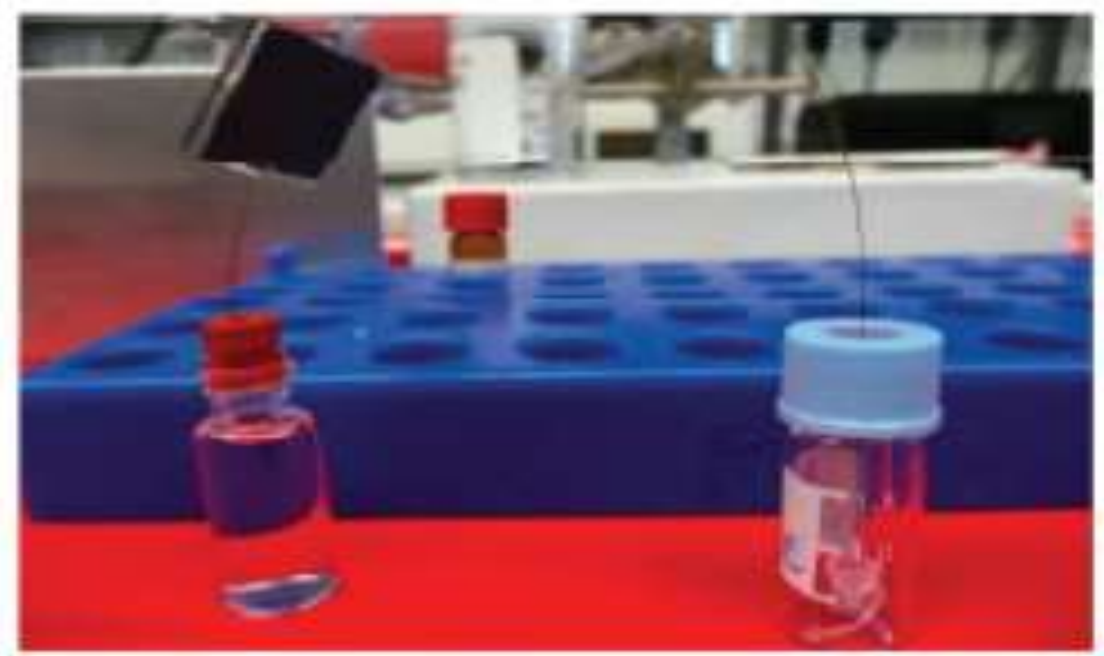

Figure 24. Reacted ATM adducts and unreacted ATM eluted from the microreactor.

\section{FTICR-MS Analysis}

The samples of methanol eluted solutions were analyzed on a hybrid linear ion trap-FTICR-MS instrument (Finnigan LTQ-FT, Thermo Electron, Bremen, Germany) equipped with a TriVersa NanoMate ion source (Advion BioSciences, Ithaca, NY) with an electrospray chip (nozzle inner diameter $5.5 \mu \mathrm{m}$ ). The TriVersa NanoMate was operated in positive ion mode by applying $2.0 \mathrm{kV}$ with no head pressure. Initially, lowresolution MS scans were acquired for $1 \mathrm{~min}$ to ensure the stability of ionization, after which high mass accuracy data were collected using the FTICR analyzer where MS scans were acquired for $10 \mathrm{~min}$ and at the target mass resolution of 100000 at $800 \mathrm{~m} / \mathrm{z}$. The AGC (automatic gain control) maximum ion time was set to $500 \mathrm{~ms}$ (but typically utilized $<10 \mathrm{~ms}$ ), and five "microscans" were acquired for each saved spectrum; thus, the cycle time for each transformed and saved spectrum was about 10s. The LTQ-FT was tuned and calibrated according to the manufacturer's default standard recommendations, 
which achieved better than $1 \mathrm{ppm}$ mass accuracy and a 400000 resolution capability at $\mathrm{m} / \mathrm{z}=400$. FTICR mass spectra were exported as exact mass lists into a spreadsheet file using QualBrowser 2.0 (Thermo Electron), typically exporting all of the observed peaks. ATM and ATM adducts were assigned on the basis of their accurate mass by first applying a small (typically <0.0005) linear correction based on the observed mass of the internal standard.

\section{Initial Study of Capture of Acetone-d6 by the Microreactor}

Before the microreactor applied in the capture efficiency study, one fact that ATM salt is adhered on the micropillars should be verified. Open chip microreactors were fabricated using a 4 " in diameter silicon wafer without anodic bonding. After dicing by a diamond scribe, one open chip microreactor was loaded with 0.271 mmole ATM salt by infusion of ATM in methanol solution and evaporate methanol in a vacuum oven. The micropillars were cut and immersed into $100 \mu \mathrm{L}$ methanol for 5 minutes. The micropillars were filtered out from the solution. The clear solution was directly analyzed by nanoelectrospray FTICR-MS for $10 \mathrm{~min}$, from $50-500 \mathrm{~m} / \mathrm{z}$. Figure 25 shows a FTICR-MS spectral region that has unreacted ATM cations $(119.11790 \mathrm{~m} / \mathrm{z}$ ion). This experiment verified that ATM salt was not only adhered on the silicon micropillars, but also easily washed out by methanol. 


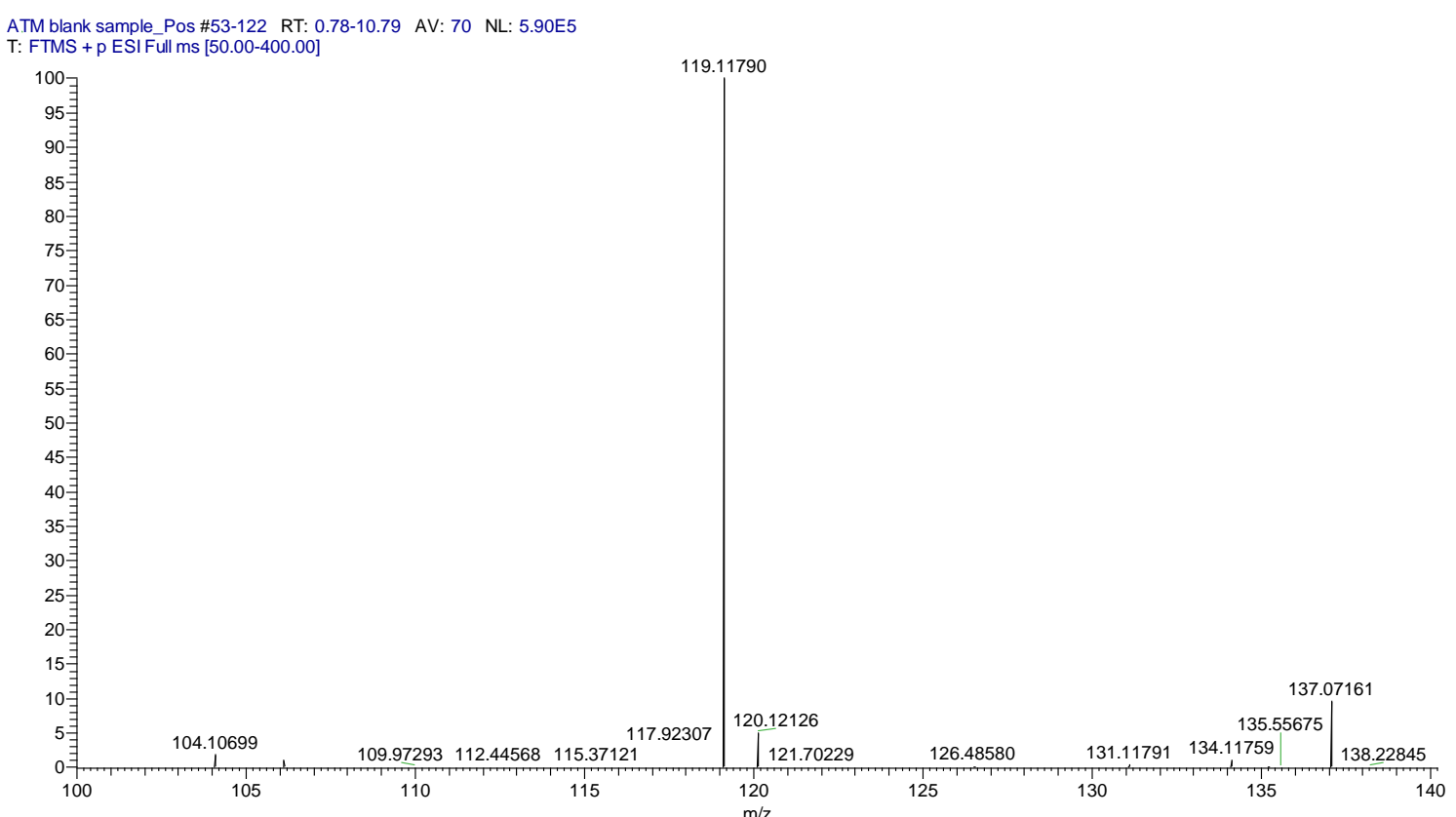

Figure 25. FTICR-MS spectrum of methanol solution after immersing silicon micropillars cut from the microreactor.

For testing the capture efficiency of acetone, various quantities of deuterated acetone, from $0.271 \mathrm{nmole}$ to $0.271 \mathrm{mmole}$ in methanol, were added to the $20 \mathrm{~mL}$ vial to evaporate into helium flowing through the vial and then the microreactor. The vial had a Teflon lined silicone septum connected to both helium source and the microreactor by the silica capillary tubing. Acetone-d6 was used in these tests to avoid bias from any environmental trace acetone contamination. The microreactor operated at an inlet helium pressure from 15 to $25 \mathrm{psi}$. The flow rate of helium through the microreactor was 3 $\mathrm{mL} / \mathrm{min}$. After adding acetone-d6 to the vial, helium flowed for at least 30 minutes to allow completion of the acetone-d6 transfer into the microreactor. After preconcentration, the microreactor was disconnected from the setup. Then, the microreactor was eluted by flowing methanol from one $2 \mathrm{~mL}$ vial through the microreactor into a septum-sealed glass vial. Several $100 \mu \mathrm{L}$ aliquots of the eluted methanol solution were collected and 
each aliquot was analyzed separately to gauge elution efficiency via mass balance. The collected elution solutions were directly analyzed by nanoelectrospray FTICR-MS for 10 min, from 50-500 m/z. Figure 26 shows a typical FTICR-MS spectral region that has oximation product of ATM with acetone-d6 (165.18688 m/z ion) as well as unreacted ATM cations (119.11793 m/z ion). Greater than $98 \%$ of total reacted ATM and unreacted ATM was collected from the microreactor with the first $100 \mu \mathrm{L}$ methanol aliquot. There was no trace detectable ATM and ATM-acetone-d6 after flushing a total $400 \mu \mathrm{L}$ methanol through the microreactor (Fig. 27). Thus, the transfer efficiency exceeded $98 \%$ for a rapid $5 \mathrm{~min}, 100 \mu \mathrm{L}$ elution at the bench top, requiring no specialized equipment other than septum-capped vials and a syringe, the total analytical recovery of the acetoned6 was $>98 \%$. Figure 26 also indicates that trace acetone contamination from ambient air was very low.

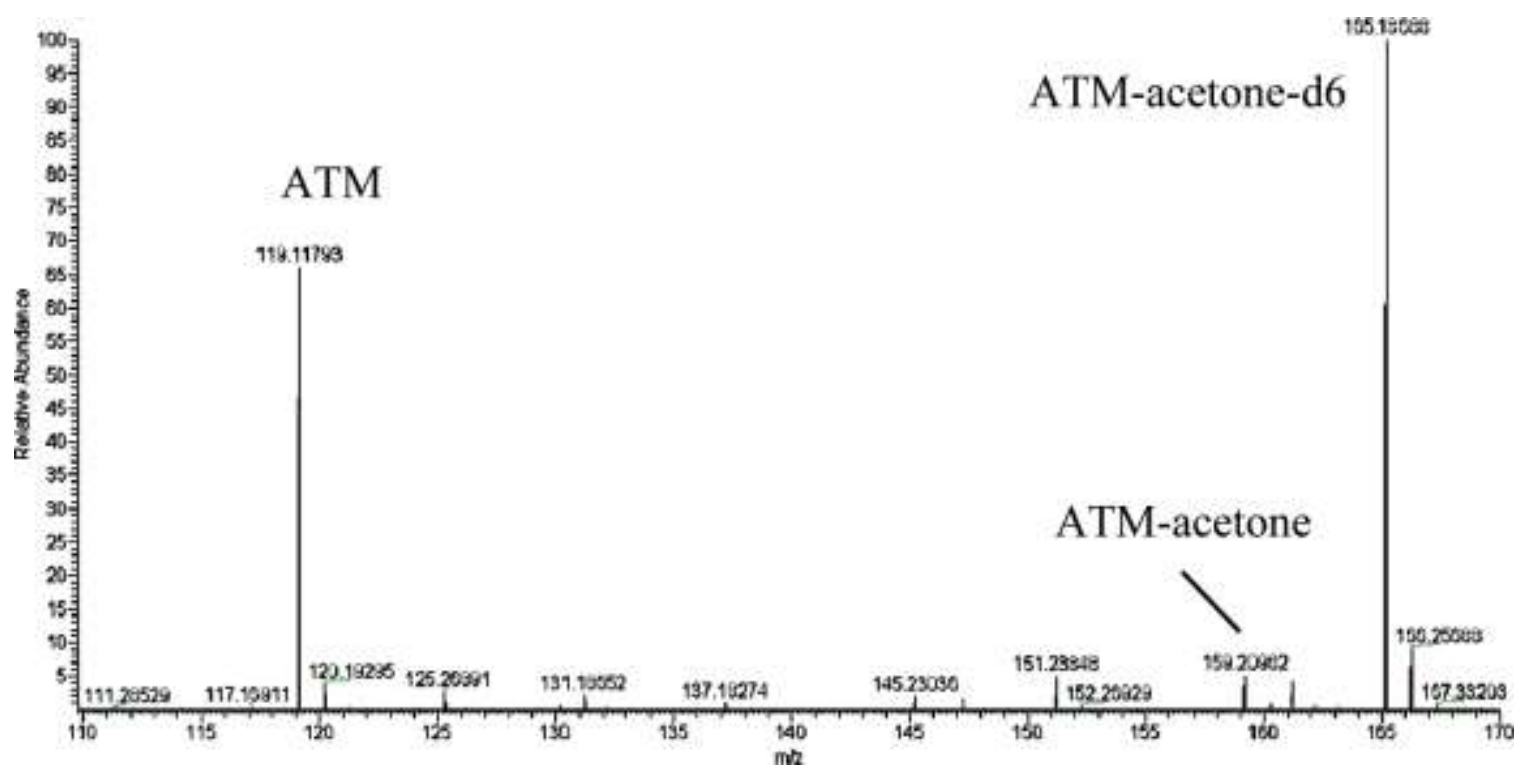

Figure 26. Typical FTICR-MS spectrum of ATM and ATM-acetone-d6 eluted from the microreactor. 


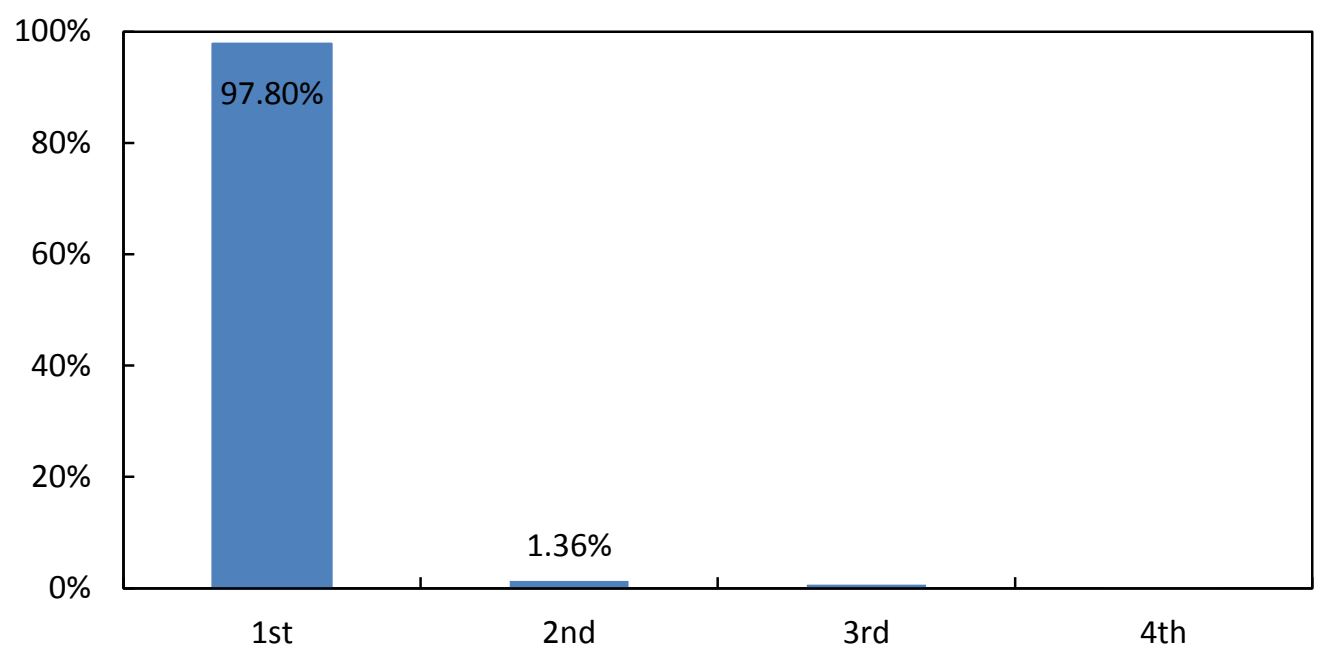

Figure 27. Capturing percentage of each time after $100 \mu \mathrm{L}$ methanol flushed.

\section{Experimental Result on Capture Efficiency in the Microreactor}

\subsection{Acetone}

To test the microreactor for capturing trace levels of acetone, $3.65 \times 10^{-7}$ to $3.65 \times 10^{-11}$ mole of acetone in methanol solutions was added to the He flow through the microreactors. A known amount of acetone-d6 that completely reacted with ATM in methanol was then added to each eluted solution as the internal reference for FTICR-MS analysis. The relationship between the capture percentage and the ATM/acetone molar ratio is shown in Figure 28. As the molar ratio of ATM to acetone increases to 10, more than $99 \%$ of acetone in the He flow stream was captured. When the molar ratio of ATM to acetone was higher than $100, \sim 100 \%$ of the acetone was captured. For the lowest amount of acetone $\left(3.65 \times 10^{-11}\right.$ mole) evaporated in the He flow stream at a flow rate of 5 $\mathrm{mL} / \mathrm{min}$ for $20 \mathrm{~min}$, an equivalent level of $8.9 \mathrm{ppbv}$ was reached. The FTICR-MS signal (abundance) of the ATM-acetone adduct for the sample of $3.65 \times 10^{-11}$ mole of acetone 
added into the He flow through the microreactor was still high ( 1E5 abundance). The reported acetone level in exhaled breath is in the range of 180-800 ppbv (Deng et al., 2004; Ueta et al., 2010). Therefore, the microreactor approach could be used for analysis of acetone in exhaled breath.

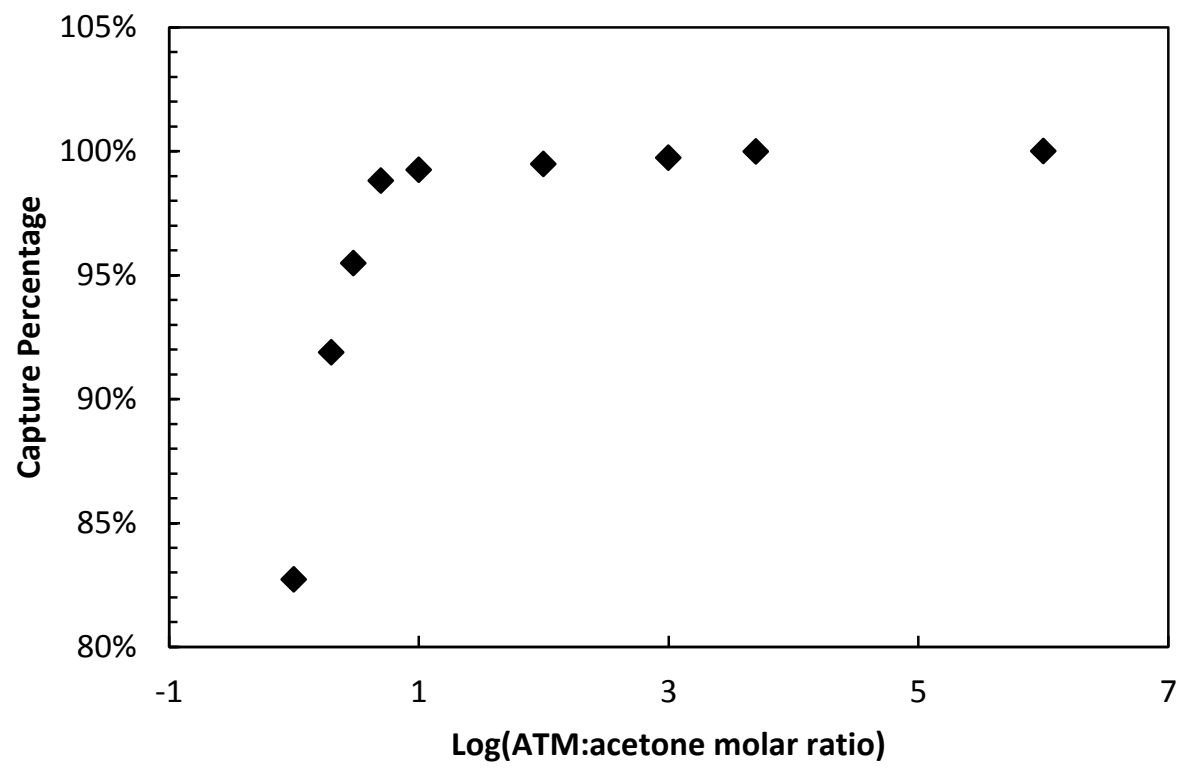

Figure 28. Relationship between capture efficiency and ATM/acetone molar ratio.

\subsection{Ketones}

2-Butanone and 2-pentanone were also used to characterize the capture percentage of the microreactors. In these experiments, a constant amount of $3.65 \times 10^{-7}$ mole of ATM was loaded into each microreactor while varying the added amount of individual ketone into the $\mathrm{He}$ flow through the microreactors. After preconcentration, unreacted ATM and reacted ATM adduct were eluted from the microreactor by methanol. Figure 29 shows that, as the ATM/ketone molar ratio increases, the capture percentage also increases. For an ATM/ketone molar ratio larger than 10, 
more than $92 \%$ of the added ketones was captured in the microreactors. The capture percentage of acetone was higher than those of 2-butanone and 2-pentanone at the same ATM/ ketone molar ratio (Li et al., 2012). The result may imply the difference in reaction kinetics of ketones with ATM.

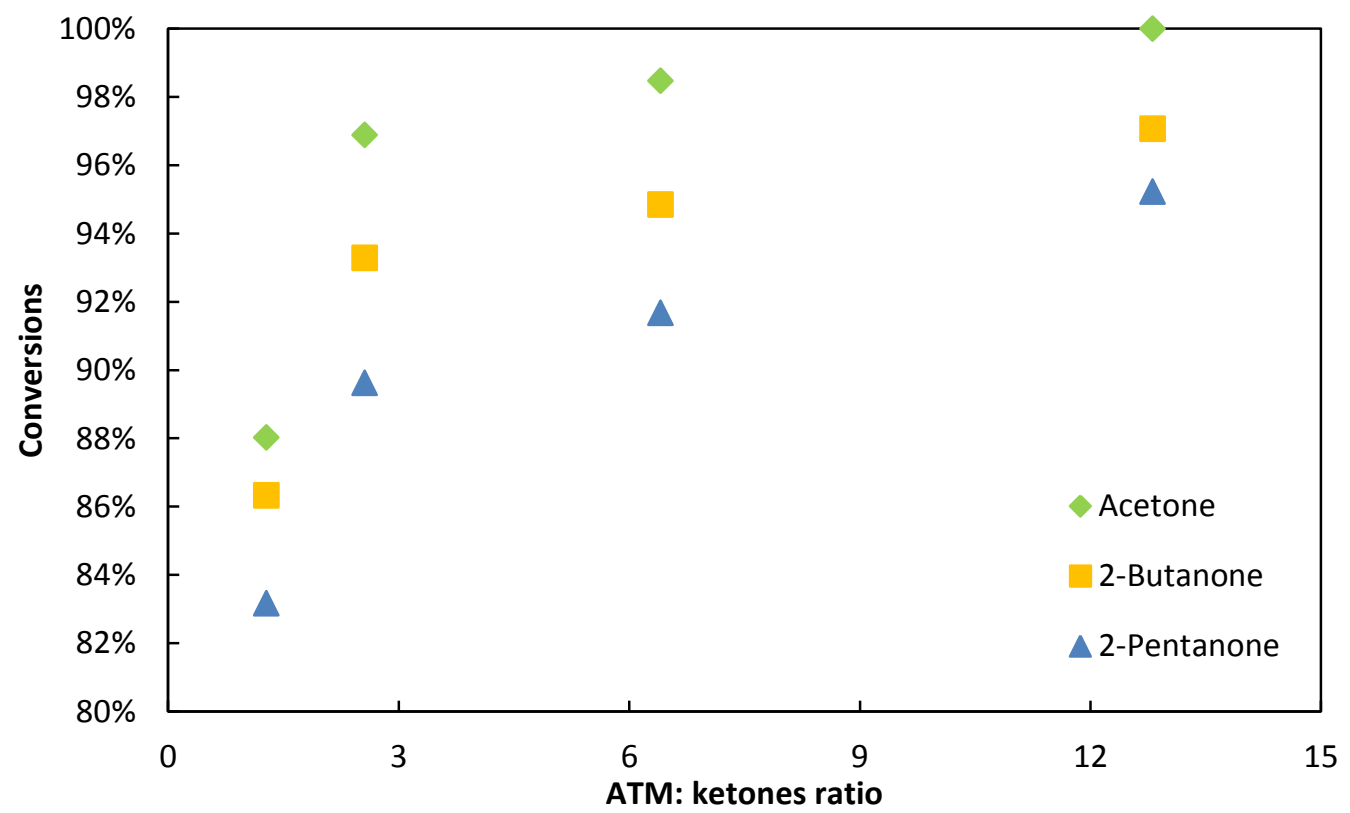

Figure 29. Relationship between capture efficiency and ATM/ketone molar ratio.

\subsection{Aldehydes}

The obvious different capture efficiencies for ketones have led us to design a series of experiments to test the effect of the ATM/aldehyde ratio on the capture percentages of propanal, n-butanal, and n-pentanal. Again, a constant amount of ATM $\left(3.65 \times 10^{-7} \mathrm{~mol}\right)$ was loaded into each microreactor while correspondingly decreasing the added amount of aldehydes in the He flow stream to increase the ATM/aldehyde molar ratio greater than 10 , the capture percentages are above $92 \%$. The reason is that, for higher ATM/aldehyde molar ratios, more ATM molecules relative to aldehydes provide 
higher reaction probability for capturing aldehydes. The capture percentage of propanal was higher than those of n-butanal and n-hexanal at the same molar ratios. These results also imply that the ATM reaction rate with low molecular weight aldehydes may be greater than that with high molecular weight aldehydes.

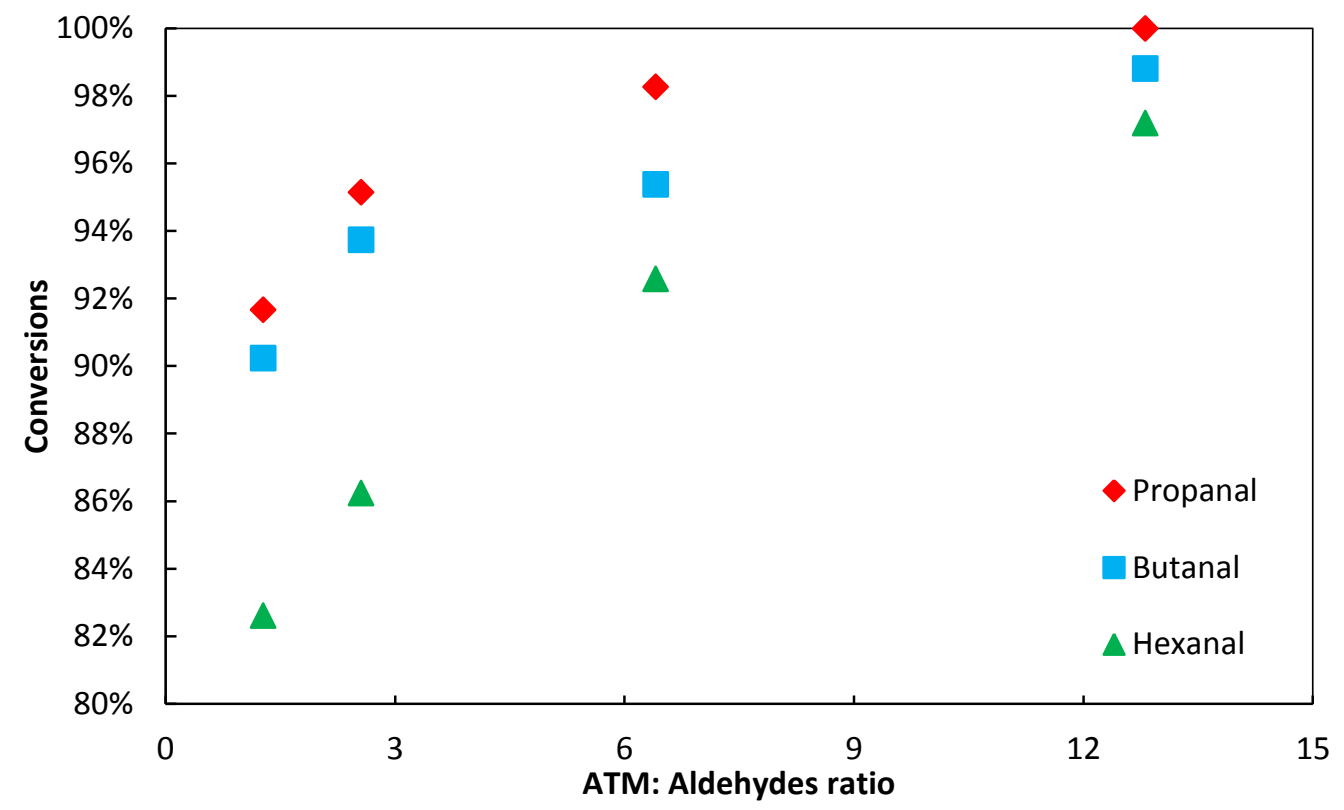

Figure 30. Relationship between capture efficiency and ATM/aldehyde molar ratio.

\subsection{Model gas mixtures}

To understand the effect of a large number of polar and nonpolar VOCs on ATM selective capture of aldehydes and ketones at trace concentrations, a standard TO-15 VOC was diluted to $1 \mathrm{ppbv}$ acetone, 0.98 ppbv methyl ethyl ketone and 1.03 ppbv methyl butyl ketone with $\mathrm{N}_{2}$ and stored in a $6 \mathrm{~L}$ stainless steel canister. The initial pressure of the canister was 30 psi. The gas mixture flowed through the microreactor at a flow rate of 5 $\mathrm{mL} / \mathrm{min}$ until the pressure of the canister reached $15 \mathrm{psi}$, and then the flow was stopped. Figure 31 shows the FTICR-MS spectrum of the preconcentrated VOCs. This result 
indicates that the microreactor is capable of preconcentrating ketones at the $1 \mathrm{ppbv}$ level in a large number of VOCs. The calculation indicates that $97 \%$ of the acetone was captured and detected by FTICR-MS while $87 \%$ of the methyl ethyl ketone and $81 \%$ of the methyl butyl ketone were captured. The molar ratio of ATM to acetone for the amount of acetone flowing through the microreactor from the canister was larger than 100. Figure 28 indicates that $100 \%$ capture efficiency was achieved for acetone added into the He flow at an ATM/acetone molar ratio greater than 100. The difference between the capture percentages of acetone in the He flow and in the TO-15 indicates slight interference of other VOCs on the capture percentage of acetone. The capture percentages for methyl ethyl ketone and methyl butyl ketone in TO-15 were lower than that of acetone. This experiment demonstrates that the microreactor with ATM coating is promising for analysis of trace ketones and aldehydes in VOC mixtures.

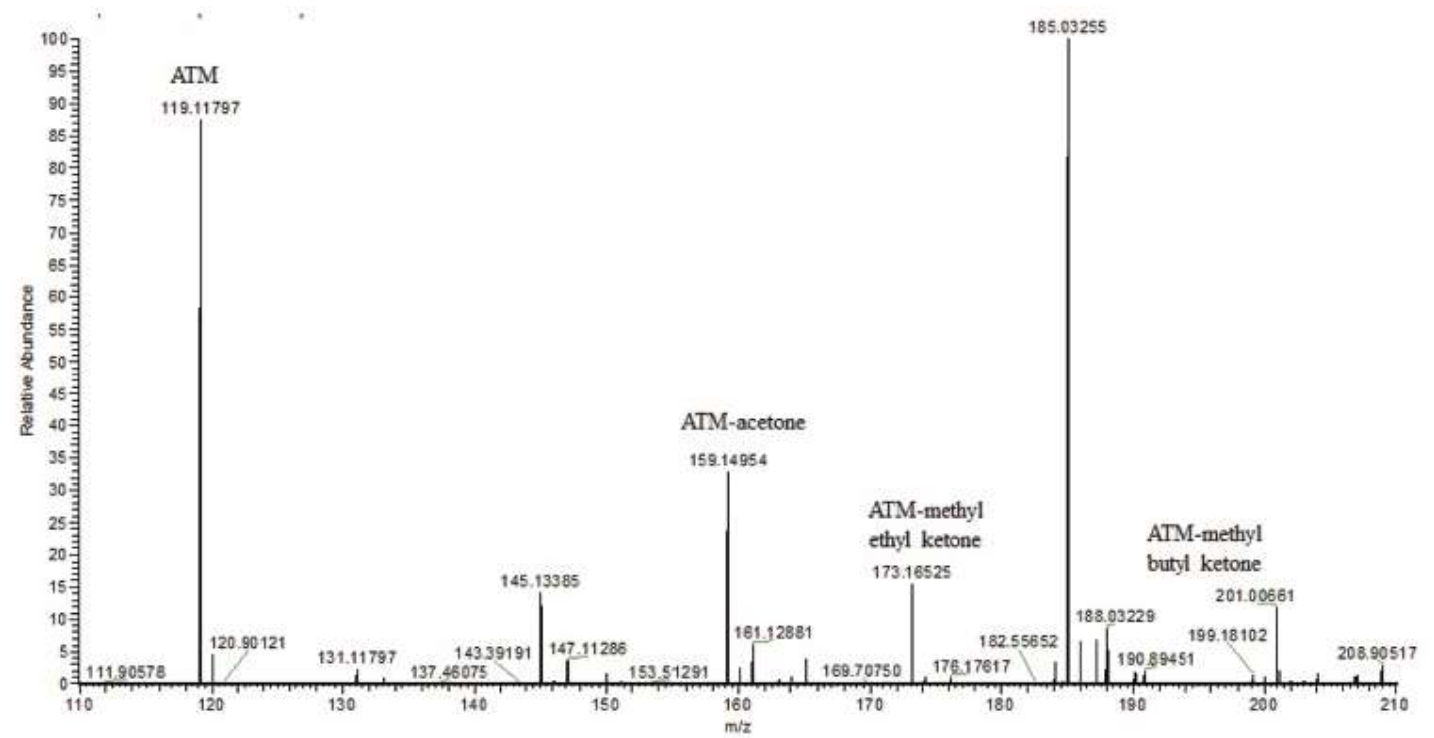

Figure 31. FTICR-MS spectrum of a preconcentrated TO-15 gas mixture with $1 \mathrm{ppb}$ acetone, 0.98 ppb methyl ethyl ketone, and 1.03 ppb methyl butyl ketone. 


\section{Kinetics Study of Oximation Reaction in Microreactor}

In order to further design of aminooxy salts for selective capture of some specific carbonyl compounds, the reaction kinetics of aminooxy salts with ketones, aldehydes were studied. The aminooxy salts were all synthesized by Professor Nantz's group in the Department of Chemistry at the University of Louisville.

$3.65 \times 10^{-7} \mathrm{~mol}$ ATM-acetone-d6 adduct was injected into $200 \mu \mathrm{L}$ methanol solution contained $3.65 \times 10^{-7}$ mol ATM before the reaction, served as the internal reference to estimate reacted ATM. $3.65 \times 10^{-7}$ mol acetone dissolved in $20 \mu \mathrm{L}$ methanol was injected into the solution at $30^{\circ} \mathrm{C}, 50^{\circ} \mathrm{C}, 70^{\circ} \mathrm{C}$ and $90^{\circ} \mathrm{C}$, respectively. $15 \mu \mathrm{L}$ reaction solution was transferred to FTICR-MS at 30s, 60s and 90s time interval, respectively.

$$
\text { ATM + acetone } \rightarrow \text { ATM - acetone }+\mathrm{H}_{2} \mathrm{O}
$$

Assume the reaction is a first order, irreversible reaction. The reaction rate ( $\mathrm{r}$ ) of ATM reacting with the same molar amount of acetone is given:

$$
\begin{gathered}
r=\frac{d C_{\text {acetone }}}{d t}=-k C_{\text {ATM }} C_{\text {acetone }}=-k C_{\text {acetone }}^{2} \\
\frac{d C_{\text {acetone }}}{C_{\text {acetone }}^{2}}=-k d t
\end{gathered}
$$

Integrating with initial condition $\mathrm{C}=\mathrm{C}_{0}$ at $\mathrm{t}=0$, we have:

$$
\begin{aligned}
& \frac{1}{C}-\frac{1}{C_{0}}=k t \\
& \frac{1}{C}=k t+\frac{1}{C_{0}}
\end{aligned}
$$


The reaction rate constant $k$ can be obtained by linear regression between the reciprocal of the amount of unreacted ATM $(1 / C)$, which can be calculated from the measured product of ATM-ketone/aldehyde from FTICR-MS spectrum, and the reaction time $(t)$. Figure 32 shows the regression plots between $1 / C$ and $t$ of the reaction between ATM and acetone.

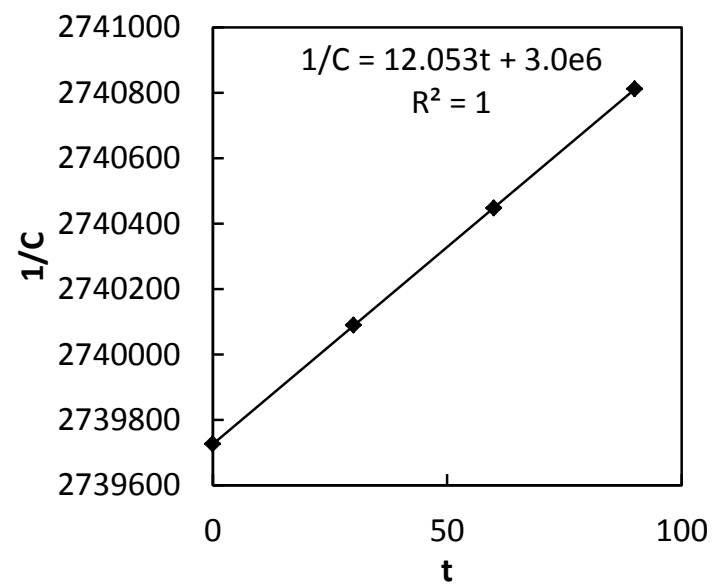

(a)

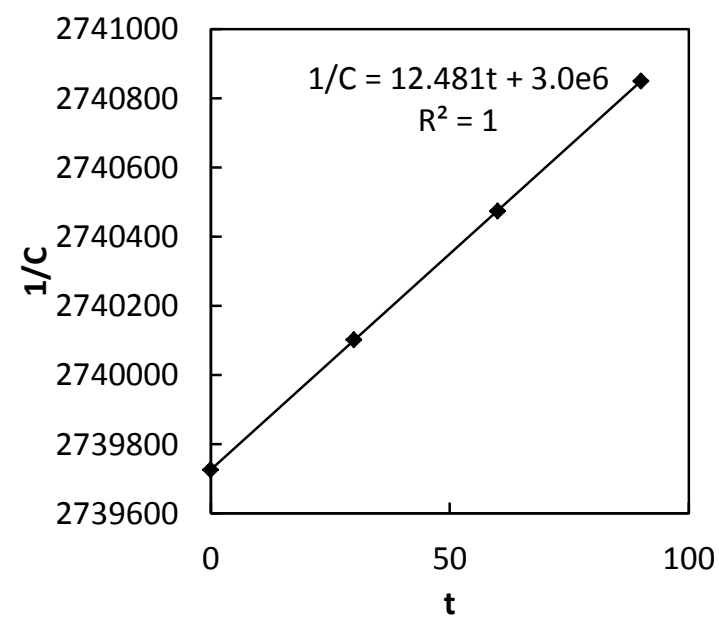

(c)

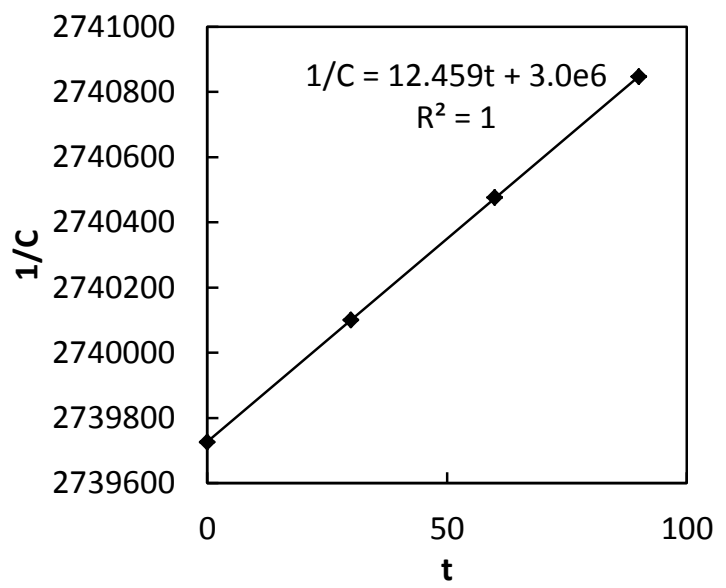

(b)

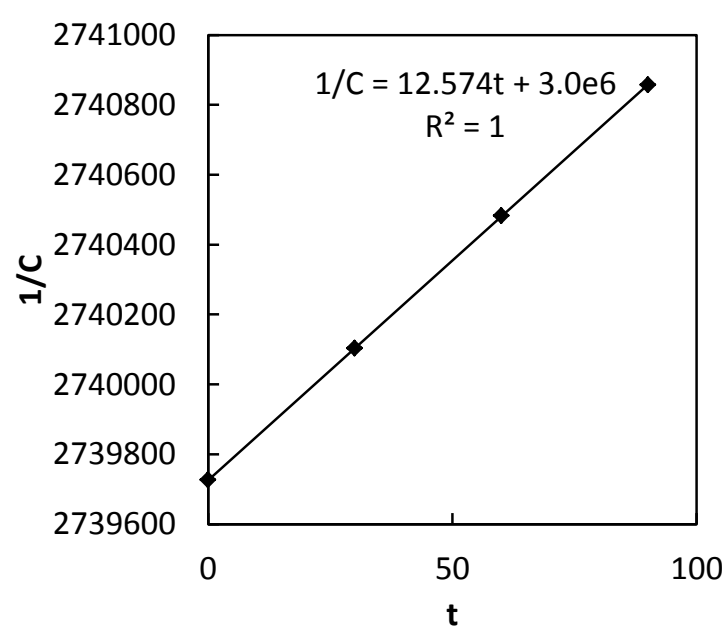

(d)

Figure 32. Linear regression plots of $1 / C$ vs $t$ between ATM and acetone reactions at (a) $30^{\circ} \mathrm{C}$, (b) $50^{\circ} \mathrm{C}$, (c) $70^{\circ} \mathrm{C}$, (d) $90^{\circ} \mathrm{C}$. 
From the Arrhenius Equation:

$$
k=k_{0} e^{-\frac{E_{a}}{R T}}
$$

where $k$ is the rate constant of the reaction, $k_{0}$ is the frequency factor, $E_{a}$ is the activation energy, $\mathrm{T}$ is the temperature (in kelvin), and $R$ is the gas constant. We can obtain:

$$
\ln k=-\left(\frac{E_{a}}{R}\right) \cdot\left(\frac{1}{T}\right)+\ln k_{0}
$$

The activation energy and frequency factor were determined after linear regression between the mean of $\ln (k)$ in three different reaction time at the same temperature and $1 / T$.

The reaction kinetics of 2-butanone, propionaldehyde, butanal, hexanal and 2nonanone were measured using the same procedures as that of acetone. Figure 33 shows the linear regression plots of the natural logarithm of reaction constant $(\ln (k))$ between ATM and carbonyl compounds.

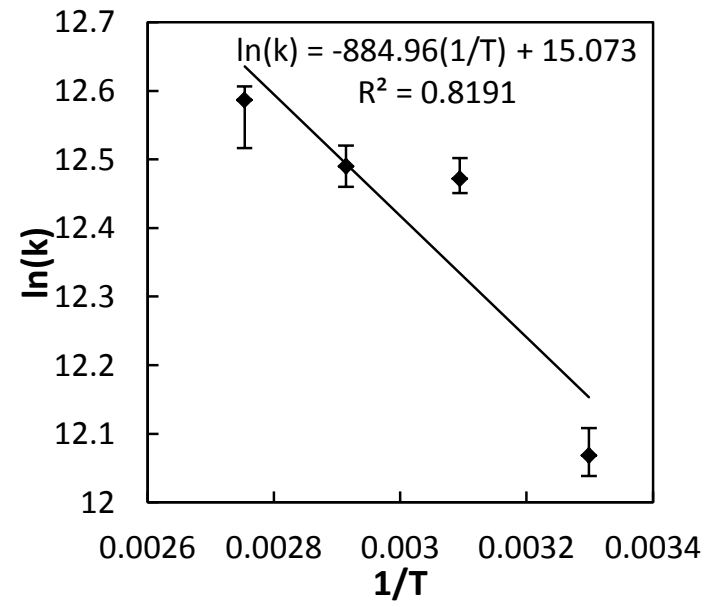

(a)

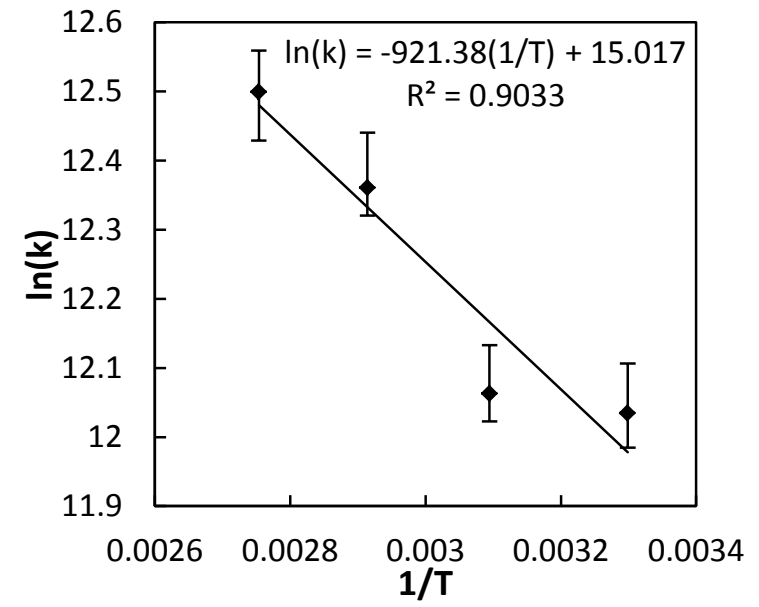

(b) 


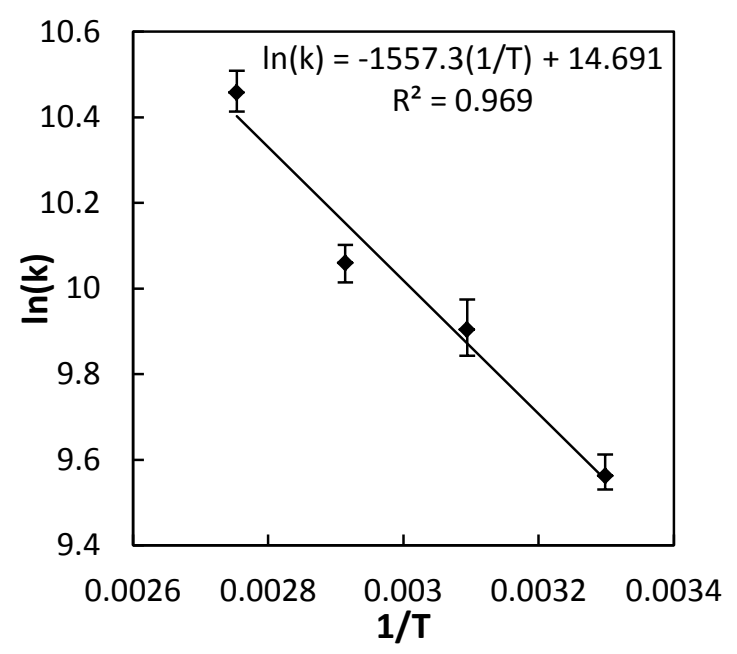

(c)

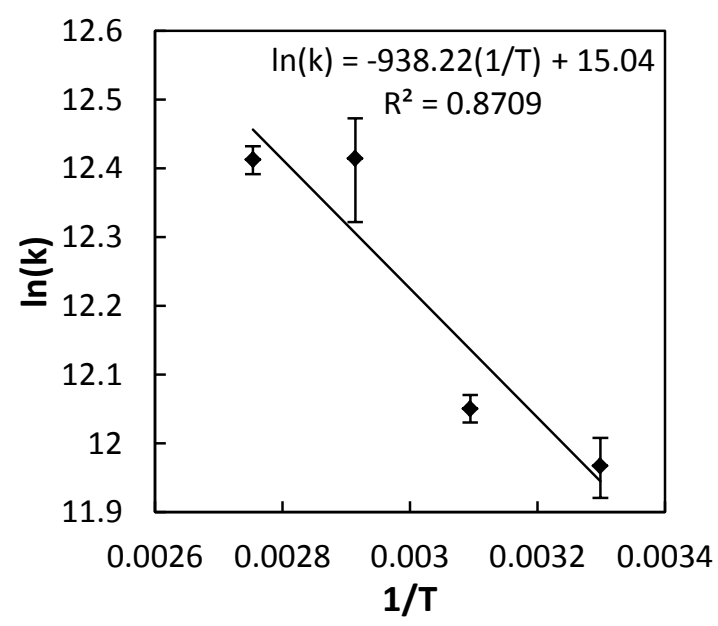

(e)

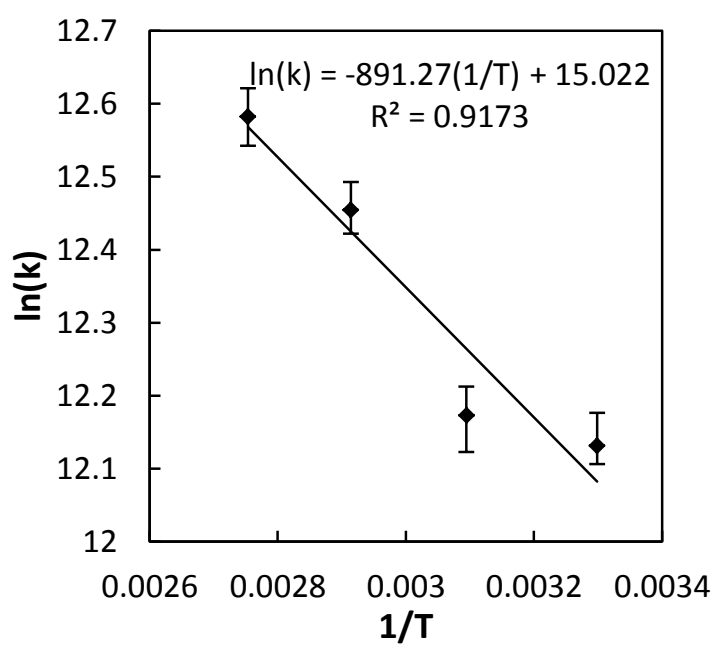

(d)

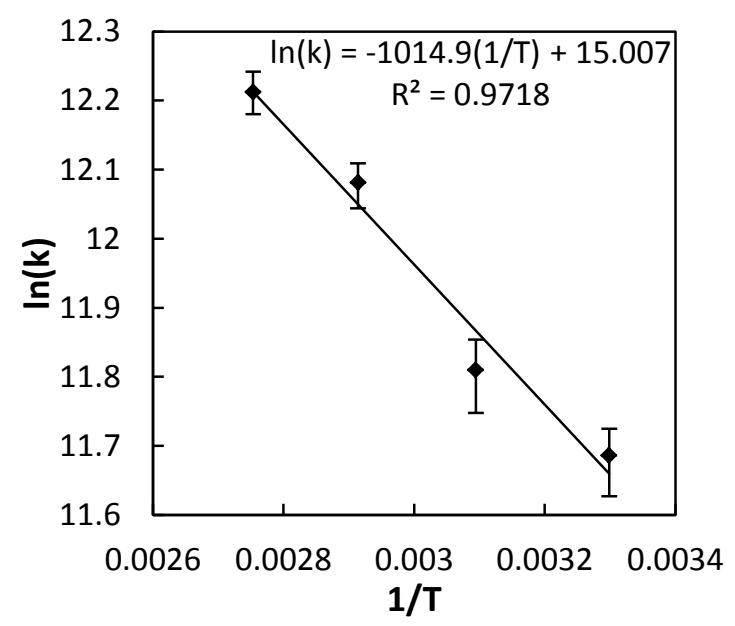

(f)

Figure 33. Linear regression plots of $\ln (k)$ vs $1 / T$ between ATM and carbonyl compounds reactions. (a) Acetone, (b) 2-Butanone, (c) 2-Nonanone, (d) Propionaldehyde, (e) Butanal, (f) Hexanal.

In order to study the effect of aminooxy salt on the reaction kinetics, one of the trimethyl groups of ATM was changed to methylbenzyl group to form a new aminooxy compounds: aminooxy dimethylbenzyl ammonium bromide (ADMB) (Fig. 34). 


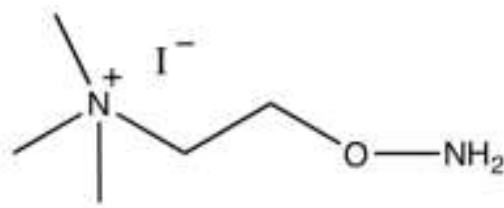

$\mathrm{C}_{5} \mathrm{H}_{15} \mathrm{IN}_{2} \mathrm{O}$

Exact Mass: 246.0229

Molecular Weight: 246.0899

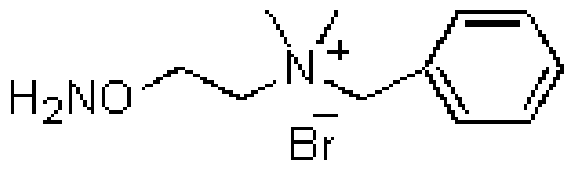

$\mathrm{C}_{11} \mathrm{H}_{19} \mathrm{BrN}_{2} \mathrm{O}$

Exact Mass: 274.0681

Mol. Wt.: 275.1854

(a)

(b)

Figure 34. The chemical structure of aminooxy salts. (a) ATM, (b) ADMB.

The same series of experiments described above were designed to study the kinetics of the reaction kinetics between ADMB and carbonyls. $3.65 \times 10^{-7}$ mol ATMacetone-d6 adduct was injected into $200 \mu \mathrm{L}$ methanol solution contained $2.44 \times 10^{-7} \mathrm{~mol}$ ADMB before the reaction, served as the internal reference to estimate reacted ADMB. $2.44 \times 10^{-7} \mathrm{~mol}$ carbonyl compounds dissolved in $20 \mu \mathrm{L}$ methanol was injected into the solution at $30^{\circ} \mathrm{C}, 50^{\circ} \mathrm{C}, 70^{\circ} \mathrm{C}$ and $90^{\circ} \mathrm{C}$, respectively. $15 \mu \mathrm{L}$ reaction solution was measured by FTICR-MS at 30s, 60s and 90s time interval, respectively.

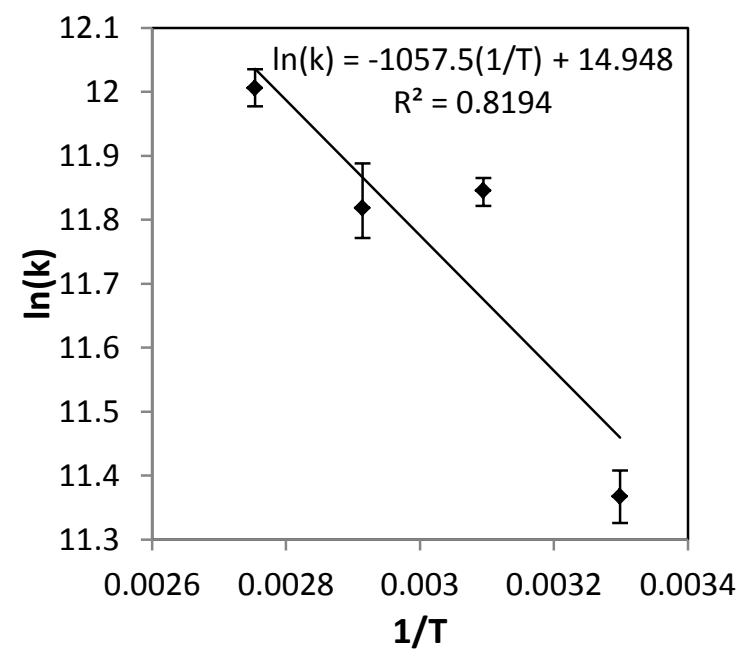

(a)

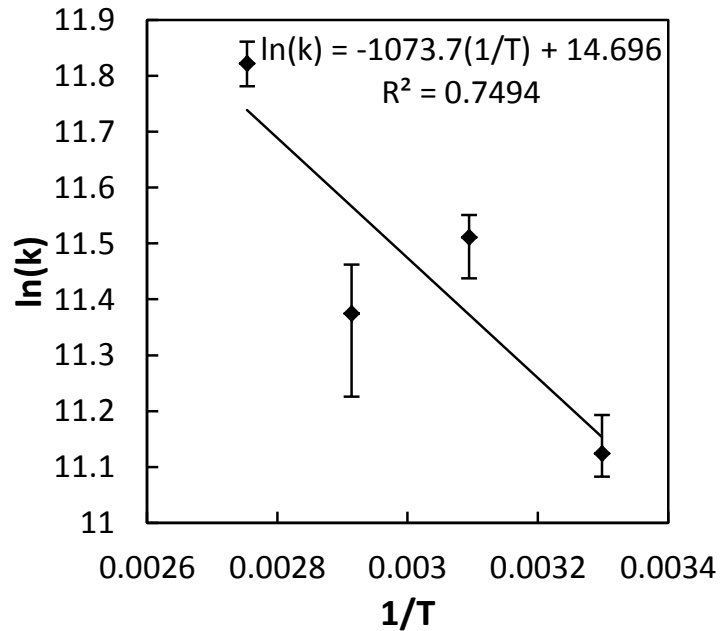

(b) 


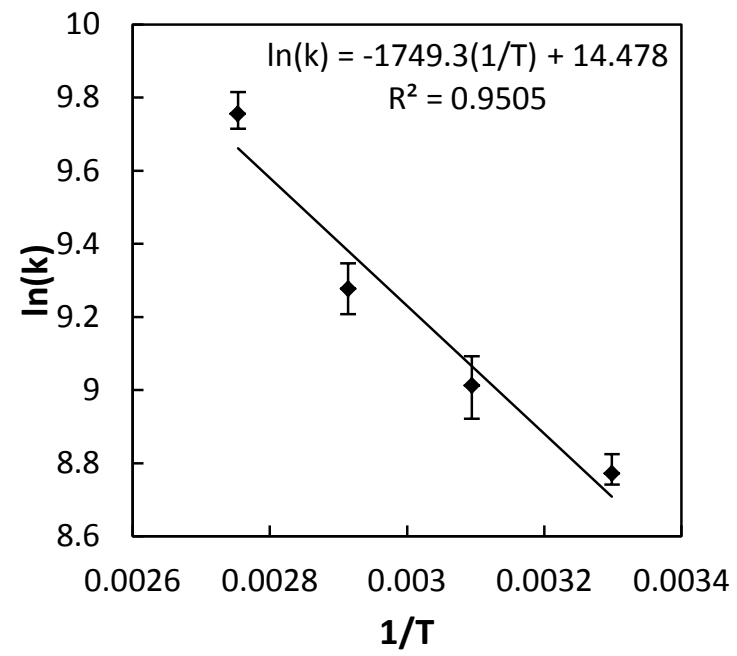

(c)

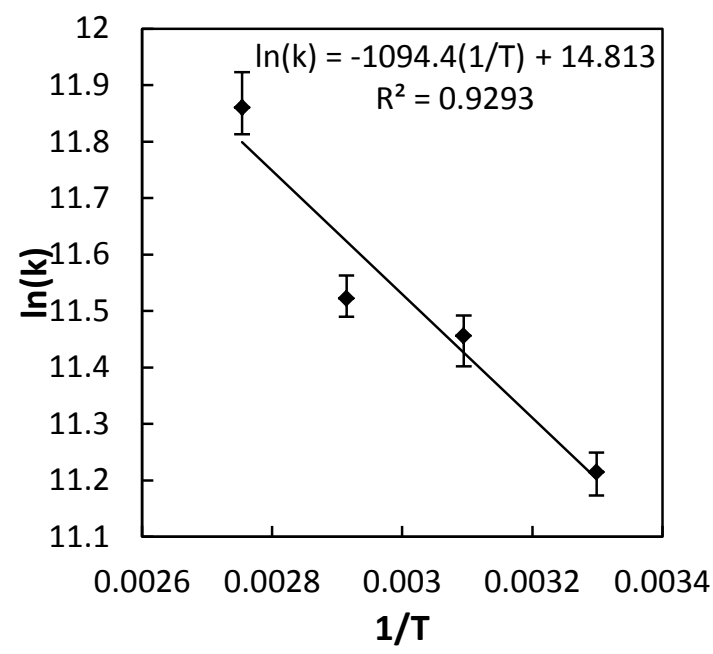

(e)

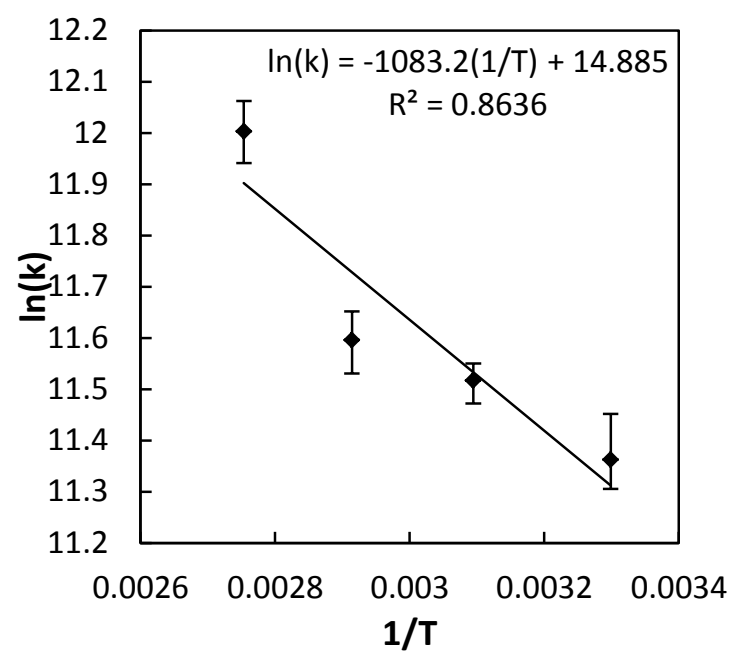

(d)

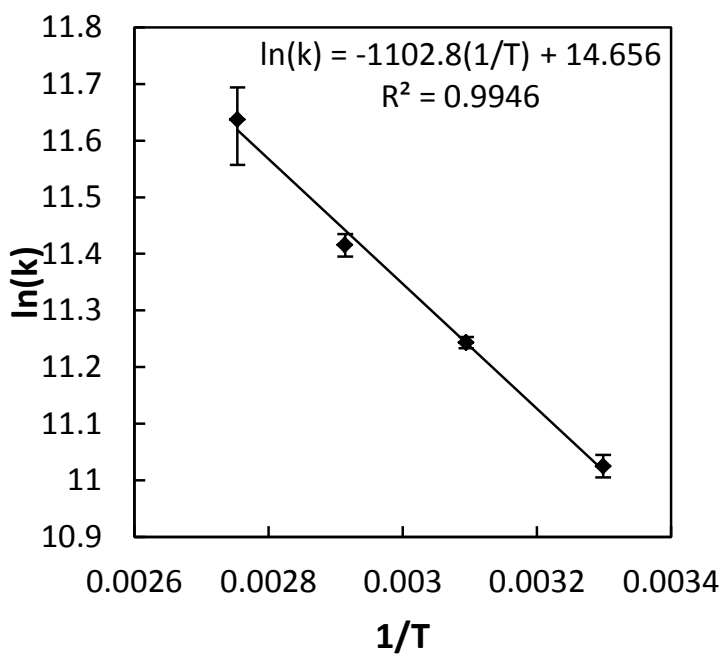

(f)

Figure 35. Linear regression plots of reactions between ADMB and carbonyl compounds.

(a) Acetone, (b) 2-Butanone, (c) 2-Nonanone, (d) Propionaldehyde, (e) Butanal, (f) Hexanal.

Table 4 shows the activation energy and frequency factor of each reaction. The reactions of ketones and aldehydes with short alkyl chain have the similar frequency factors and lower activation energy, compared with carbonyl compounds with that of long alkyl chain. ATM reactions have larger frequency factor and lower activation energy, 
compared with ADMB reacting with the same carbonyls. The experiment results reflect the steric effects of reaction, which can be used to guide design and synthesis of aminooxy compounds as the coating materials for preconcentration of specific carbonyl compounds.

\section{Table 4}

The activation energy, frequency factor and coefficient of determination of linear $\underline{\text { regression in each reaction }}$

ATM

\begin{tabular}{cccc|ccc}
\hline & $\mathrm{Ea}$ & $\mathrm{k} \mathrm{k}_{0}$ & $\mathrm{R}$ & $\mathrm{Ea}$ & $\mathrm{k}_{0}$ & $\mathrm{R}^{2}$ \\
& $(\mathrm{~J} / \mathrm{mol})$ & $\left(10^{-6} \mathrm{~L} / \mathrm{mol} / \mathrm{s}\right)$ & & $(\mathrm{J} / \mathrm{mol})$ & $\left(10^{-6} \mathrm{~L} / \mathrm{mol} / \mathrm{s}\right)$ & \\
\hline Propionaldehyde & 7410.02 & 3.342 & 0.9173 & 8810.75 & 2.914 & 0.8636 \\
Butanal & 7800.36 & 3.402 & 0.8709 & 8901.85 & 2.711 & 0.9293 \\
Hexanal & 8437.88 & 3.292 & 0.9718 & 8970.18 & 2.318 & 0.9946 \\
Acetone & 7357.56 & 3.517 & 0.8191 & 8601.71 & 3.103 & 0.8194 \\
& & & & & & \\
2-Butanone & 7660.35 & 3.327 & 0.9033 & 8733.48 & 2.412 & 0.7494 \\
& & & & & & \\
2-Nonanone & 12947.4 & 2.400 & 0.969 & 14228.8 & 1.940 & 0.9505 \\
\hline
\end{tabular}




\section{Conclusion}

A novel microreactor preconcentration approach has been developed for the analysis of trace ketones and aldehydes in gaseous mixtures. The microreactor is functionalized with the quaternary ammonium aminooxy compound ATM for oximation reactions with ketones and aldehydes. By design, thousands of micropillars in the microreactor not only increase the contact area, but also uniformly distribute gas flow to maximize the collision probability of ATM with ketones and aldehydes in the gas phase flowing through the microreactor. Since ATM and its oxime ether adducts are positively charged, analysis by FTICR-MS is greatly improved. The preconcentration efficiency varies with the molecular weight of ketones and aldehydes and is related to the ATM/ketone and ATM/aldehyde ratios. A total of $97 \%$ of acetone at a level of $1 \mathrm{ppbv}$ in TO-15 has been captured by the microreactor. The microreactor with ATM coating may provide a new approach for analysis of trace ketones and aldehydes in ambient air and in exhaled breath.

The kinetics of oximation reaction in microreactor is also studied. The reactions between ketones and aldehydes with short alkyl chain have similar frequency factors and lower activation energy, compared with carbonyl compounds with long alkyl chain. ATM and carbonyl compounds reactions have larger frequency factor and lower activation energy, compared with ADMB. The experiment results can be used to guide design and synthesis of aminooxy compounds as the coating materials for preconcentration of specific carbonyl compounds. 


\section{CHAPTER IV}

\section{ANALYSIS OF CARBONYL COMPOUNDS IN AMBIENT AIR USING THE MICROREACTOR}

\section{Introduction}

Carbonyl compounds are common atmospheric pollutants as direct emissions from motor vehicles (Schauer et al., 1999; Grosjean et al., 2001; Jakober et al., 2008; Zhao et al., 2010) and other combustion sources (Schauer et al., 2001; Kabir et al., 2010), produced by oxidation of virtually all hydrocarbons and photochemical reaction of precursors with free radicals and ozone (Baez et al., 2000; Cheng et al., 2010; Yuan et al., 2012; Guo et al., 2013). Carbonyl compound concentrations in ambient air in urban and rural areas and in emission gases from vehicles have been measured (Grosjean and Fung, 1982; Kuwata et al., 1983; Levin et al., 1985; Uchiyama et al., 2003; Uebori and Imamura, 2004). Several carbonyl compounds, such as formaldehyde, acetaldehyde, and propionaldehyde, are included in the results of 2005 national-scale air toxics assessments (NATA) (http://www.epa.gov/nata2005/). Acrolein is a severe lung irritant that, at high acute exposures, can induce oxidative stress, decrease pulmonary function and cause lung injury, including asthma and lung cancer. 
So far, SPME has been a popular preconcentration method introduced a decade ago as a rapid extraction technique for analysis of volatile organic compounds from a variety of matrixes (Arthur and Pawliszyn, 1990). However, SPME is only a semiquantitative method due to competitive adsorption on the SPME fiber. It is also difficult to determine the actual volume of air that is sampled by the SPME fiber. DNPHcoated filters or solid sorbents was also demonstrated as sampling media on which carbonyl compounds are collected as DNPH derivatives in most studies. The DNPH derivatives are subsequently eluted and analyzed by HPLC with a UV detector (Grosjean et al., 2002; Wang et al., 2007; Fusaya et al., 2004). However, only a few of the studies reported the capture efficiency of DNPH (Herrington et al., 2007; Zhang et al., 1994). And this class of reagents was not designed to aid in detection by modern ultra-sensitive MS ion sources such as nanoelectrospray ionization. In recent years, microfabricated gas preconcentrators and gas chromatography columns have demonstrated the potential for real-time, low-power, and hand-held gas detection (Tian et al., 2005; Agah et al., 2006). Preconcentrators fabricated from silicon wafers using MEMS technology typically consist of a micro hot plate and an adsorption material placed adjacent to the heating element (Alfeeli and Agah, 2009; Voiculescu et al., 2008).

In this chapter, we describe a novel preconcentration approach for analysis of trace carbonyl compounds in indoor and outdoor air. We designed and fabricated a microreactor chip using MEMS technology. The benefits of the MEMS approach are advantages in microstructure flexibility and microliter sample volume in comparison with the conventional DNPH-based packed cartridges. Thousands of micropillars in the microreactors distribute gas flow and provide large surface areas for trapping target gases. 
The surfaces of the micropillars are functionalized by a quaternary ammonium aminooxy salt, ATM, as a "capture phase" via oximation reactions with carbonyl compounds. This approach is suitable for quantitative analysis of carbonyl compounds in ambient air. For rapid analysis and identification of volatile carbonyl adducts in a microliter sample volume, we use FTICR-MS, which is benefited by the permanent positive charge of ATM.

\section{Materials and Sampling}

All reagents and solvents, including deuterated acetone (acetone-d6) (99.9\%), and methanol (99.9\%), were purchased from Sigma-Aldrich. The quaternary ammonium aminooxy compound ATM was synthesized according to a published method. The 5L Tedlar bags were purchased from Supelco (Bellefonte, PA, USA). The 0.5L clear acrylic syringe from SGE (Orlando, FL, USA). Both bags and the syringe were tested free of carbonyl compounds contamination.

0.5L Ambient air samples from indoor areas (office, laboratory and clinic site), and outdoor areas (road side and gas station), were collected with $0.5 \mathrm{~L}$ syringe on different dates, and injected into 5 L Tedlar bags for 6 times. Each air samples of 3 Liter was collected in the $5 \mathrm{~L}$ Tedlar bags using the $0.5 \mathrm{~L}$ syringe. Then, the Tedlar bags were connected to the microreactor by septa and silicon tube as shown in Figure 36. The air in Tedlar bags flowed through the fabricated microreactor at a flow rate of $5 \mathrm{~mL} / \mathrm{min}$ by vacuum. Figure 36 shows the schematic setup for preconcentration of air samples by the

microreactor. The reacted ATM adduct and unreacted ATM were eluted from the 
microreactor by flowing $100 \mu \mathrm{L}$ methanol from one slightly pressurized vial through the microreactor and then into an empty collecting sample vial. The eluted solutions were directly used for FTICR-MS analysis without any further process.

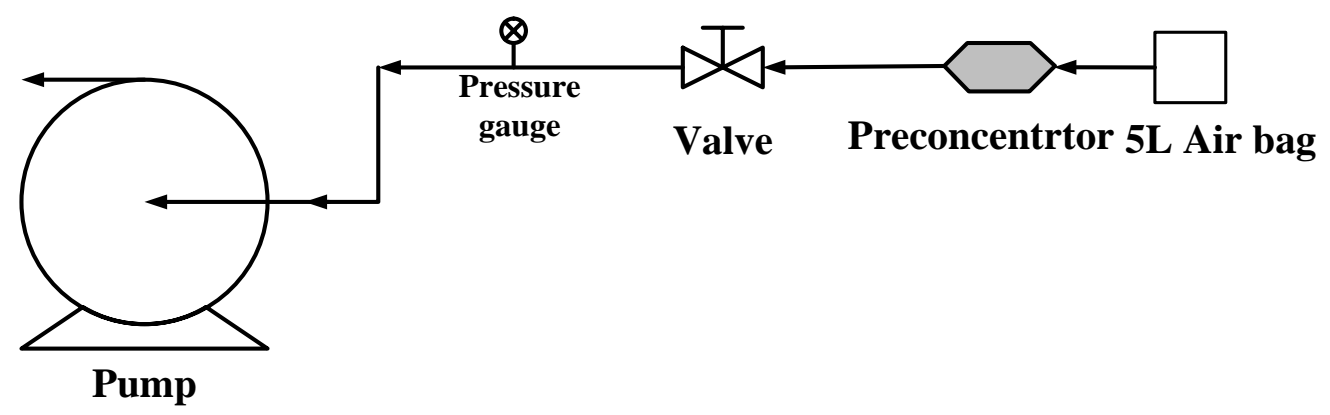

Figure 36. Schematic flow diagram of the preconcentration setup.

To determine the amounts of the captured carbonyl compounds, a $5 \mu \mathrm{L}$ solution containing $1.14 \times 10^{-8}$ mole of acetone-d6 completely reacted with ATM in methanol was added to each eluted methanol solution as an internal reference for FTICR-MS analysis. The amount of captured carbonyl compounds was determined by comparing the FTICR-MS signal abundance of ATM-acetone-d6 with that of reacted ATM-carbonyls.

\section{Data Analysis}

Twenty-one carbonyl compounds were detected in the outdoor air and indoor air. Figure 37 shows typical FTICR-MS spectra of air samples from a gas station and a clinic physical examination room. ATM- $\mathrm{C}_{2} \mathrm{HO}, \mathrm{ATM}-\mathrm{C}_{2} \mathrm{H}_{4} \mathrm{O}$ and $\mathrm{ATM}-\mathrm{C}_{3} \mathrm{H}_{6} \mathrm{O}$ are the most abundant carbonyl compounds in these two sites. Table 5 shows determined concentrations of these carbonyls concentrations. $\mathrm{CH}_{2} \mathrm{O}$ is formaldehyde and $\mathrm{C}_{2} \mathrm{H}_{4} \mathrm{O}$ is acetaldehyde. These 21 carbonyl compounds included 11 saturated carbonyls, 3 unsaturated carbonyls, 3 hydroxyl carbonyls, 4 aromatic carbonyls according to the 
formula. Constitutionally isomeric ketones and aldehydes are indistinguishable by direct infusion one dimensional FT-ICRMS, however, the measured molecular weight at a resolving power of 200,000 provides accurate chemical formulas.

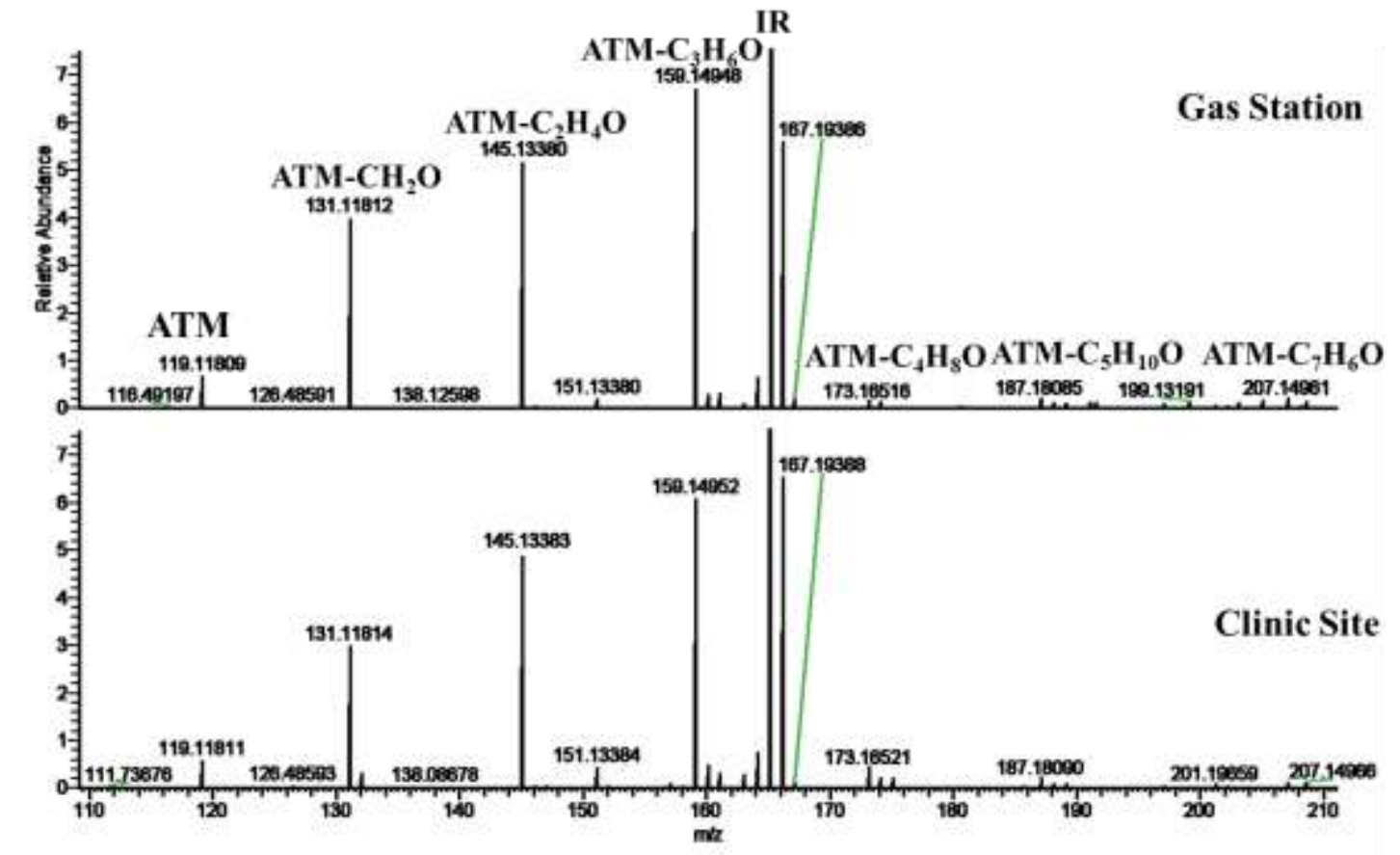

Figure 37. FTICR-MS spectra of ambient air samples from a gas station and a clinic examination room. 


\section{Table 5}

Average concentrations of carbonyl compounds in ambient air and limits of detection for $\underline{\text { several carbonyl compounds }}$

\begin{tabular}{|c|c|c|c|c|c|c|c|}
\hline $\begin{array}{l}\text { Average carbonyl } \\
\text { concentrations }\left(\mu \mathrm{g} / \mathbf{m}^{3}\right)\end{array}$ & 01 & 02-1 & O2-2 & I1 & I 2 & I3 & $\operatorname{MDL}\left(\mu \mathrm{g} / \mathrm{m}^{3}\right)$ \\
\hline Formaldehyade & 5.64 & 3.33 & 1.72 & 7.12 & 3.8 & 1.71 & 0.0056 \\
\hline Acetaldehyde & 8.8 & 7.55 & 4.19 & 9.31 & 9.65 & 8.36 & 0.0092 \\
\hline Acrolein & 0.01 & 0.02 & 0.01 & 0.11 & ND & ND & \\
\hline $\mathrm{C}_{3} \mathrm{H}_{6} \mathrm{O}$ & 14.5 & 17.4 & 8.72 & 21.2 & 12.3 & 15.2 & $0.0042^{\mathrm{a}}$ \\
\hline $\mathrm{C}_{4} \mathrm{H}_{8} \mathrm{O}$ & 3.92 & 1.26 & 0.97 & 9.23 & 6.5 & 2.43 & $0.0073^{b}$ \\
\hline $\mathrm{C}_{5} \mathrm{H}_{10} \mathrm{O}$ & 0.63 & 0.42 & 0.29 & 1.94 & 1.75 & 1.93 & \\
\hline $\mathrm{C}_{5} \mathrm{H}_{4} \mathrm{O}_{2}$ & 0.11 & 0.04 & ND & 0.07 & 0.08 & 0.04 & \\
\hline $\mathrm{C}_{6} \mathrm{H}_{10} \mathrm{O}$ & 0.08 & ND & ND & ND & 0.02 & ND & \\
\hline $\mathrm{C}_{6} \mathrm{H}_{12} \mathrm{O}$ & 0.47 & 0.39 & 0.14 & 1.13 & 0.91 & 1.47 & \\
\hline Benzaldehyde & 1.91 & 1.72 & 1.29 & 2.12 & 1.07 & 1.34 & 0.0129 \\
\hline $\mathrm{C}_{7} \mathrm{H}_{14} \mathrm{O}$ & 0.03 & ND & ND & ND & ND & ND & \\
\hline $\mathrm{C}_{8} \mathrm{H}_{8} \mathrm{O}$ & 0.51 & ND & ND & 0.32 & 0.09 & 0.07 & \\
\hline $\mathrm{C}_{7} \mathrm{H}_{7} \mathrm{O}_{2}$ & 0.05 & ND & ND & ND & ND & ND & \\
\hline $\mathrm{C}_{9} \mathrm{H}_{10} \mathrm{O}$ & 0.11 & ND & ND & ND & 0.04 & 0.05 & \\
\hline $\mathrm{C}_{9} \mathrm{H}_{14} \mathrm{O}$ & 0.06 & ND & ND & ND & 0.03 & 0.04 & \\
\hline $\mathrm{C}_{7} \mathrm{H}_{14} \mathrm{O}$ & 0.58 & 0.37 & 0.25 & 1.79 & ND & ND & \\
\hline $\mathrm{C}_{8} \mathrm{H}_{16} \mathrm{O}$ & 0.56 & 0.49 & 0.36 & 1.34 & ND & ND & \\
\hline $\mathrm{C}_{9} \mathrm{H}_{18} \mathrm{O}$ & 0.61 & 0.53 & 0.51 & 1.98 & ND & ND & \\
\hline $\mathrm{C}_{2} \mathrm{H}_{4} \mathrm{O}_{2}$ & 0.22 & 0.19 & 0.16 & 0.94 & 0.32 & 0.25 & \\
\hline $\mathrm{C}_{3} \mathrm{H}_{6} \mathrm{O}_{2}$ & 0.09 & 0.15 & 0.12 & 0.07 & 0.02 & 0.02 & \\
\hline $\mathrm{C}_{4} \mathrm{H}_{8} \mathrm{O}_{2}$ & 0.11 & 0.22 & 0.13 & 0.32 & 0.25 & 0.07 & \\
\hline
\end{tabular}


O1, Gas station; O2-1, Roadside (sunny days); O2-2, Roadside (rainy days); I1, Institution of laboratory; I2, Institution of clinic room; I3, Institution of office. MDL, method detection limit. a, acetone detection limit; b, 2-butatnone detection limit. ND, not detected. Sample date: July/2012.

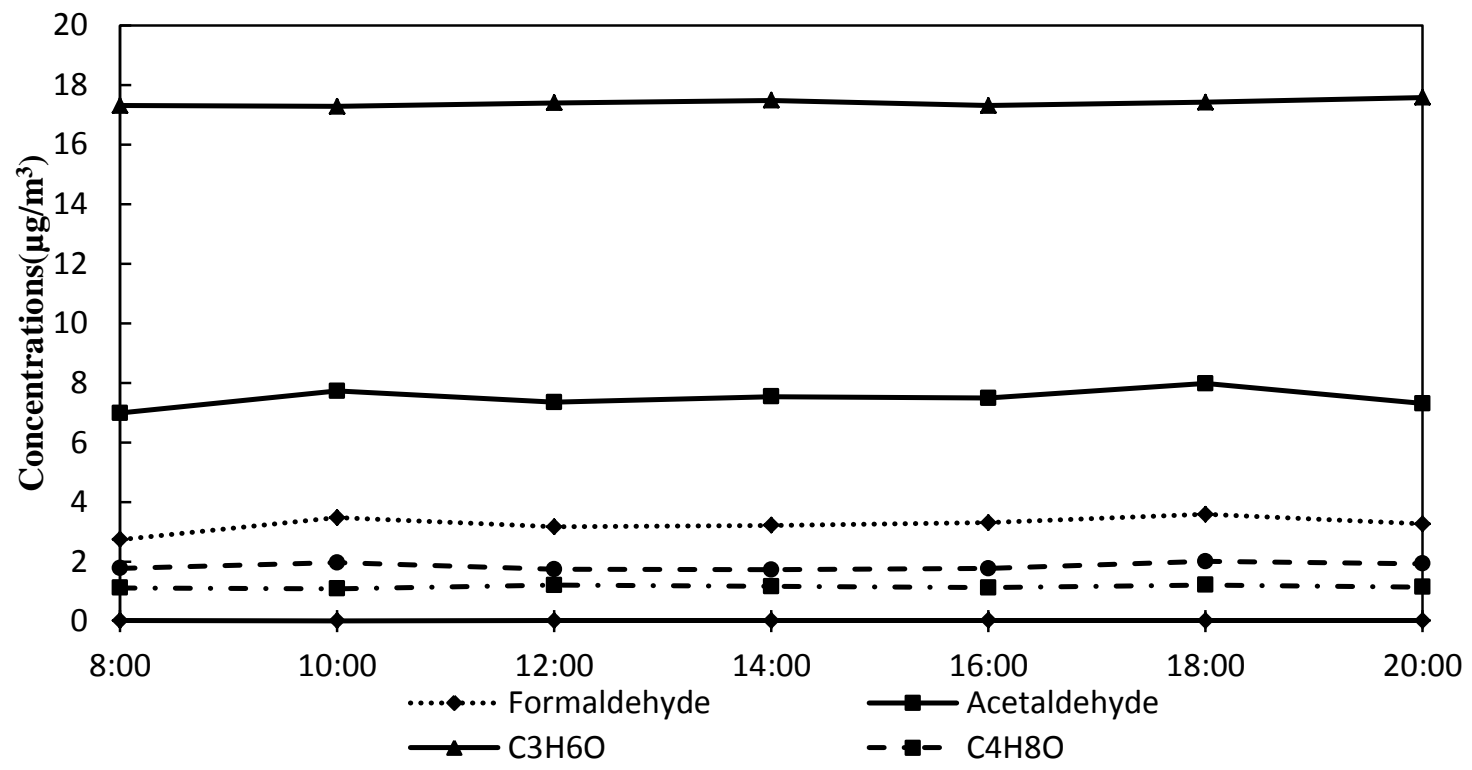

(a)

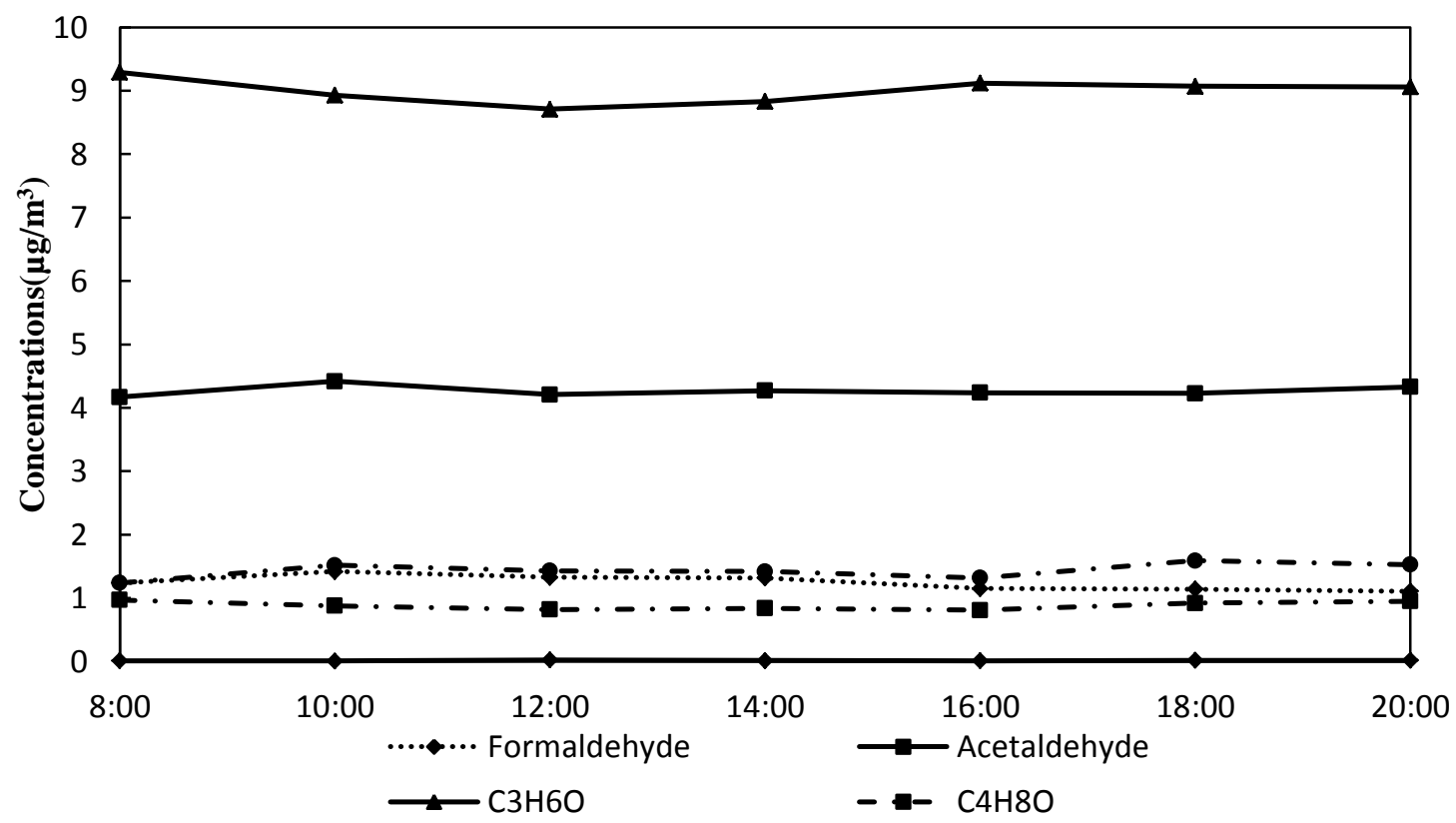

(b) 


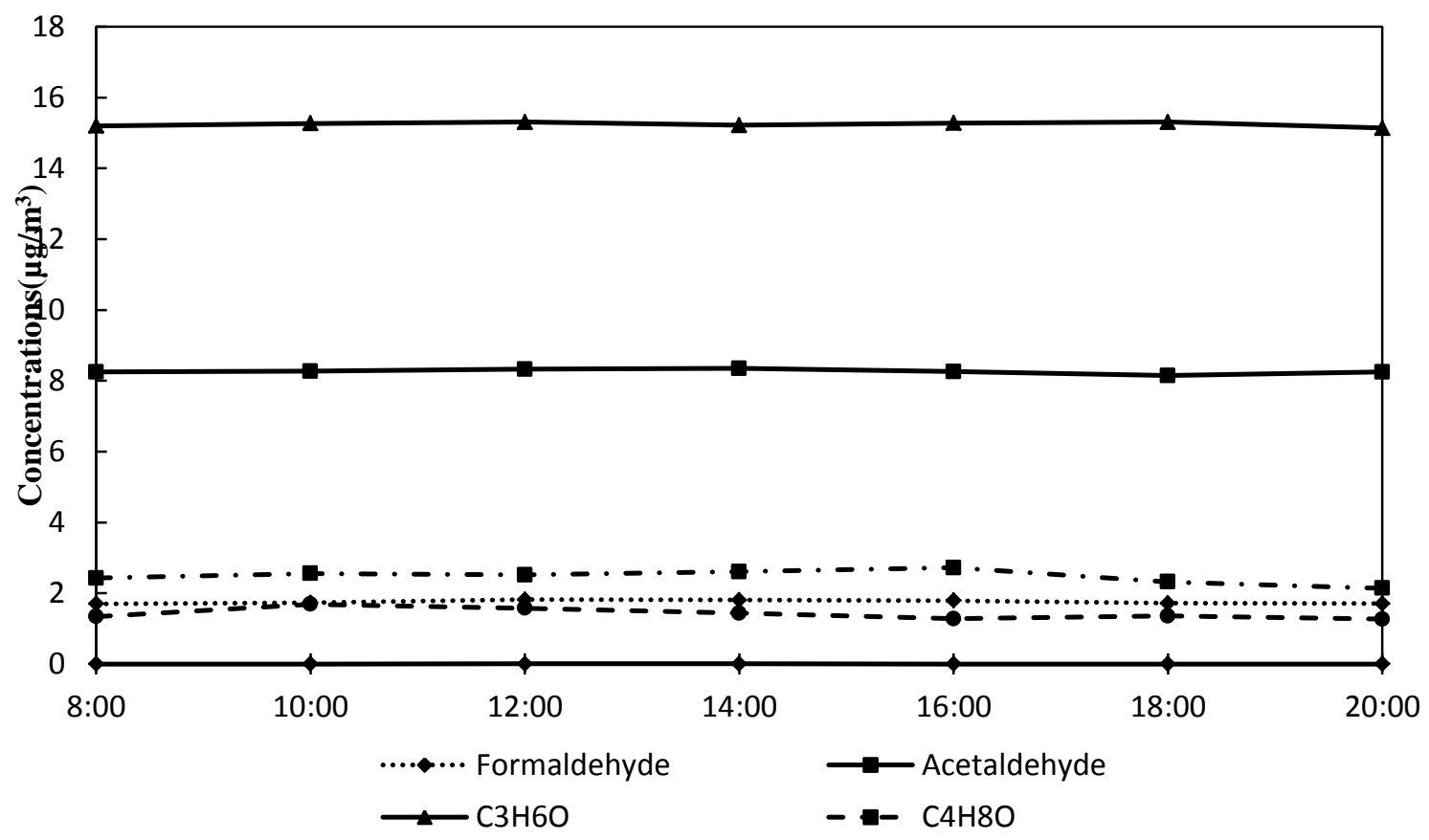

(c)

Figure 38. Average carbonyl concentrations as a function of daytime: (a) road side (sunny days), (b) road side (rainy days) and (c) office area.

Of all the carbonyls measured in the outdoor environment, formaldehyde, acetaldehyde and $\mathrm{C}_{3} \mathrm{H}_{6} \mathrm{O}$ (acetone and propanal) were the most abundant carbonyls, followed by $\mathrm{C}_{4} \mathrm{H}_{8} \mathrm{O}, \mathrm{C}_{5} \mathrm{H}_{10} \mathrm{O}$ and $\mathrm{C}_{7} \mathrm{H}_{6} \mathrm{O}$. The total concentration of all carbonyls in the gas station area had a mean level of $43.12 \mu \mathrm{g} / \mathrm{m}^{3}$, which is higher than the concentration in the roadside (sunny days $33.16 \mu \mathrm{g} / \mathrm{m}^{3}$, rainy days $16.85 \mu \mathrm{g} / \mathrm{m}^{3}$ ). $\mathrm{C}_{3} \mathrm{H}_{6} \mathrm{O}$ was the most abundant carbonyl in many samples and accounted for average 34\% of the total carbonyl concentrations at the gas station and for $57 \%$ of the total carbonyls at roadside.

In the indoor environment, $\mathrm{C}_{3} \mathrm{H}_{6} \mathrm{O}$ is also the most abundant carbonyl compound. The total concentration of all carbonyls in the laboratory had a mean level of $60.06 \mu \mathrm{g} / \mathrm{m}^{3}$, 
which is much higher than that of clinic examination room $\left(31.28 \mu \mathrm{g} / \mathrm{m}^{3}\right)$ and office $\left(21.74 \mu \mathrm{g} / \mathrm{m}^{3}\right)$. The storage of acetone and 2-butanone increases $\mathrm{C}_{3} \mathrm{H}_{6} \mathrm{O}$ and $\mathrm{C}_{4} \mathrm{H}_{8} \mathrm{O}$ level in the laboratory and the more smoking people's activity in clinic site also increase acetaldehyde level compared with office area.

Hourly average carbonyl concentrations observed in July are shown in Figure 38. An imperceptible change of the carbonyl concentrations, especially the concentrations of formaldehyde and acetaldehyde, were observed in the roadside areas over the 1-day sampling period (Fig. 38(a) and (b)). During the sunny days, the concentrations of formaldehyde and acetaldehyde increased from 8:00 am to 10:00 am, which caused by the emission gases from vehicles in the morning traffic peak. The concentrations decreased from 10:00 am to 12:00 pm followed by a slight increase from 12:00 pm to 6:00 $\mathrm{pm}$, and reached to the maximum at 6:00 $\mathrm{pm}$. Therefore, photochemical reactions also contribute to the increase of formaldehyde and acetaldehyde concentrations observed in the afternoon. The carbonyl concentrations in rainy days were lower than those observed in sunny days. The concentrations of formaldehyde and acetaldehyde also increased from 8:00 am to 10:00 am, which was the same reason as the sunny days. However, the concentrations of formaldehyde and acetaldehyde remained stable from 12:00 $\mathrm{pm}$ to $6: 00 \mathrm{pm}$, since the less photochemical reactions occurred in rainy days and also carbonyl compounds dissolve in rain. The carbonyl concentrations in the office remained stable during the 1-day sampling period (Figure 38(c)). 


\section{Conclusion}

A novel microreactor preconcentration approach has been developed for the analysis of trace volatile carbonyl compounds in ambient air. The microreactor features thousands of micropillars that uniformly distribute gas flow to efficiently increase the reactions with carbonyl compounds in the gas flow. This method can measure the instant concentration of the carbonyl compounds rather than the means in a long period. The

most abundant compound was $\mathrm{C}_{3} \mathrm{H}_{6} \mathrm{O}$, followed by formaldehyde and acetaldehyde. The micro-scale of this approach should be attractive for a broad range of other applications, such as exhaled breath analysis. 


\section{CHAPTER V}

\section{DETECTION OF LUNG CANCER FROM EXHALED BREATH USING THE MICROREACTOR}

\section{Introduction}

Lung cancer is the leading cause of cancer death and can be classified into two main types - non small cell lung cancer (NSCLC) and small cell lung cancer (SCLC). Each year, more people die of lung cancer than of combined breast, colon, and prostate cancers (Alberg et al., 2007). Lung cancer can be cured in its early stages. The 5-year survival rate can be as high as $60 \%-80 \%$ for patients with stage I lung cancer (Dominioni et al., 2000). However, only $15 \%$ of lung cancer patients are diagnosed before lung cancer develops to a regional or metastatic cancer. Thus, the overall 5-year survival rates decrease to $16 \%$ for lung cancer patients (Jemal et al., 2010). The National Lung Screening Trial Team recently reported that computed tomography (CT) screening of heavy smokers could reduce lung cancer deaths by as much as 20\% (Savage, 2011). Hence, detection of lung cancer in its early stages is critical for increasing survival rate of lung cancer patients and has become an important topic in lung cancer researches. 
One promising and noninvasive method for detection of lung cancer in early stages is the analysis of volatile organic compounds (VOCs) in exhaled breath (Gordon et al., 1985; Preti et al., 1988; Phillips et al., 1999; Chen et al., 2007; Wehinger et al., 2007; Bajtarevic et al., 2009; Peng et al., 2009). This approach is based on cancer-related changes in blood metabolites reflected in measurable changes of VOCs in exhaled breath through exchange via the lung. The cancer cell formation and growth is accomplished by gene and/or immunity system changes that may lead to emit different VOCs implicated the oxidative stress and peroxidation of the cell membrane species (Hakim et al., 2012). Compositions and concentrations of the VOCs in exhaled breath appear in significant difference between healthy controls and lung cancer patients.

Solid phase microextraction-gas chromatography mass spectrometry (SPMEGCMS) analysis has been used to identify exhaled breath biomarkers of lung cancer (Poli et al., 2005; Wang et al., 2012). However, the surface area of the SPME polymer extraction phase is small, and it is only a semiquantitative method due to competitive adsorption on the SPME fiber. Exhaled breath condensate (EBC) has also been popular in breath analysis (Khyshiktyev et al., 1994; Chan et al., 2008). While the variable dilution of moisture in exhaled breath may contribute to large variability in measurements of most parameters of EBC and this is considered to be one limitation of EBC. Gas sensor array or Electronic noses (eNose) relying on chemical vapor sensor arrays is a rapidly evolving field, driven by the increasing demand for fast detection of VOCs (Machado et al., 2005; Peng et al. 2009; Mazzone et al., 2012). However, the disadvantage of inability to identify specific VOCs and interference of VOCs limits its practical application. 
The carbonyl metabolites are produced in biochemical pathways as intermediates and some can be unique to a given pathway or process. Volatile ketones and aldehydes are also generated from oxidative reactions, such as lipid peroxidation (Long and Picklo, 2010; Riahi et al., 2010).

The MEMS based microreactor chips has been proved for capture of trace level carbonyl compounds with high capture efficiency (Fu et al., 2011, Li et al., 2012) Thousands of micropillars in the microreactors distribute gas flow and provide large surface areas for trapping target gases. This approach can be used for quantitative analysis of trace carbonyls in exhaled breath.

\section{Breath Samples from Smokers}

Smoking is one of the leading causes for many lung diseases, such as emphysema, chronic obstructive pulmonary disease (COPD) and lung cancer. Many researches indicated that tobacco smoking can also affect the VOCs in exhaled breath (Wang et al., 2012; Bajtarevic et al., 2009). To find the relevance between smoking and lung disease, and distinguish the VOC compounds which are caused by smoking or lung cells with pathological changes, a total of 85 subjects, 45 current smokers (CS) and 40 never smokers (NS) free from chronic lung disease or respiratory tract infection in the age range from 20 to 70 were recruited to provide exhaled breath samples in this study, after approval by the Internal Review Board (IRB) at the University of Louisville and after having obtained written informed consent from the subjects. 


\subsection{Breath sampling and detection}

Each volunteer breathed to fill a 1L Tedlar bag. A mixed alveolar and tidal breath is collected. 3 Liter size air samples in clinic were also collected in the 5 L Tedlar bags using the $0.5 \mathrm{~L}$ syringe as the background study of carbonyl compounds in the room air. The Tedlar bag was directly connected to the silicon microreactor through deactivated silica tubes and septa as shown in Figure 39. Then, the vacuum pump forced gaseous breath in Tedlar bags flowing through the fabricated microreactor (Li et al., 2012; Fu et al., 2011) at a flow rate of $5 \mathrm{~mL} / \mathrm{min}$. Figure 39 shows a schematic setup for preconcentration of all carbonyl compounds in air samples by the silicon microreactor. There are thousands of micropillars in the microreactor which were functionalized by a quaternary ammonium aminooxy, ATM salt for capture of all carbonyl compounds by oximation reactions. The unreacted ATM and reacted ATM adducts were eluted from the microreactor by flowing $100 \mu \mathrm{L}$ methanol from one slightly pressurized vial through the microreactor and then into an empty collecting sample vial (Fu et al., 2011). The eluted solutions were directly used for FTICR-MS analysis without any further process. To determine the concentrations of the carbonyl compounds, a $5 \mu \mathrm{L}$ solution containing 1.14 $\times 10^{-8}$ mole of acetone-d6 completely reacted with ATM in methanol was added to each eluted methanol solution as an internal reference for FTICR-MS analysis. The amount of captured carbonyl compounds was determined by comparing the FTICR-MS signal abundance of ATM-acetone-d6 with that of ATM-carbonyls. The samples of methanol eluted solutions were analyzed on a hybrid linear ion trap-FTICR-MS. 


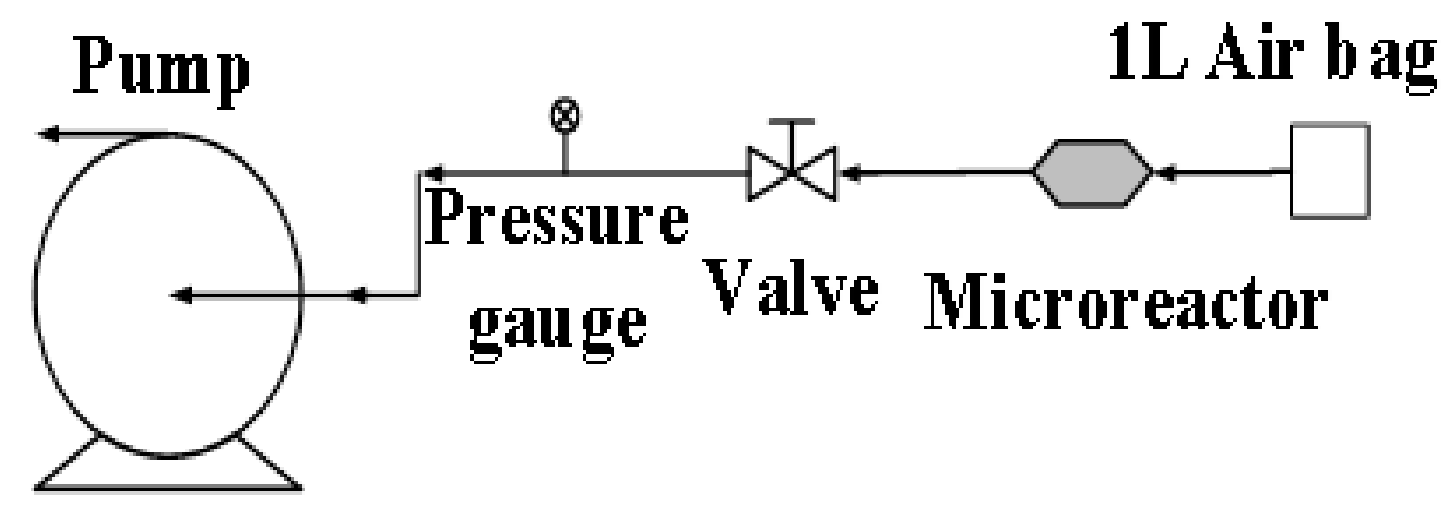

Figure 39. Schematic flow diagram of the preconcentration setup for breath anaylsis.

Sixteen carbonyl formulas were found in exhaled breath samples and their concentrations were determined. They are $\mathrm{CH}_{2} \mathrm{O}, \mathrm{C}_{2} \mathrm{H}_{4} \mathrm{O}, \mathrm{C}_{3} \mathrm{H}_{6} \mathrm{O}, \mathrm{C}_{3} \mathrm{H}_{4} \mathrm{O}, \mathrm{C}_{4} \mathrm{H}_{8} \mathrm{O}$, $\mathrm{C}_{5} \mathrm{H}_{10} \mathrm{O}, \mathrm{C}_{6} \mathrm{H}_{12} \mathrm{O}, \mathrm{C}_{7} \mathrm{H}_{14} \mathrm{O}, \mathrm{C}_{8} \mathrm{H}_{16} \mathrm{O}, \mathrm{C}_{9} \mathrm{H}_{18} \mathrm{O}, \mathrm{C}_{10} \mathrm{H}_{20} \mathrm{O}, \mathrm{C}_{2} \mathrm{H}_{4} \mathrm{O}_{2}, \mathrm{C}_{3} \mathrm{H}_{4} \mathrm{O}_{2}, \mathrm{C}_{4} \mathrm{H}_{8} \mathrm{O}_{2}$, $\mathrm{C}_{6} \mathrm{H}_{10} \mathrm{O}_{2}$ and $\mathrm{C}_{9} \mathrm{H}_{16} \mathrm{O}_{2}$. Constitutionally isomeric ketones and aldehydes are indistinguishable by direct infusion one dimensional FTICR-MS, however, the measured molecular weight at a resolving power of 200,000 provides accurate chemical formulas. Separation and identification of isometric ketones and aldehydes need to be done.

\subsection{Identification of the VOCs}

A new aminooxy salt, 4-(2-aminooxy) ethyl) morpholin-4-ium chloride (AMAH) combined with open chips approach was used to identify carbonyl VOCs in exhaled breath. The positive charge of AMAH contributes to electrostatic adsorption on the surfaces of micropillars in the microreactor. AMAH is also easily converted into neutral molecules 4-(2-aminooxy) ethyl) morpholine (AMA) by adding poly (4-vinylpyridine), 
and applied in GC-MS. The open chip microreactors were fabricated using the same process as closed chips demonstrated in Chapter II, without anodic bonding galss wafers and connecting deactivated fused silica tubes. $3.57 \times 10^{-7}$ mole of AMAH in methanol solution was loaded into the open chip placed in a $20 \mathrm{~mL}$ vial. Methanol was evaporated under vacuum, and the vials were sealed by silicon rubber coated with PTFE faced silicon septa. The volunteers were asked to blow gently into the vial using a straw directly on the open chip for 5 minutes. The reacted AMAH adducts and unreacted AMAH were eluted from the microreactor by injecting $10 \mu \mathrm{L}$ methanol on the chip, and transferred to a $400 \mu \mathrm{L}$ vial. After repeating 10 times, about $80 \mu \mathrm{L}$ of methanol solution sample for analyzing was prepared. $40 \mu \mathrm{L}$ solution was transferred to another vial contained $2 \mathrm{mg}$ poly (4-vinylpyridine) for AMAH neutralization. $2 \mu \mathrm{L}$ neutralized method solution was analyzed by GC (Hewlett Packard 5890 series II) - MS (Hewlett Packard 5971 series). The GC column (Rtx-5MS) is $30 \mathrm{~m}$ long, $0.25 \mathrm{~mm}$ ID, made by crosslinking 5\% diphenyl and 95\% dimethyl polysiloxane. The recipe of GC column separation was set as followed: the initial step was at $40{ }^{\circ} \mathrm{C}$ for 1 minute, the temperature was increased at the rate of $10{ }^{\circ} \mathrm{C} / \mathrm{min}$ till $250{ }^{\circ} \mathrm{C}$, and kept at $250{ }^{\circ} \mathrm{C}$ for 5 minutes. The total running time was 27 minutes. MS was turn off during the first 5 minutes for solvent delay. The rest $40 \mu \mathrm{L}$ solution was analyzed by FTICR-MS.

Reacted AMA adducts and unreacted AMA were not found from the database of MS, so methanol solutions of $\mathrm{C}_{2}-\mathrm{C}_{10}$ n-aldehyde reacted and $\mathrm{C}_{3}-\mathrm{C}_{10}$ 2-ketones reacted with AMA prepared in the laboratory were analyzed respectively as standard references using the same recipe of GC for the breath samples. The retention time and the MS spectra of each peak in the GC-MS spectra of breath samples GC was compared with the 
standard references, and some carbonyl compounds were identified: $\mathrm{CH}_{2} \mathrm{O}$ is formaldehyde, $\mathrm{C}_{2} \mathrm{H}_{4} \mathrm{O}$ is acetaldehyde, $\mathrm{C}_{3} \mathrm{H}_{6} \mathrm{O}$ is acetone, $\mathrm{C}_{4} \mathrm{H}_{8} \mathrm{O}$ is 2-butanone, and $\mathrm{C}_{5} \mathrm{H}_{10} \mathrm{O}$ contains both n-pentanal and 2-pentanone. The GC spectra in Figure 40 show difference between current smoker and never smoker. However, other carbonyl compounds with lower concentrations detected by FTICR-MS cannot be found in GC spectrum.

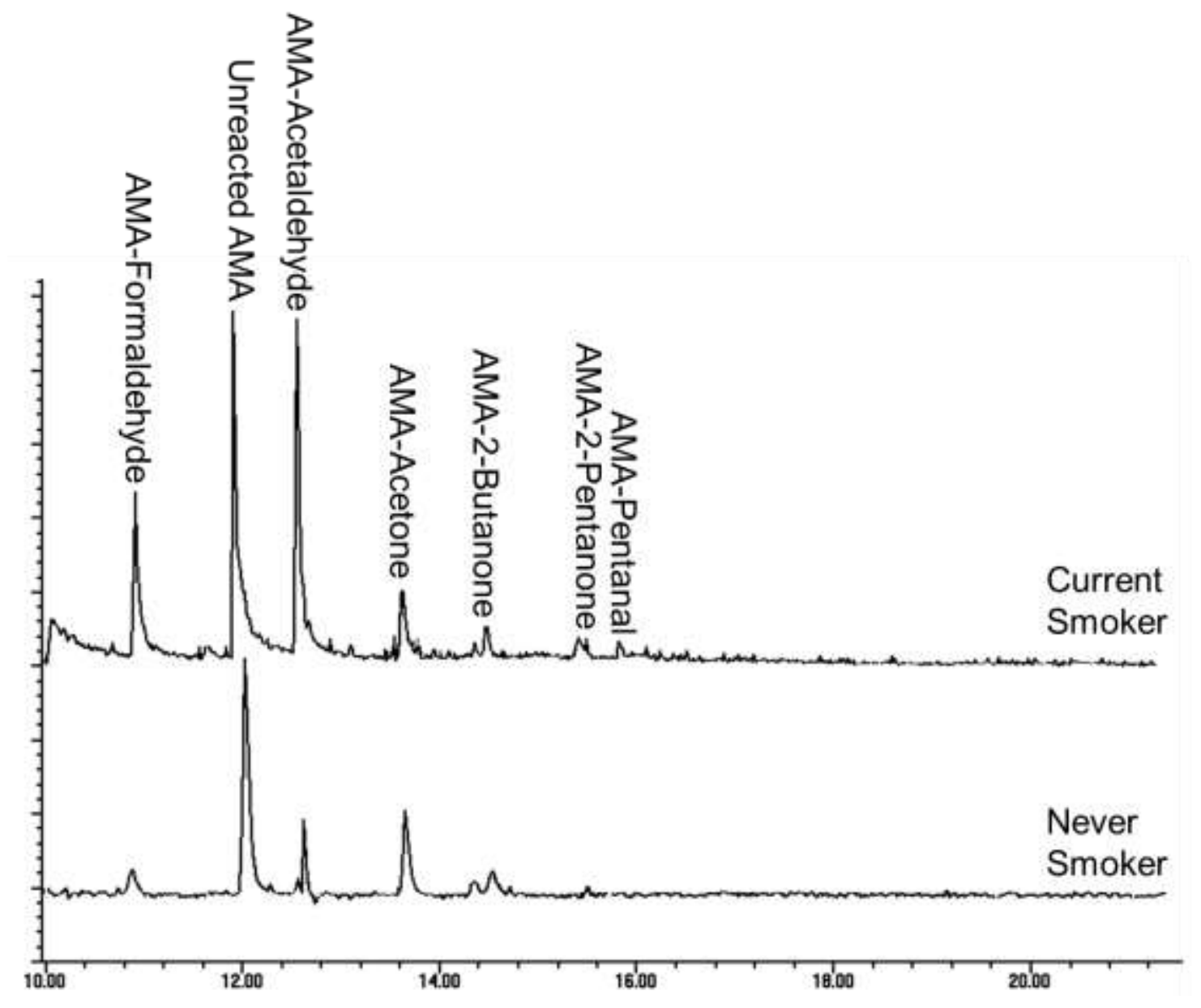

Figure 40. Extracted ion chromatogram $(\mathrm{m} / \mathrm{z} 131)$ of breath samples from a never smoker and a current smoker. 


\subsection{Statistical analysis}

The measured carbonyl VOC concentrations in exhaled breath sample of current smokers and never smokers were separated and analyzed. The normality of data in each group was tested, however, most groups cannot be assumed to be normally distributed $(\mathrm{p}<0.05)$. Figure 41 shows an example that one dataset does not follow the normal distribution. Thus, the Wilcoxon test was applied to determine statistically significant differences between the groups, which can be used for comparing two related samples to assess whether their population means differ when the population cannot be assumed to be normally distributed. After Wilcoxon test, Formaldehyde $(\mathrm{p}=0.001)$, acetaldehyde $(\mathrm{p}<0.0001)$ and acetone $(\mathrm{p}=0.011)$ presented significant higher concentrations for smokers in comparison with nonsmokers. Figure 42 shows boxplots of the concentrations of the three compounds in exhaled breath samples from never smokers and current smokers.

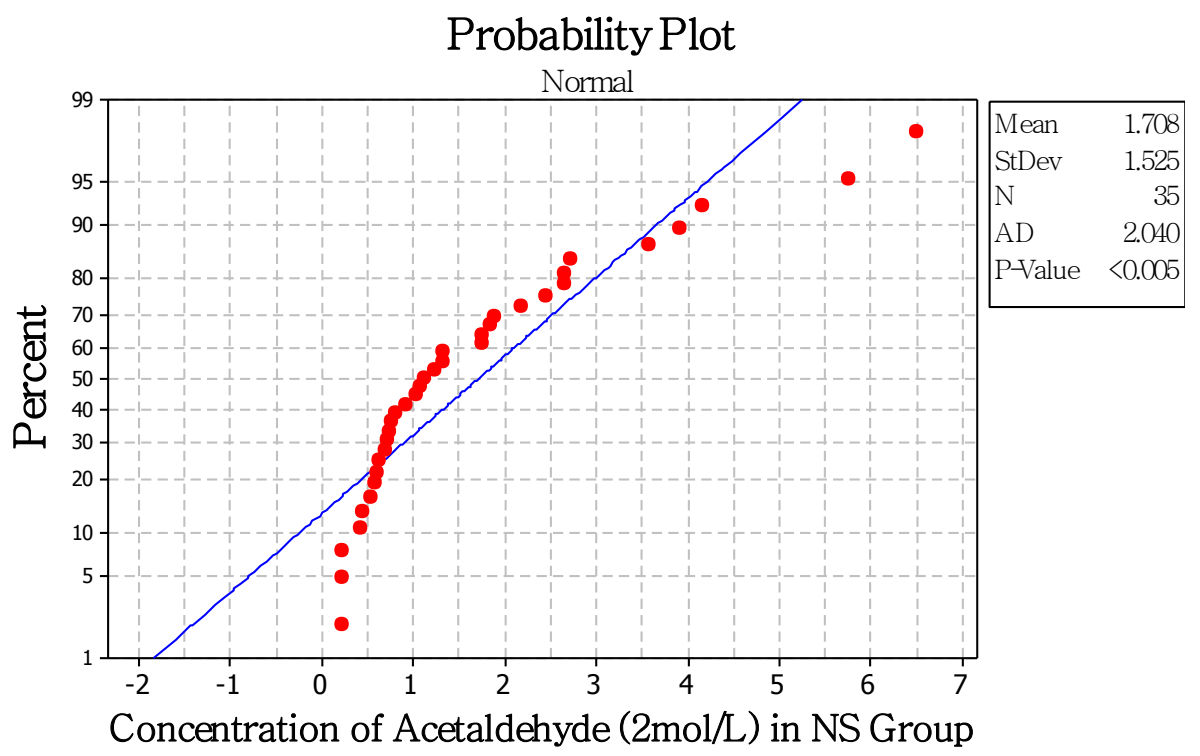

Figure 41. Normality test of acetaldehyde concentration in NS group 

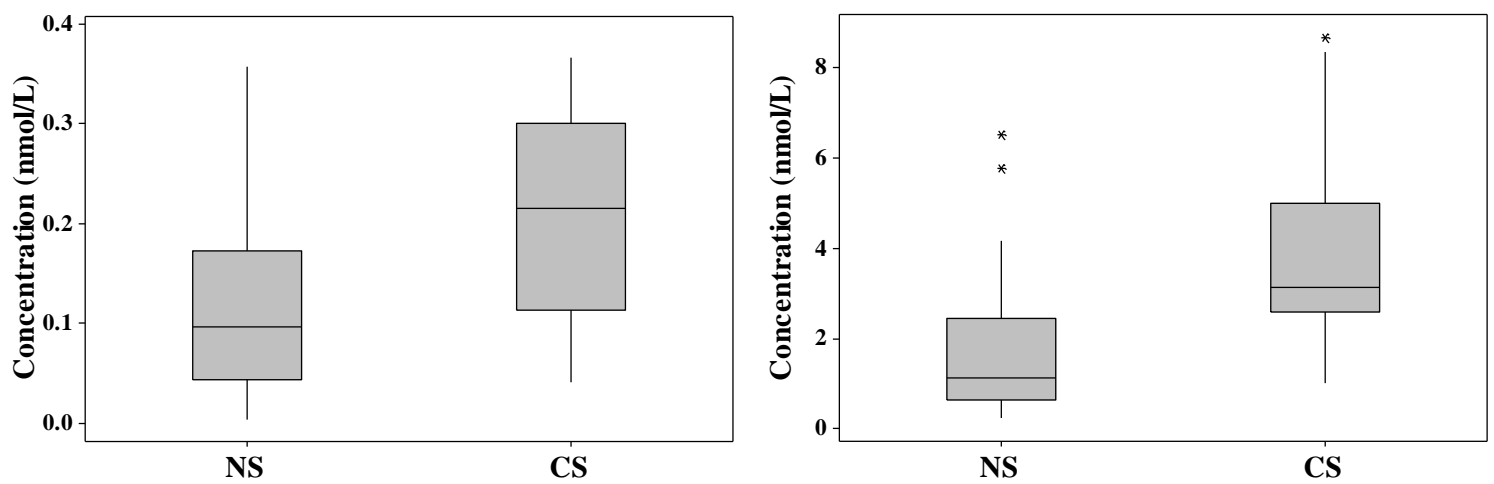

(a) Formaldehyde

(b) Acetaldehyde

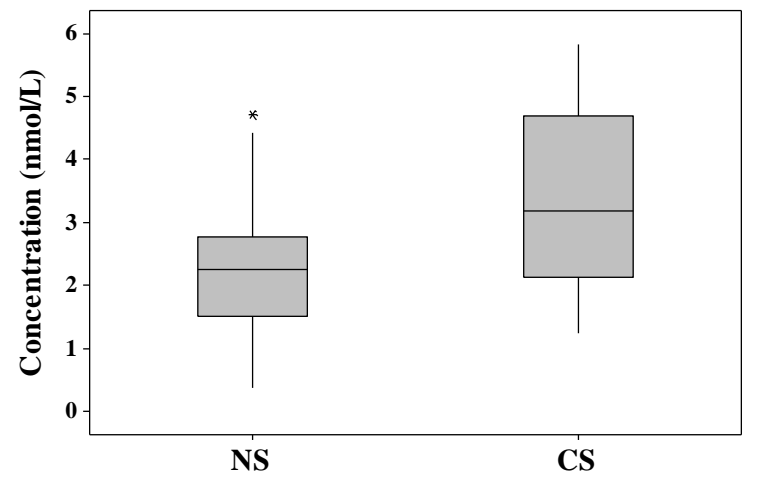

(c) Acetone

Figure 42. Comparisons of three compounds from NS group and CS group. (a) Formaldehyde, (b) Acetaldehyde, (c) Acetone.

\section{Breath Analysis of Lung Cancer Patient}

\subsection{Test population}

After approval by the Internal Review Board at the University of Louisville in Kentucky and after having obtained written informed consent, exhaled breath samples of 106 patients with untreated LC, 32 patients with benign pulmonary nodules $(\mathrm{BN})$ were collected and analyzed. All patients with pulmonary nodules were recruited in the James 
Graham Brown Cancer Center at the University of Louisville. 45 current smokers and 40 never smokers mentioned previously were considered as healthy control (HC) group. Wilcoxon test was applied to identify specific VOCs as lung cancer markers from the first 12 clinically diagnosed lung cancer subjects in comparison with healthy controls. All other subjects were patients with pulmonary nodules to be diagnosed at the time of collection of exhaled breath samples. The concentration ranges of these VOC markers were determined for healthy controls, patients with cancer. Then these VOC markers were used to diagnose cancer for all other breath analysis results. A diagnostic conclusion was made based on the concentration levels of the specific VOCs. The diagnostic conclusions from breath analysis were late confirmed by the clinical diagnosis. Sensitivity and specificity were calculated based on the diagnostic conclusions from breath analysis results. All clinical diagnosis involved various diagnostic methods including computed tomography (CT) scan, positron emission tomography (PET) scan, and pathological analysis of tissue from biopsy. The general sample information is listed in Table 6 and the stage of NSCLC and pathological category of lung cancer is presented in Table 7. The same ATM-closed chip and AMAH-open chip approaches mentioned in last section were used to collect and analyze the exhaled breath samples from patients with untreated LC and patients with BN. 
Table 6

$\underline{\text { Subject information }}$

\begin{tabular}{|c|c|c|c|c|c|}
\hline \multirow[t]{2}{*}{ Subjects } & \multirow[t]{2}{*}{$\mathbf{M} / \mathbf{T}^{*}$} & \multirow[t]{2}{*}{ Age(mean \pm SD) } & \multicolumn{3}{|c|}{ Smoking History } \\
\hline & & & Current & Former & Never \\
\hline Lung cancers & $35 / 106$ & $66.12 \pm 10.1$ & 40 & 54 & 12 \\
\hline Benign nodules & $14 / 32$ & $51.71 \pm 15.3$ & 11 & 10 & 11 \\
\hline Healthy controls & $51 / 85$ & $42.15 \pm 14.2$ & 45 & & 40 \\
\hline
\end{tabular}

Table 7

$\underline{\text { Lung cancer features }}$

\begin{tabular}{lc}
\hline Stage & \\
\hline 0 & 1 \\
I & 36 \\
II & 17 \\
III & 25 \\
IV & 13 \\
Unknown & 14 \\
\hline Histology & \\
\hline Adenocarcinoma & 37 \\
Squamous cell & 35 \\
Other non-small cell & 25 \\
Small cell & 9 \\
\hline
\end{tabular}




\subsection{Detection of the markers}

Sixteen carbonyl formulas were also found in exhaled breath samples and their concentrations were determined. They are $\mathrm{CH}_{2} \mathrm{O}, \mathrm{C}_{2} \mathrm{H}_{4} \mathrm{O}, \mathrm{C}_{3} \mathrm{H}_{6} \mathrm{O}, \mathrm{C}_{3} \mathrm{H}_{4} \mathrm{O}, \mathrm{C}_{4} \mathrm{H}_{8} \mathrm{O}$, $\mathrm{C}_{5} \mathrm{H}_{10} \mathrm{O}, \mathrm{C}_{6} \mathrm{H}_{12} \mathrm{O}, \mathrm{C}_{7} \mathrm{H}_{14} \mathrm{O}, \mathrm{C}_{8} \mathrm{H}_{16} \mathrm{O}, \mathrm{C}_{9} \mathrm{H}_{18} \mathrm{O}, \mathrm{C}_{10} \mathrm{H}_{20} \mathrm{O}, \mathrm{C}_{2} \mathrm{H}_{4} \mathrm{O}_{2}, \mathrm{C}_{3} \mathrm{H}_{4} \mathrm{O}_{2}, \mathrm{C}_{4} \mathrm{H}_{8} \mathrm{O}_{2}$, $\mathrm{C}_{6} \mathrm{H}_{10} \mathrm{O}_{2}$ and $\mathrm{C}_{9} \mathrm{H}_{16} \mathrm{O}_{2}$. The compounds were identified using the same process applied for HC, and no unique biomarker for LC was found. However, the patterns of the FTICRMS spectra were different between LC patients and HC (Fig. 43). After analyses of exhaled breath samples from the first 12 clinically diagnosed lung cancer subjects, acetaldehyde ( $\mathrm{p}=0.002), \mathrm{C}_{4} \mathrm{H}_{8} \mathrm{O}(\mathrm{p}<0.0001), \mathrm{C}_{6} \mathrm{H}_{10} \mathrm{O}_{2}(\mathrm{p}<0.0001), \mathrm{C}_{2} \mathrm{H}_{4} \mathrm{O}_{2} \quad(\mathrm{p}<0.0001)$ and $\mathrm{C}_{4} \mathrm{H}_{8} \mathrm{O}_{2}(\mathrm{p}=0.002)$ were found to have statistical significance between the LC group and the HC group. Since acetaldehyde is affected by smoking, it is not a good marker for lung cancer. Therefore, $\mathrm{C}_{4} \mathrm{H}_{8} \mathrm{O}, \mathrm{C}_{6} \mathrm{H}_{10} \mathrm{O}_{2}, \mathrm{C}_{2} \mathrm{H}_{4} \mathrm{O}_{2}$, and $\mathrm{C}_{4} \mathrm{H}_{8} \mathrm{O}_{2}$ were chosen as the markers of lung cancer for diagnosis purpose. Table 8 shows the concentration ranges of these marker compounds in exhaled breath of never smoker controls, current smoker controls and lung cancer patients. Simple rules were made from the concentration ranges for lung cancer diagnosis: if 2 or more marker concentrations are in the lung cancer range (including the overlap area), the subject was assigned as lung cancer patient; otherwise the subject was considered as patient with benign pulmonary nodules. 106 patients clinically diagnosed as lung cancer patients while 32 patients were with benign pulmonary nodules. Table 9 shows the result of the elevated VOCs counting method. The method indicated the overall sensitivity for diagnosis of lung cancer there is $90.6 \%$ and the overall specificity for diagnosis of non-cancer is $81.3 \%$. 


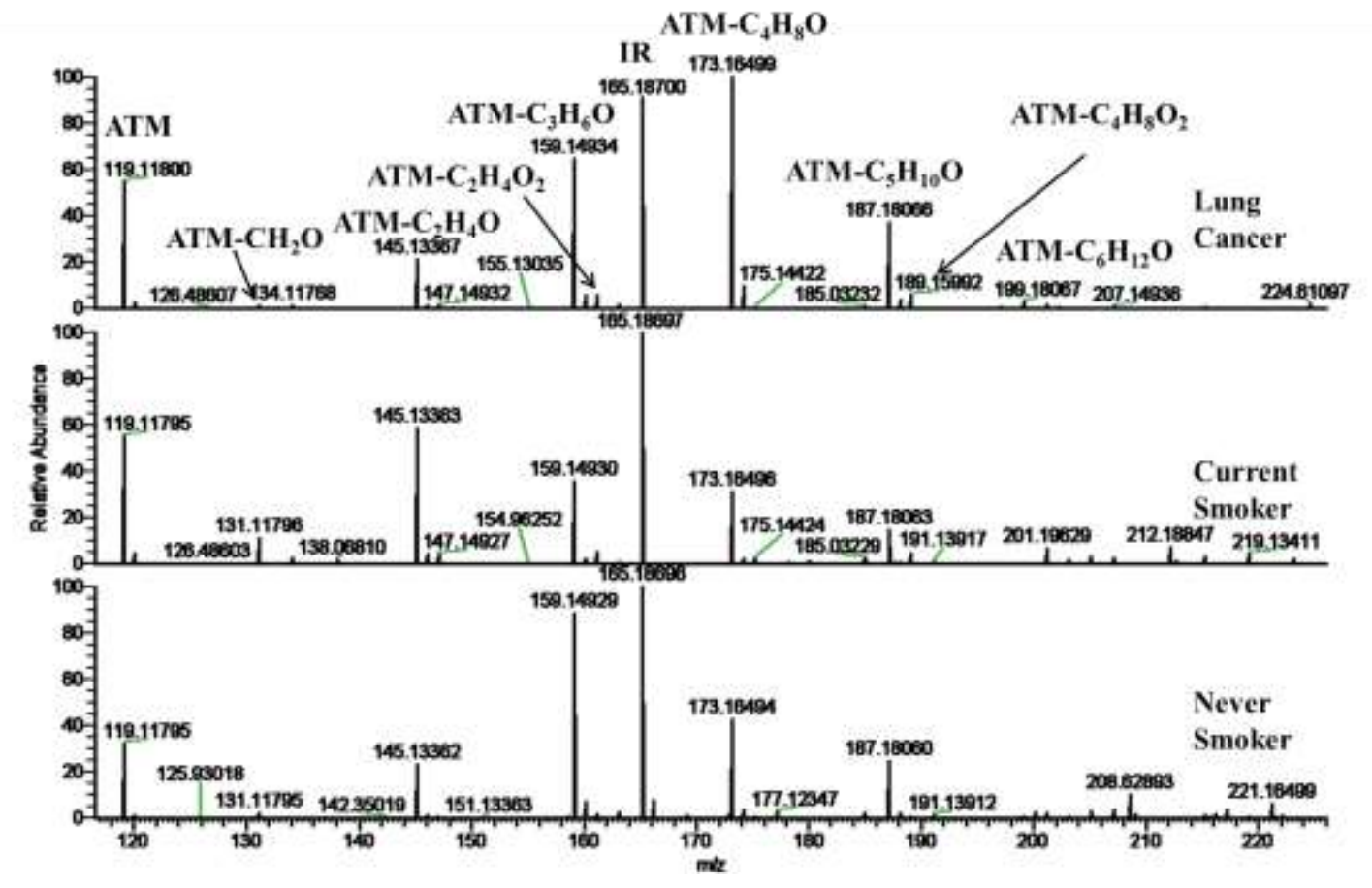

Figure 43. A comparison of the FTICR-MS spectra of exhaled breath samples from a lung cancer patient, a current smoker control and a never smoker control

\section{Table 8}

A comparison of identified lung cancer marker concentration range for three different groups of people and ambient air in clinic

\begin{tabular}{ccccc}
\hline & $\begin{array}{c}\mathbf{C}_{4} \mathbf{H}_{8} \mathbf{O} \\
(\mathbf{n m o l} / \mathbf{l})\end{array}$ & $\begin{array}{c}\mathbf{C}_{4} \mathbf{H}_{8} \mathbf{O}_{2} \\
(\mathbf{n m o l})\end{array}$ & $\begin{array}{c}\mathbf{C}_{2} \mathbf{H}_{4} \mathbf{O}_{2} \\
(\mathbf{n m o l} / \mathbf{l})\end{array}$ & $\begin{array}{c}\mathbf{C}_{6} \mathbf{H}_{10} \mathbf{O}_{2} \\
(\mathbf{n m o l} / \mathbf{l})\end{array}$ \\
\hline $\mathbf{N S}$ & $0.47-2.23$ & $0.02-0.15$ & $0.06-0.45$ & $7 \times 10^{-5}-6.5 \times 10^{-3}$ \\
$\mathbf{C S}$ & $0.45-2.34$ & $0.02-0.17$ & $0.03-0.39$ & $1.5 \times 10^{-4}-9 \times 10^{-3}$ \\
$\mathbf{L C}$ & $1.78-8.38$ & $0.13-0.77$ & $0.23-1.13$ & $5 \times 10^{-3}-0.05$ \\
$\mathbf{B N}$ & $0.79-4.25$ & $0.01-0.42$ & $0.01-0.8$ & $2.8 \times 10^{-4}-0.029$ \\
$\mathbf{A A}$ & 0.09 & 0.003 & 0.005 & 0 \\
\hline *AA $=$ ambient air. & & & &
\end{tabular}




\section{Table 9}

\section{Elevated VOCs counting}

\begin{tabular}{cccccc}
\hline $\begin{array}{c}\text { No. of elevated } \\
\text { VOCs }\end{array}$ & 4 & 3 & 2 & 1 & 0 \\
\hline LC & 31 & 46 & 19 & 8 & 2 \\
BN & 0 & 1 & 5 & 8 & 18 \\
\hline
\end{tabular}

Each of the sixteen carbonyl formula was used to discriminate the LC group, BN group and control group after collecting all the data. Two more compounds $\left(\mathrm{C}_{5} \mathrm{H}_{10} \mathrm{O}\right.$, $\mathrm{p}=0.0003$ and $\left.\mathrm{C}_{9} \mathrm{H}_{16} \mathrm{O}_{2}, \mathrm{p}=0.0005\right)$ were late found to have statistically significant higher concentrations for lung cancer patients, and thus can be used to discriminate LC patients from controls. However, there is no significant difference in concentrations of these lung cancer markers between $\mathrm{BN}$ patients and HC. Figure 44 shows boxplots of the concentrations of the six identified markers of lung cancer in exhaled breath samples from HC group, BN group and LC group. 


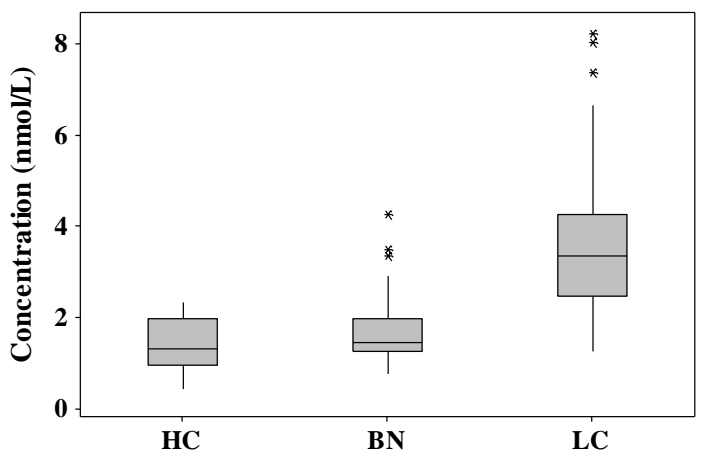

(a) $\mathrm{C}_{4} \mathrm{H}_{8} \mathrm{O}$

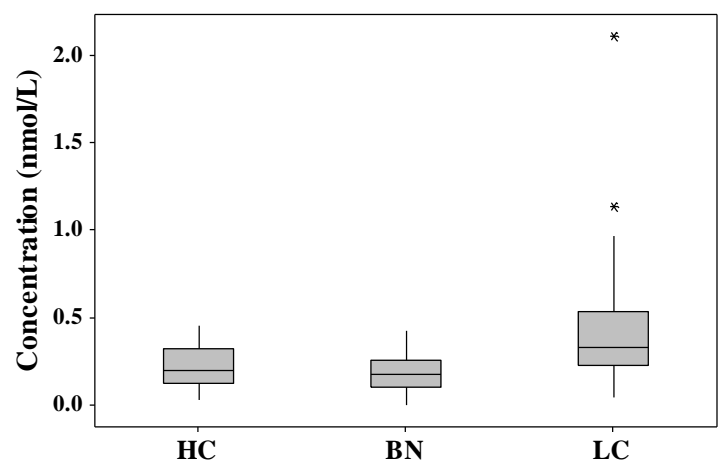

(c) $\mathrm{C}_{2} \mathrm{H}_{4} \mathrm{O}_{2}$

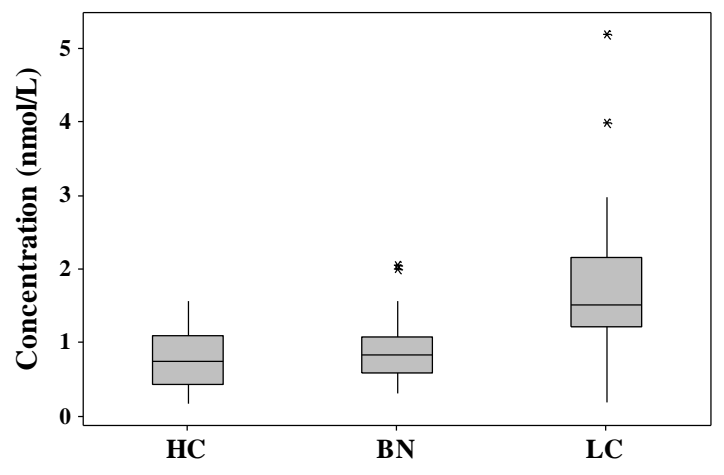

(e) $\mathrm{C}_{5} \mathrm{H}_{10} \mathrm{O}$

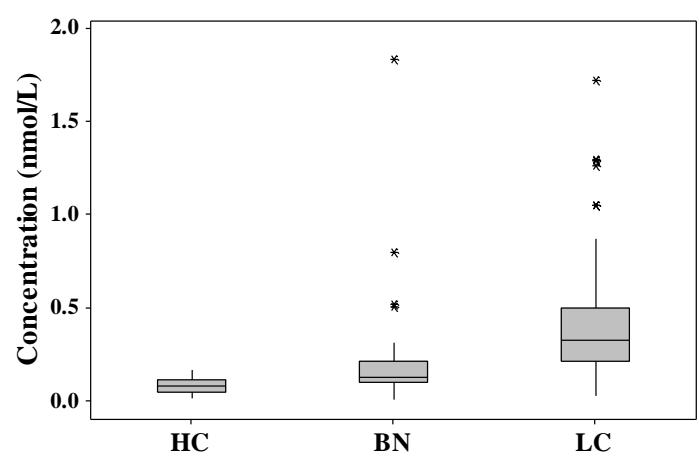

(b) $\mathrm{C}_{4} \mathrm{H}_{8} \mathrm{O}_{2}$

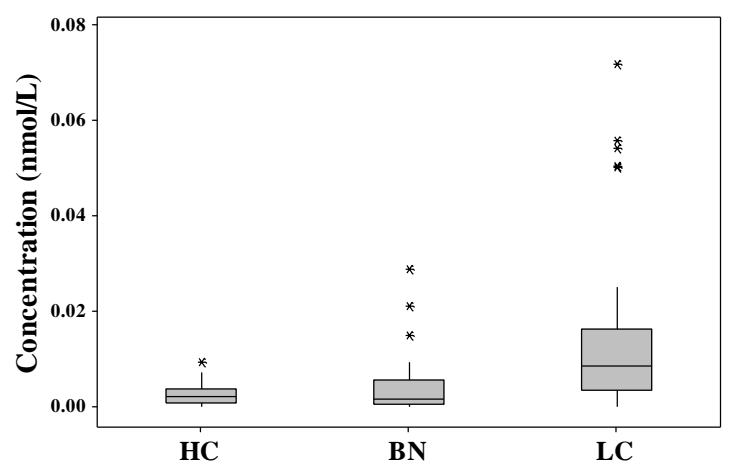

(d) $\mathrm{C}_{6} \mathrm{H}_{10} \mathrm{O}_{2}$

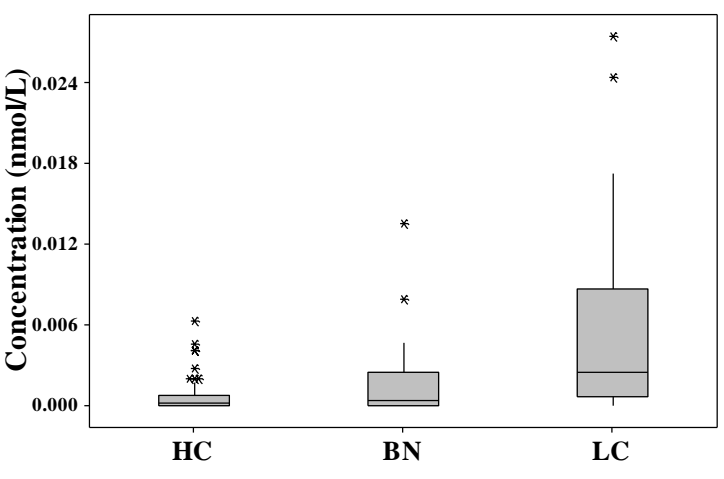

(f) $\mathrm{C}_{9} \mathrm{H}_{16} \mathrm{O}_{2}$

Figure 44. Comparisons of six markers from HC group, BN group and LC group. (a) $\mathrm{C}_{4} \mathrm{H}_{8} \mathrm{O}$, (b) $\mathrm{C}_{4} \mathrm{H}_{8} \mathrm{O}_{2}$, (c) $\mathrm{C}_{2} \mathrm{H}_{4} \mathrm{O}_{2}$, (d) $\mathrm{C}_{6} \mathrm{H}_{10} \mathrm{O}_{2}$, (e) $\mathrm{C}_{5} \mathrm{H}_{10} \mathrm{O}$, (f) $\mathrm{C}_{9} \mathrm{H}_{16} \mathrm{O}_{2}$. 


\subsection{Identification of the markers}

Hydroxy-acetaldehyde is the only possibility that can react with ATM to form ATM- $\mathrm{C}_{2} \mathrm{H}_{4} \mathrm{O}_{2}$ chemical formula. We presumed that $\mathrm{C}_{4} \mathrm{H}_{8} \mathrm{O}$ is 2-butanone, $\mathrm{C}_{5} \mathrm{H}_{10} \mathrm{O}$ is npentanal, $\mathrm{C}_{4} \mathrm{H}_{8} \mathrm{O}_{2}$ is 3-hydroxy-2-butanone, $\mathrm{C}_{6} \mathrm{H}_{10} \mathrm{O}_{2}$ is 4-hydroxyhexenal (4-HHE) and $\mathrm{C}_{9} \mathrm{H}_{16} \mathrm{O}_{2}$ is 4-hydroxynonenal (4-HNE) according to previous breath analysis studies (Preti et al., 1988; Phillips et al., 1999; Chen et al., 2007; Wehinger et al., 2007; Bajtarevic et al., 2009; Peng et al., 2009; Long and Picklo, 2010; Riahi, et al.; 2010).

FTICR-MS/MS was used for confirming all the markers. $5.56 \times 10^{-7} \mathrm{~mol}$ of 2 butanone, pentanal, 2-pentanone, 3-hydroxy-2-butanone, 4-HHE and 4-HNE reacted with ATM in $100 \mu \mathrm{L}$ methanol were made as the standard references. The TriVersa NanoMate was operated in positive ion mode by applying $2.0 \mathrm{kV}$ with no head pressure. Lowresolution ion trap MS scans were acquired for $1 \mathrm{~min}$ to ensure the stability of ionization. The 1st scan event was a broad range FT-ICR-MS scan $(50-500 \mathrm{~m} / \mathrm{z})$ with 100,000 resolution for parent ion selection followed by the other scan event with data dependent MS/MS for fragmentation of each marker reacted with ATM (2-butanone, $173.16489 \mathrm{~m} / \mathrm{z}$; pentanal and 2-pentanone, $187.18060 \mathrm{~m} / \mathrm{z} ; 3$-hydroxy-2-butanone, $189.15987 \mathrm{~m} / \mathrm{z} ; 4$ HHE, $215.17558 \mathrm{~m} / \mathrm{z} ; 4$-HNE $257.22259 \mathrm{~m} / \mathrm{z}$ ). The ion fragmentation process was conducted in the ion trap (30-50 eV CID energy) with a parent mass feature isolation width of $1 \mathrm{~m} / \mathrm{z}$. The lung cancer samples were analyzed using the same procedure, and compared with the standard references (Fig. 45). 


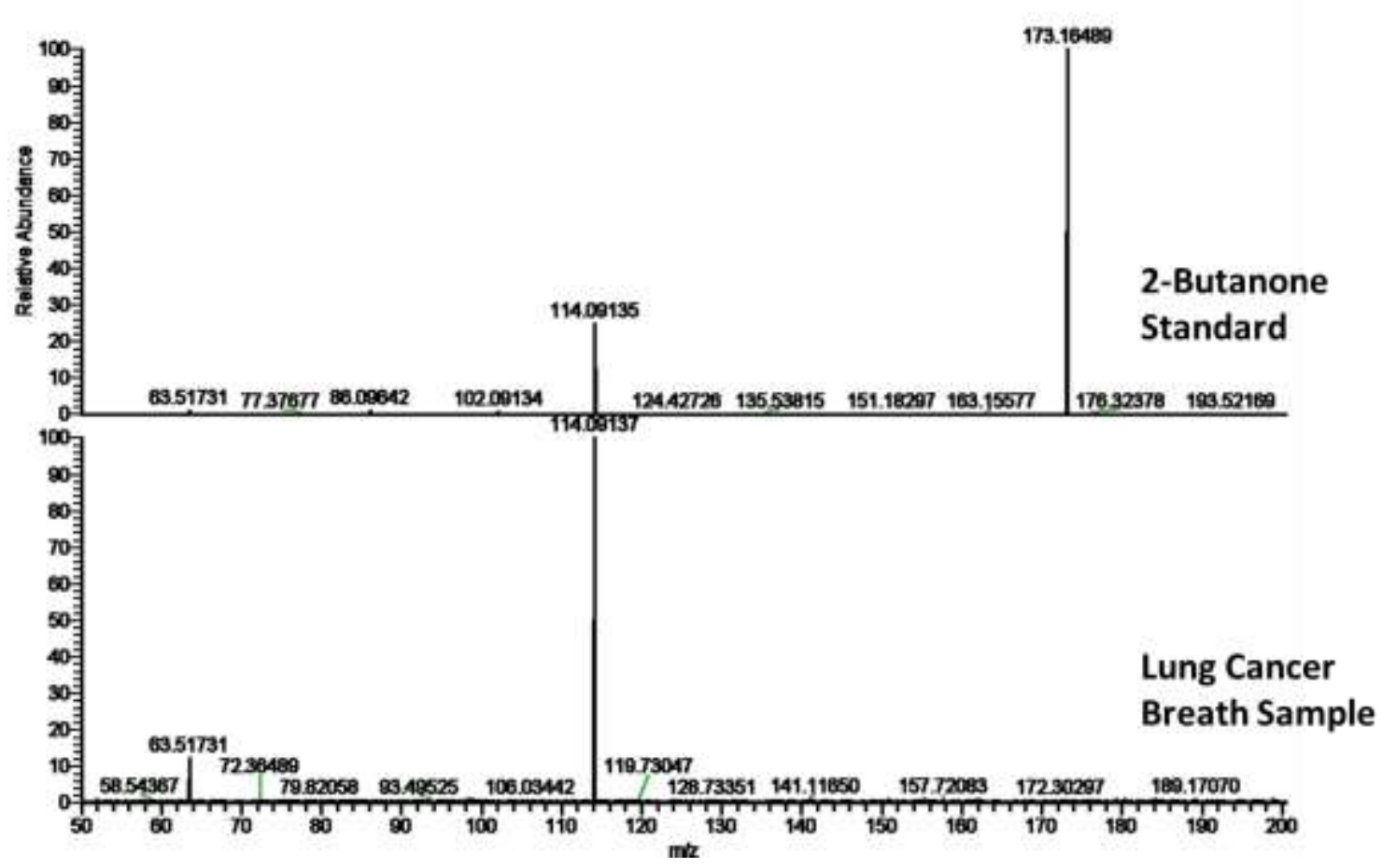

(a)

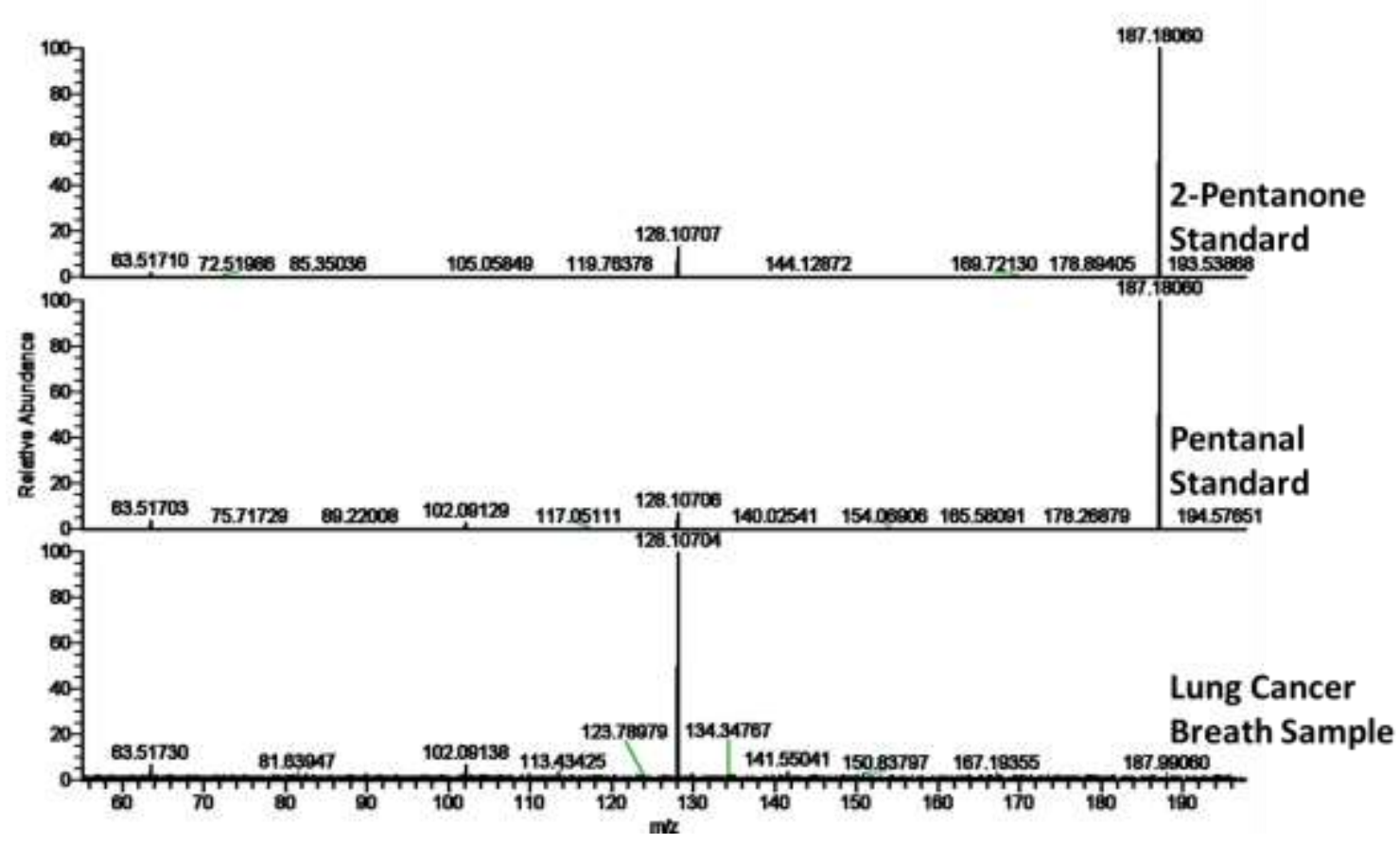

(b) 


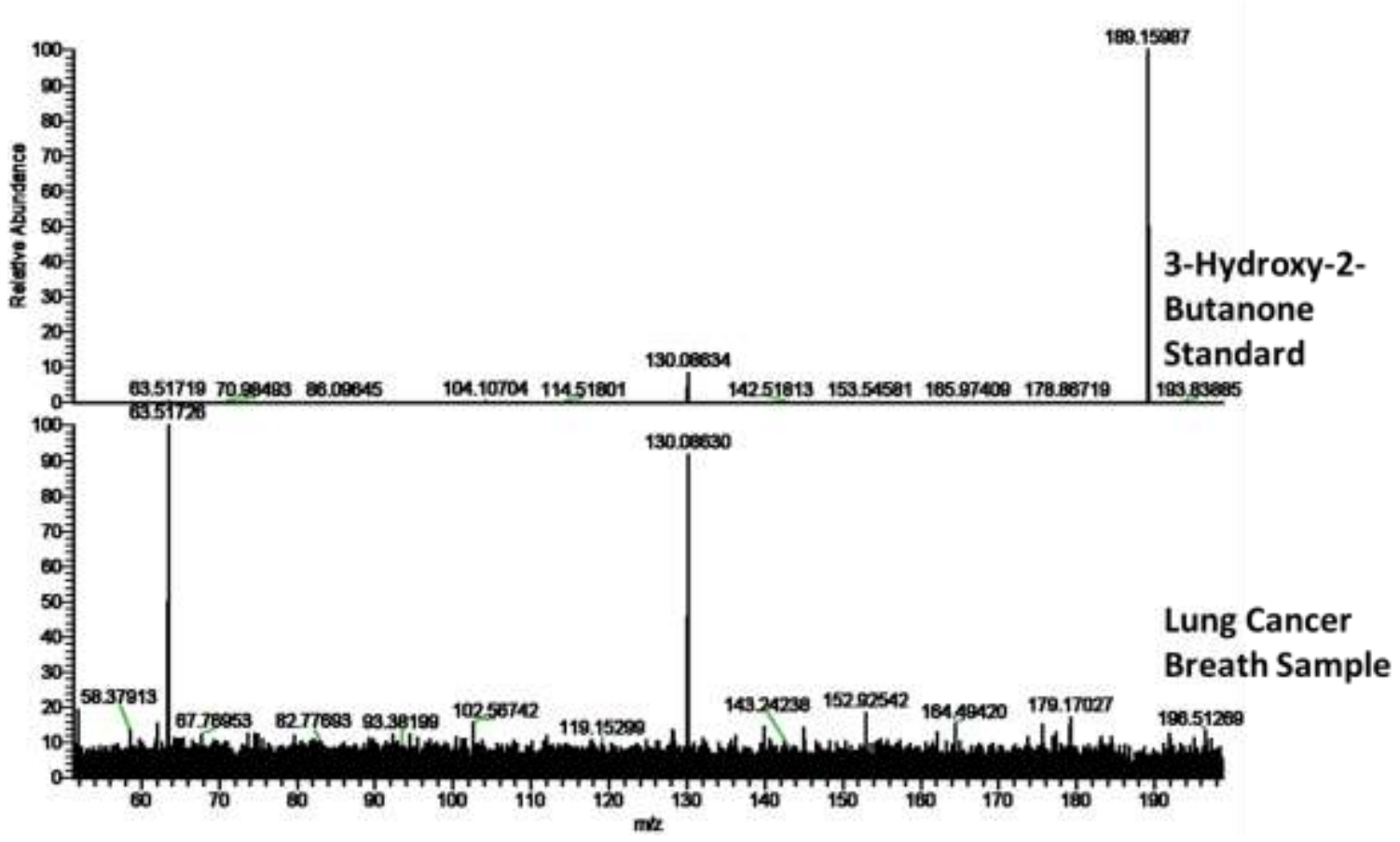

(c)

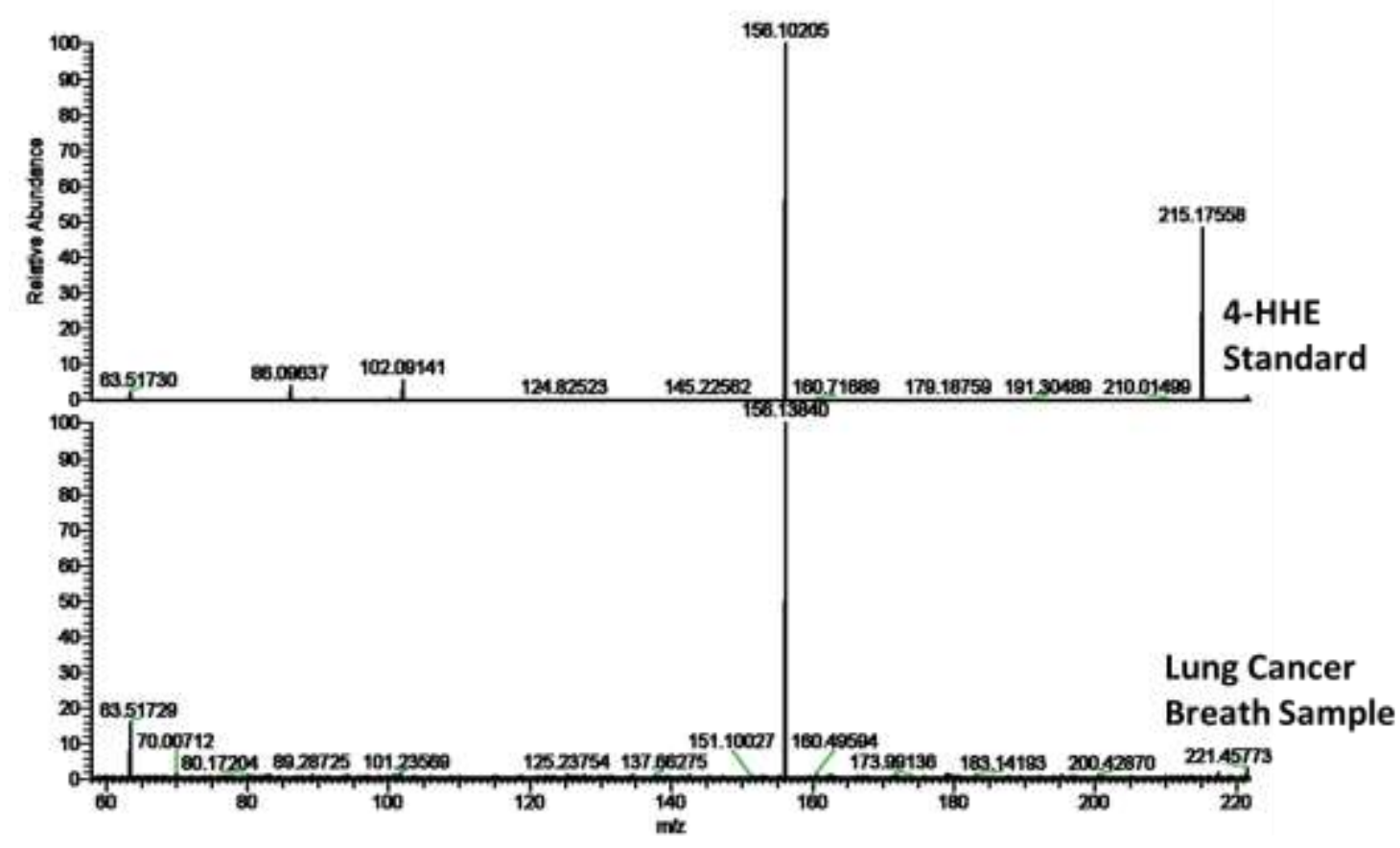

(d) 


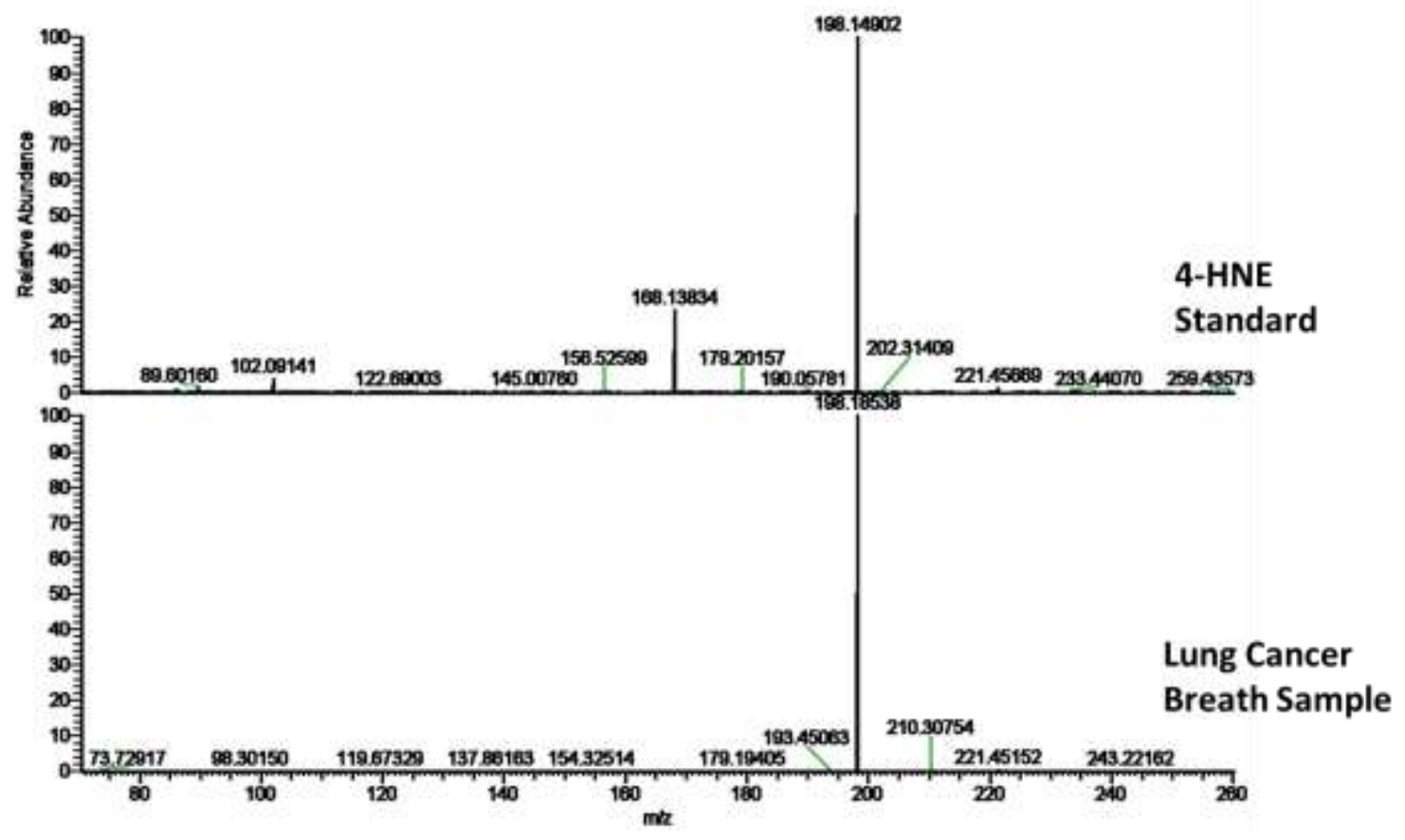

(e)

Figure 45. FTICR-MS/MS spectra for marker identification. (a) 2-Butanone, (b) $\mathrm{C}_{5} \mathrm{H}_{10} \mathrm{O}$ (pentanal and 2-pentanone), (c) 3-Hydroxy-2-butanone, (d) 4-HHE, (e) 4-HNE.

\subsection{Statistical analysis}

The receiver operating characteristic (ROC) curve of every marker VOC was used to evaluate their diagnostic capability of lung cancer according the area under curve (AUC). Figure 46 shows the ROC curve of six markers with AUC $>0.70$. 


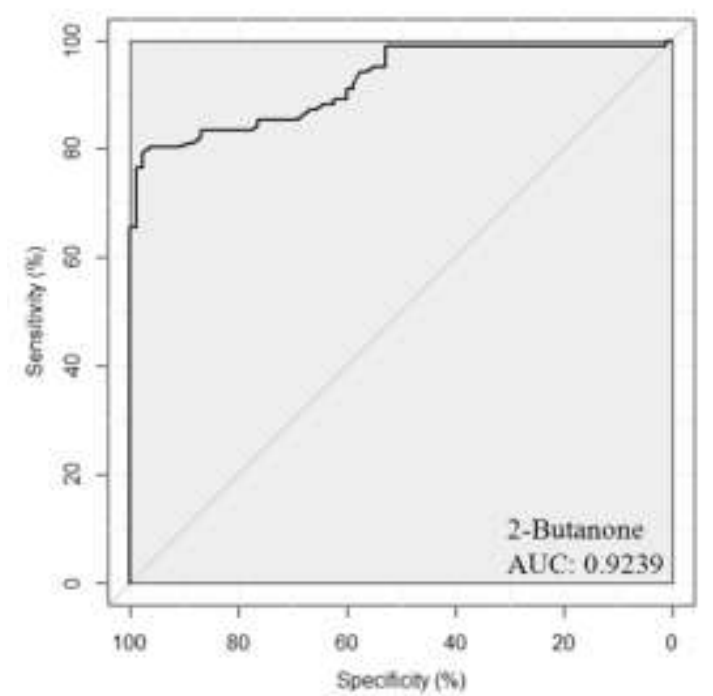

(a)

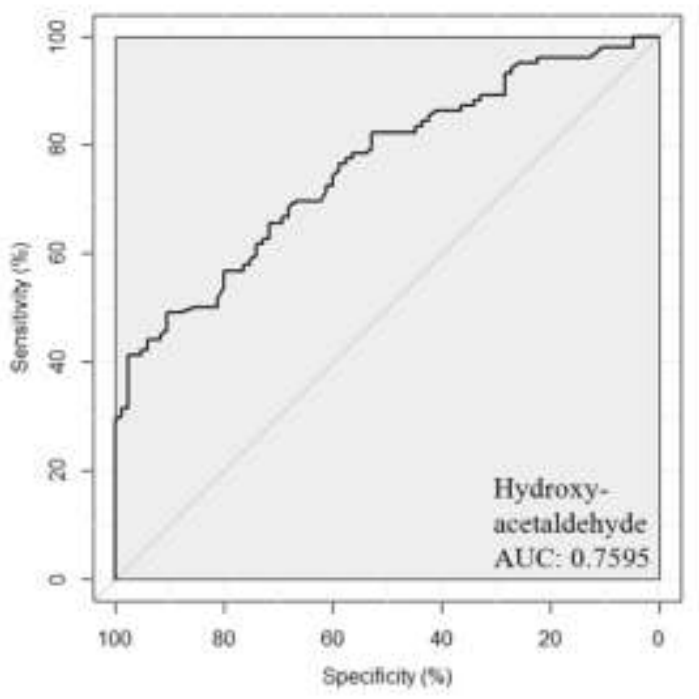

(c)

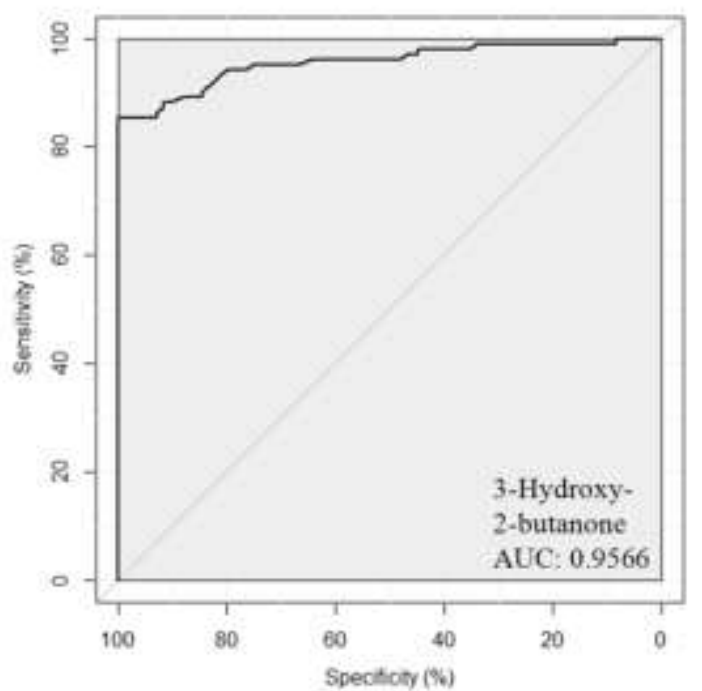

(b)

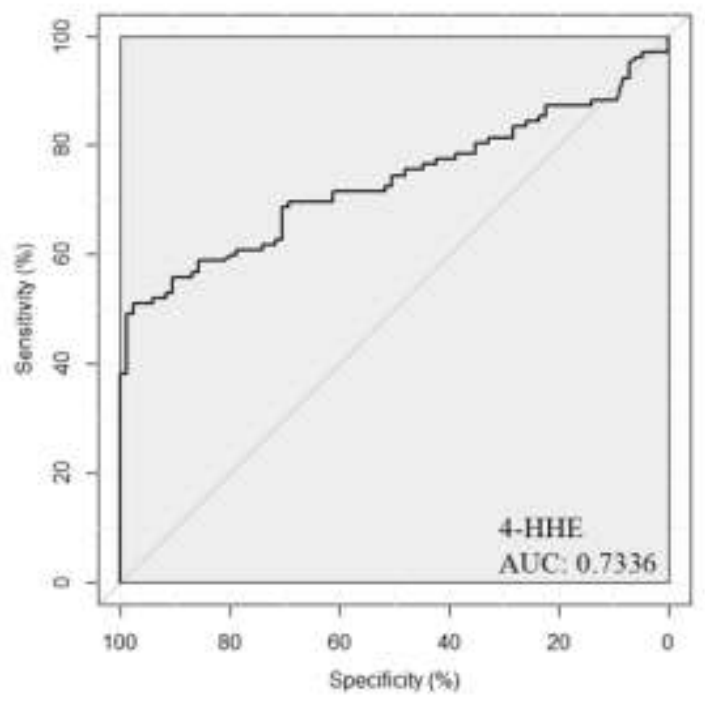

(d) 


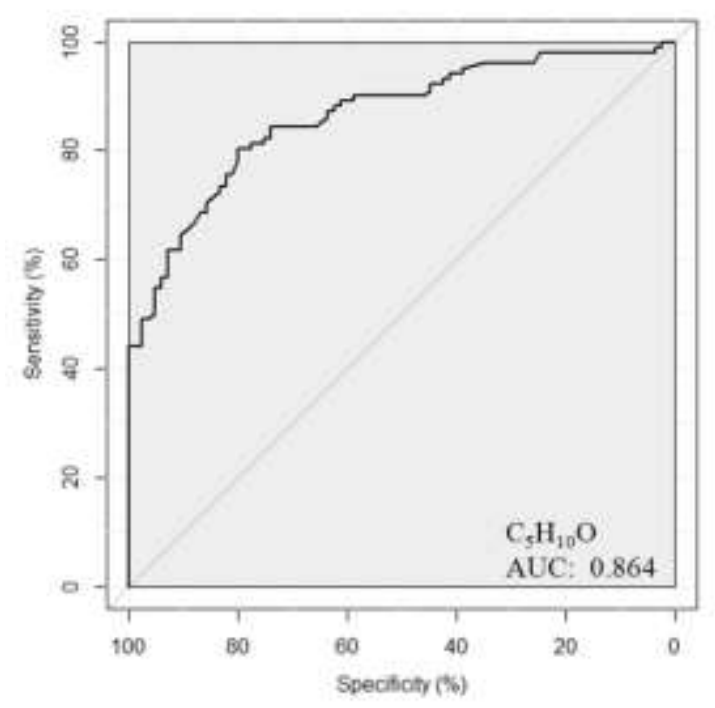

(e)

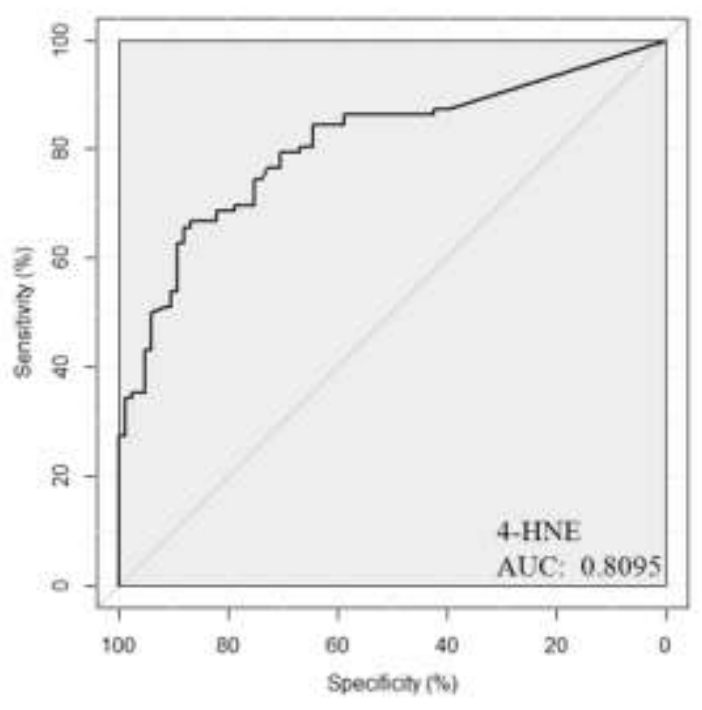

(f)

Figure 46. The ROC curve of six markers, (a) 2-Butanone, (b) 3-Hydroxy-2-butanone, (c) Hydroxy-acetaldehyde, (d) 4-HHE, (e) $\mathrm{C}_{5} \mathrm{H}_{10} \mathrm{O}$ (pentanal and 2-pentanone), (f) 4-HNE

Then Linear Discriminant Analysis (LDA) was employed to establish the lung cancer diagnosis model to discriminate the LC group, BN group and HC group. Three optimal compounds (2-butanone, 3-hydroxy-2-butanone, and $\mathrm{C}_{5} \mathrm{H}_{10} \mathrm{O}$ ) with the highest AUC value was chosen as the variances. $70 \%$ data was treated as the training set, and rest $30 \%$ was input to test the model. Two principal components, which are the linear combinations of the variances, were generated using $\mathrm{R}$ programming language in machine learning process. Figure 47 is the classification of the model. The result shows that these models can easily discriminate lung cancer patients from controls with the boundary of LD1=0 and LD2=2, but can't discriminate BN group and HC group well. 


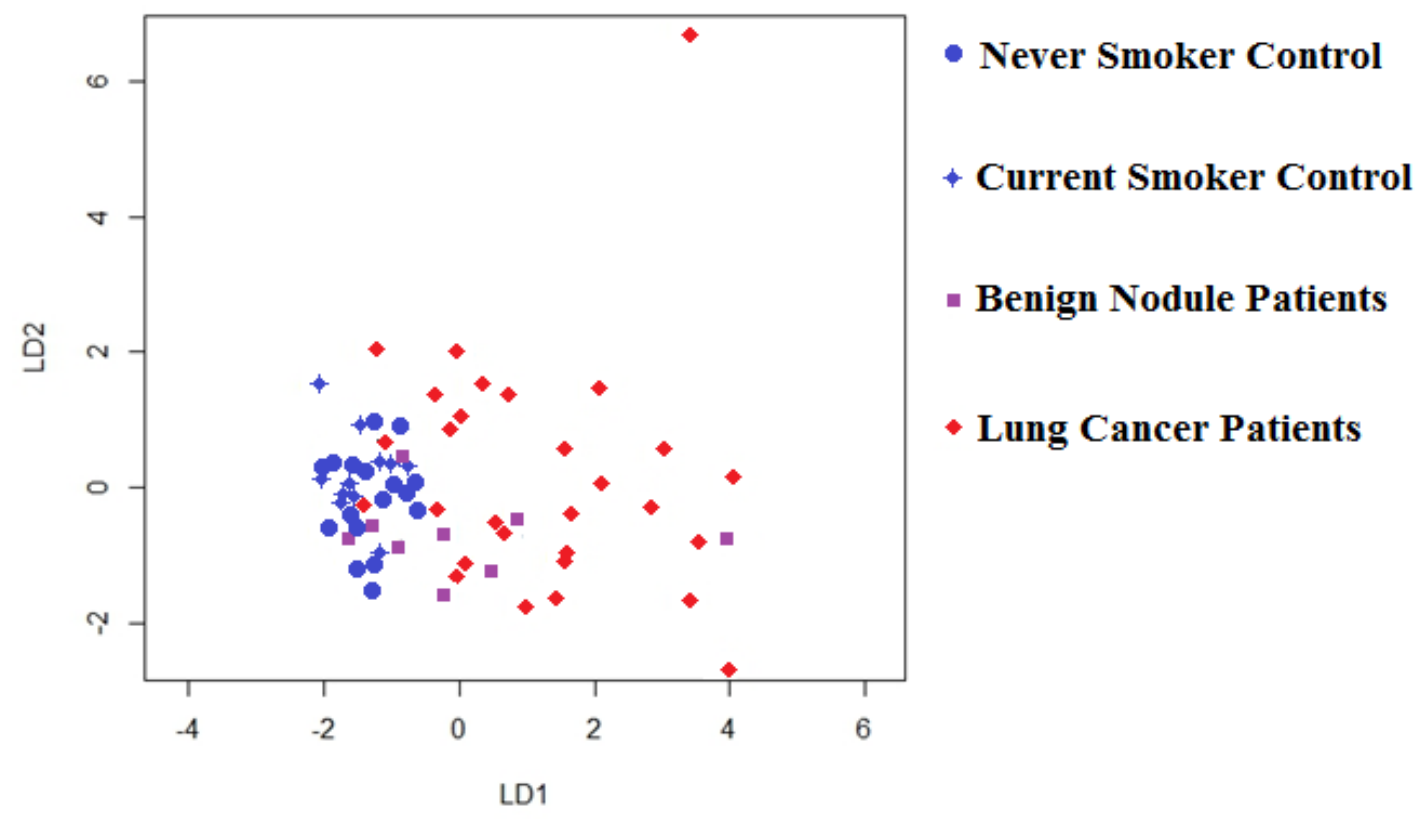

Figure 47. The classification of the LDA model.

\subsection{Stage and type analysis}

To further determine the capability of identifying and characterizing lung cancer using these identified carbonyl VOC markers, the subjects were grouped into different stages and types. The lung cancer group was first split into different stages, including Stage I, II, III and IV. 2-Butanone was found to distinguish the stages, especially early stage (including stage I and II) and advanced stage (including stag III and IV) ( $\mathrm{p}=0.0045)$. (Fig. 48) Then, the lung cancer group was divided into NSCLC and SCLC subgroups. Two compounds showed significant differences between these two groups, which are $\mathrm{C}_{5} \mathrm{H}_{10} \mathrm{O}(\mathrm{p}=0.0001)$ and 4-HNE $(\mathrm{p}<0.0001)$ (Fig. 49(a) and (b)). Within the NSCLC group, distinction could be achieved between squamous cell NSCLC and adenocarcinoma NSCLC by the concentration of 4-HHE ( $\mathrm{p}=0.0079)$ (Fig. 50). 


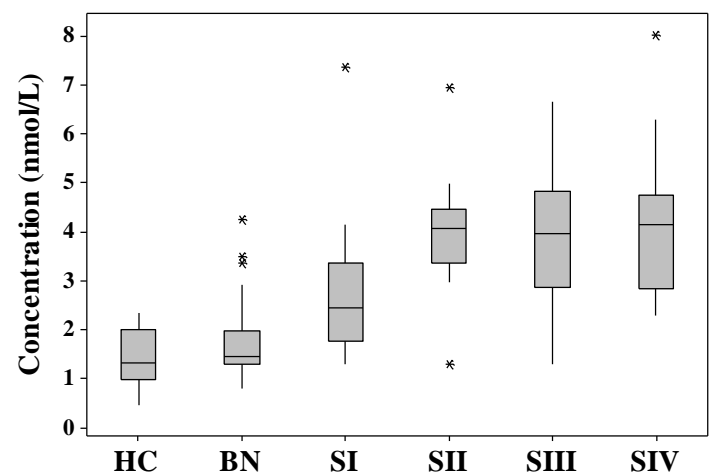

(a)

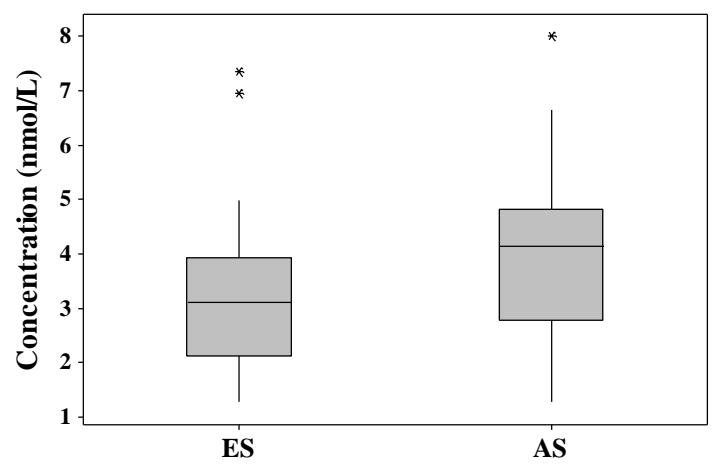

(b)

Figure 48. Comparisons of 2-butanone with different stages. (a) Different stages, (b) Early stages versus advanced stages.

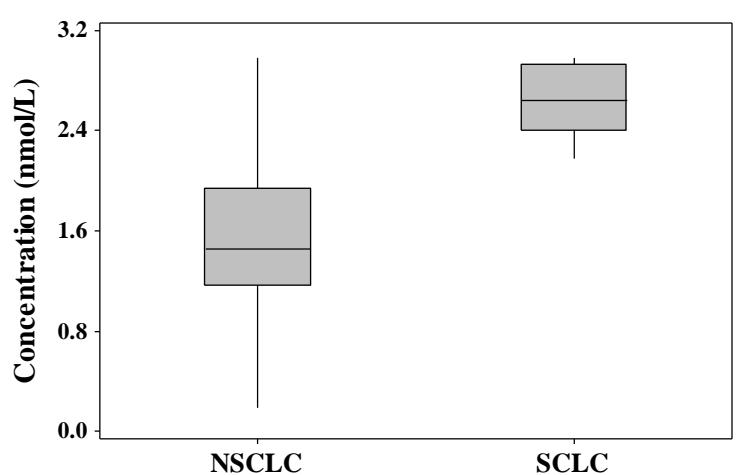

(a)

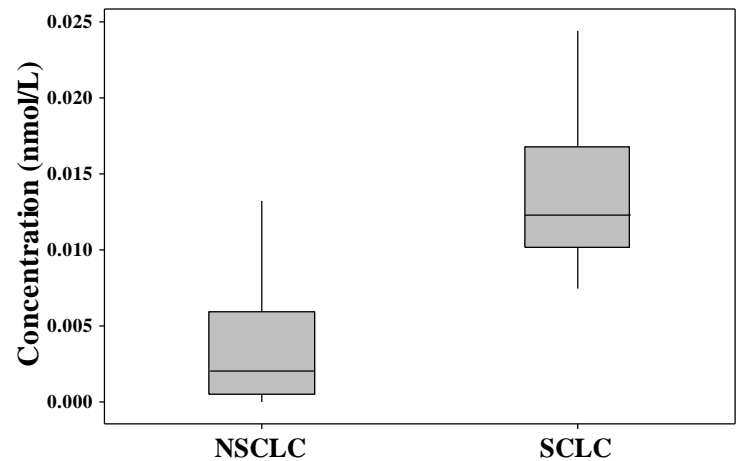

(b)

Figure 49. Comparisons of markers with NSCLC and SCLC. (a) $\mathrm{C}_{5} \mathrm{H}_{10} \mathrm{O}$ (n-pentanal and 2-pentanone mixture), (b) 4-HNE 


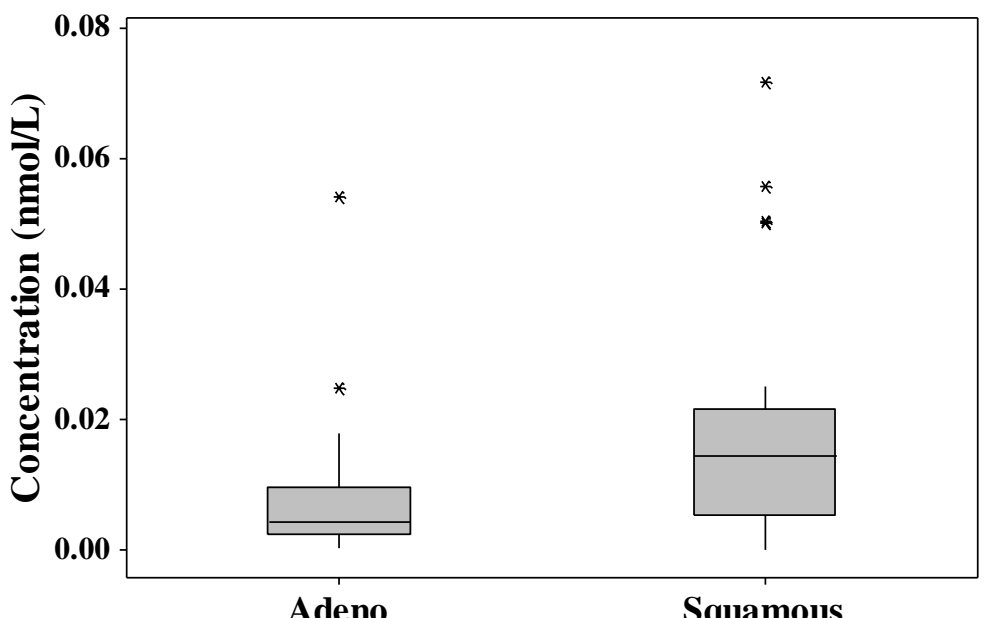

Figure 50. Comparisons of 4-HHE with adenocarcinoma NSCLC and squamous cell NSCLC.

\section{Post Resection Follow-up}

The management of LC depends critically on the ability to follow up the development of the disease during the course of the treatment. To test the feasibility for short-term follow-up after LC-resection, the exhaled breath samples of 20 patients, aged 50-80 years before and after resection for 1-6 months of lung cancer resection, were collected and analyzed again after surgery for 1-6 months. The collection and analysis processes of breath samples after cancer resection are the same as before resection. The FTICR-MS spectra of pre-surgery and post-surgery breath samples of same patient were compared, and the six identified markers of lung cancer found were tracked. The concentrations of four VOCs (2-butanone, hydroxy-acetaldehyde, 4-HHE and $\mathrm{C}_{5} \mathrm{H}_{10} \mathrm{O}$ (2pentanone and n-pentanal mixture)) that were on average significantly reduced after surgery, using Wilcoxon test with a cutoff value of $p=0.05$ (2-butanone, $p<0.0001$; 3- 
hydroxy-2-butanone, $\mathrm{p}=0.164$; hydroxy-acetaldehyde, $\mathrm{p}=0.0004$; 4-HHE, $\mathrm{p}=0.0005$; $\mathrm{C}_{5} \mathrm{H}_{10} \mathrm{O}$ (2-pentanone and n-pentanal mixture), $\mathrm{p}=0.0003$; 4-HNE, $\mathrm{p}=0.256$ ). Figure 50 shows boxplots of the concentrations of the six identified markers of lung cancer in exhaled breath samples before and after surgery.

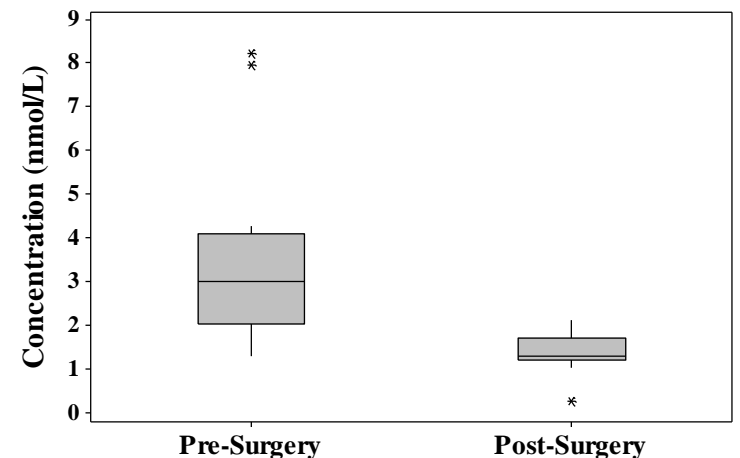

(a)

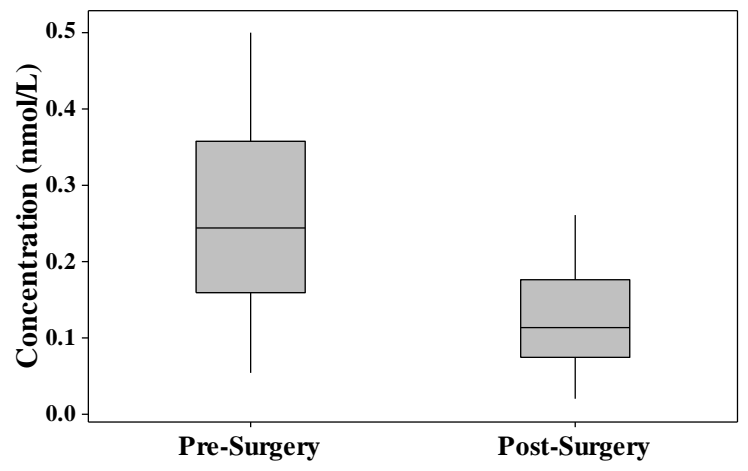

(c)

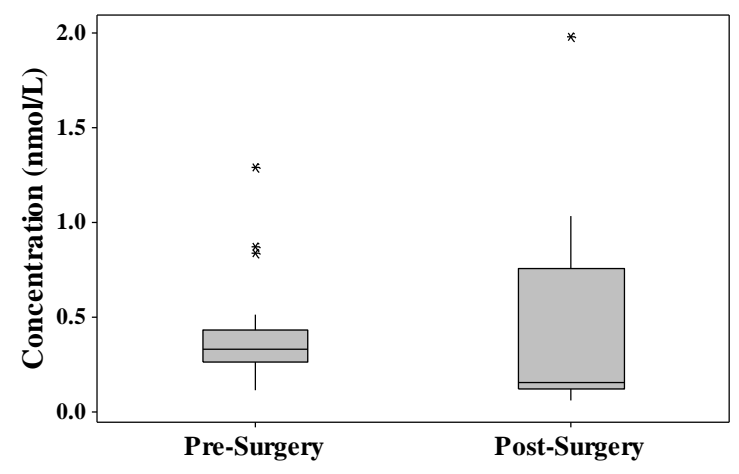

(b)

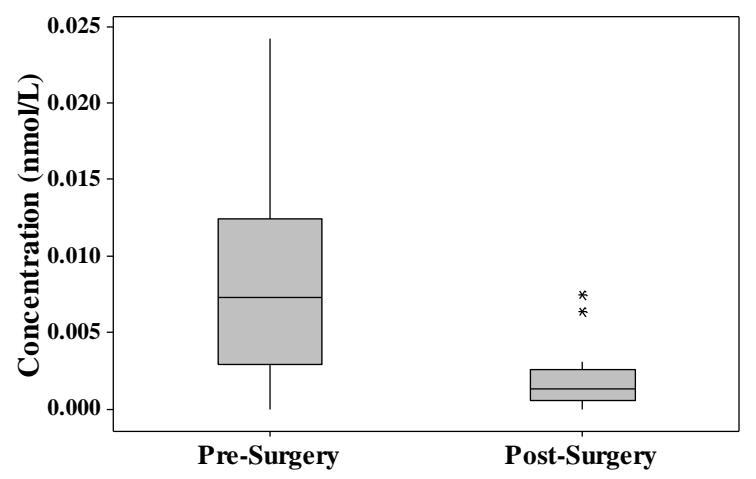

(d) 


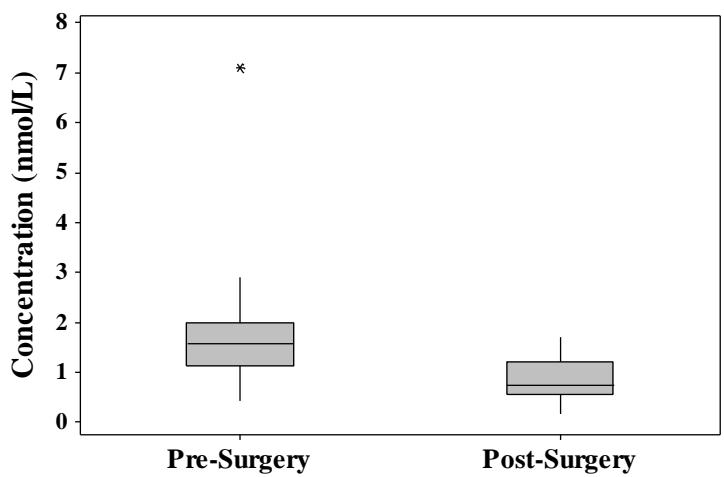

(e)

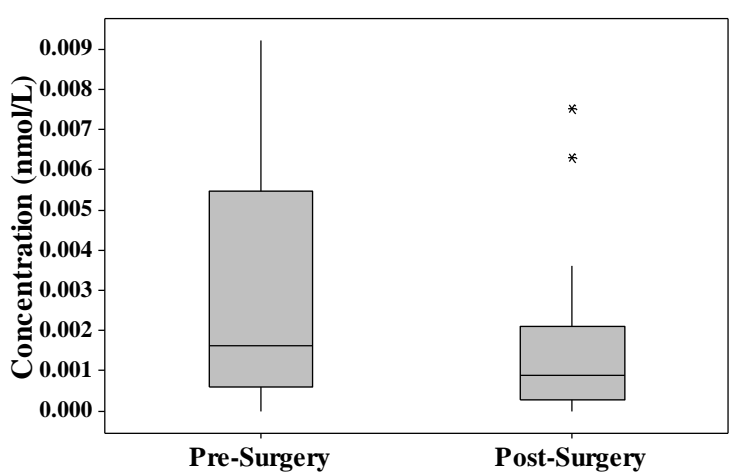

(f)

Figure 51. Comparisons of six markers before and after surgery. (a) 2-butanone, (b) 3hydroxy-2-butanone, (c) hydroxy-acetaldehyde, (d) 4-HHE, (e) 2-pentanone and npentanal mixture, (f) 4-HNE

The VOCs from exhaled breath could either be exhaled directly from the affected area of the lung or be of systemic origin. Compounds that stem directly from the lung could include: (i) metabolic products from a tumor at the alveolar membrane, which marks the gas-exchange surface that is in direct contact with the respiratory air; (ii) metabolic products from a deeper lying lung tumor that reach the alveoli via the pulmonary or bronchial circulation; (iii) environmental toxins or smoking related compounds that were accumulated in locally confined regions of the lung (and could eventually cause tumor genesis); (iv) products of bacteria or necrotic reactions due to local inflammation and/or necrosis around the tumor (Darwiche et al., 2011). The four markers (2-butanone, hydroxy-acetaldehyde, 4-HHE and $\mathrm{C}_{5} \mathrm{H}_{10} \mathrm{O}$ (2-pentanone and npentanal mixture) $)$ that were significantly reduced $(\mathrm{p}<=0.005)$ in the breath of the postsurgery, could stem directly from the affected lung area that was resected. However, their connection to tumor activity is not yet clear. The other two markers (3-hydroxy-2- 
butanone and 4-HNE) that were not significantly different between pre- and post-surgery could proceed from the change of immune system that cannot be back to normal in several months.

Although the low number of patients does not yet allow drawing solid conclusions, the encouraging preliminary results can be used to design a larger post-surgery follow-up study.

\section{Discussion}

This study demonstrates the potential of MEMS based microreactors combined with FTICR-MS system to identify lung cancer breath markers for the distinction of subjects with lung cancer from subjects with benign pulmonary nodules and healthy controls. The results also indicate that breath markers can discriminate between lung cancers of different histology. The significant differences in concentrations of these identified markers in exhaled breath are related to metabolic differences of different types of lung cancers. The characteristics of lung cancer, including histology and stages, can be diagnosed by breath analysis, since rapid growth and spread of cancer cells is likely to induce magnified metabolic alterations. The analysis in this study did not require complicated biostatistics models. The simple elevated VOC concentration and diagnosis method can achieve high sensitivity and specificity. This would imply that breath test may be capable of screening and detection of lung cancer for the high risk subjects of lung cancer, such as heavy smokers and post resection of lung cancer patients

This study has several significant advantages related to its design and other advantages based on the nature of FTICR-MS. First of all, the microrectors are designed to have high capture efficiencies of all carbonyl compounds. Second, chemosective 
capture of carbonyl compounds through aminooxy reactions enable to analyze carbonyl compounds relevant to biochemical metabolites. This method eliminates interference of other VOCs. The ultra-high resolution FTICR-MS provides unambiguous identification of carbonyl formula. Diet and smoking are known to influence the relative composition of breath (Miekisch et al., 2008; Cope et al., 2004). Although no diet (Pauling et al., 1971) control measures were used in the study, the results of analysis of carbonyl compounds identified the six carbonyl compounds related to lung cancers. The breath samples contained both dead space breath and alveolar breath. However, we studied both never smoker and current smoker controls. Three compounds presented significant difference, and were excluded as markers to identify lung cancer subjects. Ambient air also contains many volatiles that are present in the breath (Dragonieri et al., 2007). We also collected and analyzed ambient air from the location of breath sampling. The concentrations of carbonyls in ambient air are much lower than exhaled breath and do not affect the diagnosis results.

One limitation of using FTICR-MS is that it is not able to identify the components of a breath mixture, although it provides accurate chemical formula. The breath analysis method using microreactors is inexpensive and noninvasive, can be used for regular monitoring, and will not require advanced training for their use and analysis. The microreactors system is also adaptable, and can be loaded with other chemical or physical adsorbent to capture other VOCs in breath. The eluted analytes can be analyzed by gas chromatography-mass spectrometry or proton transfer reaction mass spectrometry to satisfy the need to explain the metabolism mechanism of VOCs in breath. 


\section{Conclusion}

We have used a novel silicon microreactor chip for preconcentration and analysis of carbonyls compounds in exhaled breath. We have found six VOCs (2-butanone, 3hydroxy-2-butanone, hydroxy-acetaldehyde, 4-HHE, $\mathrm{C}_{5} \mathrm{H}_{10} \mathrm{O}$ (pentanal and 2-pentanone), 4-HNE) to distinguish LC from patients with benign pulmonary nodules and healthy controls, two VOCs $\left(\mathrm{C}_{5} \mathrm{H}_{10} \mathrm{O}\right.$ and 4-HNE) to distinguish NSCLC from SCLC, and one VOC (4-HHE) distinguish squamous cell carcinoma from adenocarcinoma LC. In the double-blind study, we have identified LC patient with $90.6 \%$ sensitivity and $81.3 \%$ specificity using uncomplicated statistics model. This approach can also be used for short-term follow-up after LC-resection. Furthermore, we have found that four VOCs significantly decrease after resection of lung cancer. 


\section{CHAPTER VI}

\section{SUMMARY AND FUTURE WORK}

This dissertation has presented MEMS based microreactors combined with FTICR-MS for chemoselective capture and analysis of trace level carbonyl compounds in ambient air and human exhaled breath.

\section{Summary}

A novel MEMS based microreactor with inlet, outlet and thousands of cylindrical micropillars was designed using CFD software, and fabricated using MEMS microfabrication techniques.

The results show that the silicon-based microreactor can capture trace acetone with an efficiency of $99 \%$ or higher. The unique microstructure provides uniform gas flow and high probability of oximation reaction between ATM on the surfaces of micropillars and gaseous carbonyl compounds. The oximation reaction between the functional cationic aminooxy compounds coated on the surfaces of micropillars and gaseous carbonyl species is the key for chemoselective capture of ketones and aldehydes. 
The unique combination of aminooxy and quaternary ammonium groups also enables direct positive mode analysis by mass spectrometry, as demonstrated here using FTICR-MS. Furthermore, simple elution of the entire microreactor coating including all captured analytes eliminates sample transfer problems that have plagued previous preconcentration approaches. The preconcentration efficiency is improved by avoiding the current practices of physical adsorption and thermal desorption for analyte detection. The use of solvent elution is effective for recovery of more than $98 \%$ of the oxime ether adducts.

This method can be applied for environment monitoring of VOCs. The concentration of carbonyl VOCs in ambient air at ppb level can be measured periodically. The imperceptible change of carbonyl VOCs was observed in one day.

This method also identified lung cancer markers in breath for the distinction of subjects with lung cancer from subjects with benign pulmonary nodules and healthy controls. The results indicate that breath markers can discriminate between lung cancers of different histology. The significant differences in concentrations of these identified markers in exhaled breath are related to metabolic differences of different types of lung cancers. The characteristics of lung cancer, including histology and stages, can be diagnosed by breath analysis, since rapid growth and spread of cancer cells is likely to induce magnified metabolic alterations. The analysis in this study did not require complicated biostatistics models. The simple elevated VOC concentration and diagnosis method can achieve high sensitivity and specificity.

We have used a novel silicon microreactor chip for preconcentration and analysis of carbonyls compounds in exhaled breath. We have found six VOCs (2-butanone, 
$\mathrm{C}_{5} \mathrm{H}_{10} \mathrm{O}$ (n-pentanal and 2-pentanone mixture), hydroxy-acetaldehyde, 3-hydroxy-2butanone, 4-HHE and 4-HNE) to distinguish LC from patients with benign pulmonary nodules and healthy controls, two VOCs $\left(\mathrm{C}_{5} \mathrm{H}_{10} \mathrm{O}\right.$ (n-pentanal and 2-pentanone mixture) and 4-HNE) to distinguish NSCLC from SCLC, and one VOC (4-HHE) to distinguish squamous cell carcinoma from adenocarcinoma LC. In the double-blind study, we have identified LC patient with $90.6 \%$ sensitivity and $81.3 \%$ specificity using uncomplicated statistics model. This approach can also be used for short-term follow-up after LCresection. Also, we have found that four VOCs significantly decrease after surgery.

A study with a larger study population is necessary to verify the method. This method has great potential to be developed into an inexpensive, portable, and reliable tool for screening and diagnosis of lung cancer. Furthermore, this method holds potential as

regularly monitoring test for subjects at risk of developing LC, and as follow-up diagnostic test for LC patient post cancer resection or with radiation or chemotherapy treatments. This approach could have a significant impact on LC screening and diagnosis in the future.

\section{Future Directions}

There are several areas or directions in the near future, which we could further enhance the work presented in this dissertation.

1. More microreactor structures can be designed and simulated to pursue more optimized fluid flow in the microreactor. The shape of the micropillars can be changed to crisscross, diamond, or triangle; the angle of inlet and outlet can also be adjusted. 
2. Many VOCs were found as the biomarkers of lung cancer or other lung diseases, such as thiols, aromatic and aliphatic hydrocarbons (Phillips et al., 1999; Chen et al., 2007; Wehinger et al., 2007; Bajtarevic et al., 2009; Peng et al., 2009). In this study, only aminooxy salt was used as the coating materials in microreactors to capture specific carbonyl VOCs. However, the microreactors system is adaptable, and can be loaded with other chemical or physical adsorbent to capture other VOCs in breath.

3. One limitation of study is that it is not able to identify all the components of a breath mixture, although it provides accurate chemical formula. The eluted analyte can be analyzed by FTICR-MS-MS, or proton transfer reaction mass spectrometry to unambiguously identify all compounds in breath.

4. The metabolism mechanism of VOCs in lung cancer patients' breath is still not known in this study. A direct way to find the mechanism of generation of lung cancer related VOCs in breath is to analyze the VOCs released by lung cancer cells which are cultured in vitro. If we can find the uniform or similar VOCs in exhaled breath, headspace air in lung cancer cell lines or tissues culture, it can be proved that these VOCs in lung cancer patients' breath may be released by lung cancer cells or tissues. It is another significant evidence for these VOCs to be lung cancer VOCs biomarkers. After confirming the source of these VOCs, the research on the generation mechanism of these VOCs can be implemented on cells and tissues cultured in vitro.

5. Many biomarkers were found in exhaled breath of other lung diseases, such as asthma and chronic obstructive pulmonary disease (COPD) (Snell and Newbold, 
2008), tuberculosis (TB) (Phillips et al., 2007), and cystic fibrosis (CF) (Savelev et al., 2011). The microreactor chip approach can be applied for detection of these diseases.

6. The encouraging solid results can be used to extend a larger study of post-surgery follow-up and daily screening of the lung cancer patient with chemotherapy or radiation treatment.

In the next ten years, I believe we will learn the mechanism of the unique VOC profiles in exhaled breath, learn how to obtain these profiles, learn how breath analysis can influence screening and diagnosis and develop breath analysis as a diagnostic tool to guide treatment and prognosis. 


\section{REFERENCES}

Agah M, Lambertus GR, Sacks R, Wise KD (2006) High-performance temperatureprogrammed microfabricated gas chromatography columns. J Microelectromech $S$, 15: $1371-1378$.

Agah M, Potkay JA, Lambertus GR, Sacks R, Wise K (2006) High-speed MEMS-based gas chromatography. J Microelectromech S, 4: 1039 - 1050.

Alberg AJ, Ford JG, Samet JM; American College of Chest Physicians (2007) Epidemiology of lung cancer: ACCP evidence-based clinical practice guidelines (2nd edition). Chest, 132: 29S - 55S.

Alfeeli B and Agah M (2008) Micro preconcentrator with embedded 3D pillars for breath analysis applications. IEEE SENSORS 2008 Conference, 736 - 739.

Alfeeli B and Agah M (2009) MEMS-based selective preconcentration of trace level breath analytes. IEEE Sens J, 9: 1068 - 1075.

Alfeeli B, Cho D, Ashraf-Khorassani M, Taylor LT, Agah M (2008) MEMS-based multiinlet/outlet preconcentrator coated by inkjet printing of polymer adsorbents. Sensors and Actuators B, 133: $24-32$.

Antus B, Barta I, Horvath I, Csiszer E (2010) Relationship between exhaled nitric oxide and treatment response in COPD patients with exacerbations. Respirology, 15: $472-477$.

Apel EC, Emmons LK, Karl T, Flocke F, Hills AJ, Madronich S (2010) Chemical evolution of volatile organic compounds in the outflow of the Mexico City Metropolitan area. Atmos Chem Phys, 10: 2353 - 2376.

Apel EC, Hills AJ, Lueb R, Zindel S, Eisele S, Riemer DD (2003) A fast-GC/MS system to measure C-2 to C-4 carbonyls and methanol aboard aircraft. J. Geophys Res, 108: 8794

Baez AP, Padilla H, Cervantes J, Pereyra D, Torres MC, Garcia R, Belmont R (2000) Preliminary study of the determination of ambient carbonyls in Xalapa City, Veracruz, Mexico. Atmos Environ, 35: 1813 - 1819. 
Bajtarevic A, Ager C, Pienz M, Klieber M, Schwarz K, Ligor M, Ligor T, Filipiak W, Denz H, Fiegl M, Hilbe W, Weiss W, Lukas P, Jamnig H, Hackl M, Haidenberger A, Buszewski B, Miekisch W, Schubert J, Amann A (2009) Noninvasive detection of lung cancer by analysis of exhaled breath. BMC Cancer, 9: $348-363$.

Biswas S, Huang X, Badger WR, Nantz MH, (2010) Nucleophilic cationization reagents. Tetrahedron Lett, 51: 1727 - 1729.

Casalnuovo SA, Frye-Mason GC, Kottenstette RJ, Heller EJ, Matzke CM, Lewis PR, Manginell PR, Baca AG, Hietala VM, Wendt JR (1999) Gas phase chemical detection with an integrated chemical analysis system. Eur Frequency Time Forum, 1999, IEEE Int Frequency Control Symp, Proc 1999 Joint Meeting, Besançon, France, 991 - 996.

Chan HP, Tran V, Lewis C, Thomas P (2008) Markers of oxidative stress in exhaled breath of subjects with lung cancer. Respirology, 13: A58.

Chapman EA, Thomas PS, Stone E, Lewis C, Yates DH (2012) A breath test for malignant mesothelioma using an electronic nose. Eur Resp J, 40: 448 - 454.

Chen X, Xu F, Wang Y, Pan Y, Lu D, Wang P, Ying K, Chen E, Zhang W (2007) A study of the volatile organic compounds exhaled by lung cancer cells In vitro for breath diagnosis. Cancer, 110: 835 - 844.

Cheng H, Guo H, Wang X, Saunders SM, Lam SHM, Jiang F, Wang T, Ding A, Lee S, Ho KF (2010) On the relationship between ozone and its precursors in the Pearl River Delta: application of an observation-based model (OBM). Environ Sci Pollut Res, 17: 547 - 560.

Conrad DH, Goyette J, Thomas PS (2007) Proteomics as a Method for Early Detection of Cancer: A Review of Proteomics, Exhaled Breath Condensate, and Lung Cancer Screening. J Gen Intern Med, 23: 78 - 84.

Cope KA, Watson MT, Foster WM, Sehnert SS, Risby TH (2004) Effects of ventilation on the collection of exhaled breath in humans. J Appl Physiol, 97:1371 - 1379.

Corradi M, Rubinstein I, Andreoli R, Manini P, Caglieri A, Poli D, Alinovi R, Mutti A (2003) Aldehydes in Exhaled Breath Condensate of Patients with Chronic Obstructive Pulmonary Disease. Am J Respir Crit Care Med, 167: 1380 - 1386.

Cristofanilli M, Budd GT, Ellis MJ, Stopeck A, Matera J, Miller MC, Reuben JM, Doyle GV, Allard WJ, Terstappen LWMM, Hayes DF (2004) Circulating tumor cells, disease progression, and survival in metastatic breast cancer. $N$ Engl $J$ Med, 351: $781-791$.

Czebe K, Barta I, Antus B, Horvath I, Kullmann T (2008) Influence of condensing equipment and temperature on exhaled breath condensate $\mathrm{pH}$, total protein and leukotriene concentrations. Resp Med, 102: 720 - 725. 
Darwiche K, Baumbach JI, Sommerwerck U, Teschler H, Freitag L (2011) Bronchoscopically obtained volatile biomarkers in lung cancer. Lung, 189: 445 52.

Deal BE (1974) The current understanding of charges in the thermally oxidized silicon structure. J Electrochem Soc, 121: 198C - 205C.

Delen FM, Sippel JM, Osborne ML, Law S, Thukkani N, Holden WE (2000) Increased exhaled nitric oxide in chronic bronchitis - Comparison with asthma and COPD. Chest, 117: $695-701$.

Dettmer K and Engewald W (2002) Adsorbent materials commonly used in air analysis for adsorptive enrichment and thermal desorption of volatile organic compounds. Anal Bioanal Chem, 373: 490 - 500.

Deng C, Zhang J, Yu X, Zhang W, Zhang X (2004) Determination of acetone in human breath by gas chromatography-mass spectrometry and solid-phase microextraction with on-fiber derivatization. J Chromatogr B: Anal Technol Biomed Life Sci, 810: 269 - 275.

Dhooghe F, Amelynck C, Rimetz-Planchon J, Schoon N, Vanhaecke F (2009) Flowing afterglow selected ion flow tube (FA-SIFT) study of ion/molecule reactions in support of the detection of biogenic alcohols by medium-pressure chemical ionization mass spectrometry techniques, Int J Mass Spectrom, 285: 31 - 41.

Dominioni L, Imperatori A, Rovera F, Ochetti A, Torrigiotti G, Paolucci M (2000) Stage I nonsmall cell lung carcinoma: analysis of survival and implications for screening Cancer, 89: 2334 - 2344.

Esterbauer H, Schaur RJ, Zollner H (1991) Chemistry and biochemistry of 4hydroxynonenal, malonaldehyde and related aldehydes. Free Radic Biol Med, 11: $81-128$.

Fleischer M, Simon E, Rumpel E, Ulmer H, Harbeck M, Wandel M, Fietzek C, Weimar U, Meixner H (2002) Detection of volatile compounds correlated to human diseases through breath analysis with chemical sensors. Sensors and Actuators B, 83: $245-249$.

Fu X, Li M, Biswas S, Nantz MH, Higashi RM (2011) A novel microreactor approach for analysis of ketones and aldehydes in breath Analyst, 136: 4662 - 4666.

Fuchs P, Loeseken C, Schubert JK, Miekisch W (2010) Breath gas aldehydes as biomarkers of lung cancer. Int J Cancer, 126: 2663 - 2670.

Fusaya M, Ohura MT, Suzuki M, Amagai T, Matsushita H (2004) Development of a highly sensitive method for determining atmospheric carbonyl compounds by passive sampling and application of the method to a survey of indoor air. Int $J$ Environ Anal Chem, 84: 1035 - 1044. 
Gilpin T, Apel E, Fried A, Wert B, Cakvert B, Zhang G, Duasgupta P (1997) Intercomparison of six ambient $\left[\mathrm{CH}_{2} \mathrm{O}\right]$ measurement techniques. $J$ Geophys Res, 102: $21161-21188$.

Gordon SM, Szidon JP, Krotoszynski BK, Gibbons RD, O'Neill HJ (1985) Volatile organic compounds in exhaled air from patients with lung cancer, Clin Chem, 31: $1278-1282$.

Grosjean D and Fung K (1982) Collection efficiencies of cartridges and micro-impingers for sampling of aldehydes in air as 2,4-dinitrophenylhydrazones. Anal Chem, 54: $1221-1224$.

Grosjean D, Grosjean E, Gertler AW (2001) On-road emissions of carbonyls from lightduty and heavy-duty vehicles. Environ Sci Technol, 35: 45 - 53.

Grosjean D, Grosjean E, Moreira LR (2002) Speciated ambient carbonyls in Rio de Janeiro, Brazil. Environ Sci Technol, 36: 1389 - 1395.

Guo H, Ling ZH, Cheung K, Wang DW, Simpson IJ, Blake DR (2013) Acetone in the atmosphere of Hong Kong: Abundance, sources and photochemical precursors. Atmos Environ, 65: 80 - 88.

Hakim M, Broza YY, Barash O, Peled N, Phillips M, Amann A, Haick H (2012) Volatile Organic Compounds of Lung Cancer and Possible Biochemical Pathways Chem Rev, 112: 5949 - 5966.

Hansel A, Jordan A, Holzinger R, Prazeller P, Vogel W, Lindinger W (1995) Proton transfer reaction mass spectrometry: on-line trace gas analysis at ppb level, Int $J$ Mass Spectrom Ion Proc, 149: 609 - 619.

Hryniuk A and Ross BM (2009) Detection of acetone and isoprene in human breath using a combination of thermal desorption and selected ion flow tube mass spectrometry. Int J Mass Spectrom, 285: 26 - 30.

Jemal A, Siegel R, Xu J, Ward E (2011) Cancer statistics, 2010. CA Cancer J Clin, 60: $277-300$.

Jakober CA, Robert MA, Riddle SG, Destaillats H, Charles MJ, Green PG, Kleeman MJ (2008) Carbonyl emissions from gasoline and diesel motor vehicles. Environ Sci Technol, 42: 4697 - 4703.

Kabir E, Kim K, Ahn J, Hong O, Sohn JR (2010) Barbecue charcoal combustion as a potential source of aromatic volatile organic compounds and carbonyls. $J$ Hazard Mat, 174: 492 - 499 .

Khyshiktyev BS, Khyshiktueva NA, Ivanov VN, Darenskaia SD, Novikov SV (1994) Diagnostic value of investigating exhaled air condensate in lung cancer. Vopr Onkol, 40: $161-164$. 
Kuwata K, Uebori M, Yamasaki H, Kuge Y, Kiso Y (1983) Determination of aliphaticaldehydes in air by liquid-chromatography. Anal Chem, 55: 2013 - 2016.

Laakso O, Haapala M, Jaakkola P, Laaksonen R, Nieminen J, Pettersson M, Rasanen M, Himberg JJ (2000) The use of low-resolution FT-IR spectrometry for the analysis of alcohols in breath. J Anal Toxicol, 24: $250-256$.

Lee TK, Murthy SRK, Cawley NX, Dhanvantari S, Hewitt SM, Lou H, Lau T, Ma S, Huynh T, Wesley RA, Ng IO, Pacak K, Poon RT, Loh YP (2011) An N-terminal truncated carboxypeptidase $\mathrm{E}$ splice isoform induces tumor growth and is a biomarker for predicting future metastasis in human cancers. J Clin Invest, 121: $880-892$.

Levin JO, Andersson K, Lindahl R, Nilsson CA (1985) Determination of sub-part-permillion levels of formaldehyde in air using active or passive sampling on 2,4dinitrophenylhydrazine-coated glass-fiber filters and high-performance liquidchromatography. Anal Chem, 57: $1032-1035$.

Lewis PR, Manginell PR, Adkins DR, Kottenstette RJ, Wheeler DR, Sokolowski SS, Trudell DE, Byrnes, JE, Okandan M, Bauer JM, Manley RG, Frye-Mason GC Recent Advancements in the Gas-Phase MicroChemLab. IEEE Sens J, 6: 784 795.

Li M, Biswas S, Nantz MH, Higashi RM, Fu X, (2012) Preconcentration and analysis of trace volatile carbonyl compounds. Anal Chem, 84: $1288-1293$.

List of Air Toxics in the 2005 NATA Assessment. http://www.epa.gov/nata2005/

Long EK, Picklo MJ (2010) Trans-4-hydroxy-2-hexenal, a product of n-3 fatty acid peroxidation: Make some room HNE... Free Radical Biology \& Medicine, 49: 1 -8 .

Machado RF, Laskowski D, Deffenderfer O, Burch T, Zheng S, Mazzone PJ, Mekhail T, Jennings C, Stoller JK, Pyle J, Duncan J, Dweik RA, Erzurum SC (2005) Detection of lung cancer by sensor array analyses of exhaled breath. Am J Respir Crit Care Med, 171: 1286 - 1291.

Manginell PR, Okandan M, Kottentstette RJ, Lewis PR, Adkins DR, Shul RJ, Bauer JM, Manley RG, Sokolowski SS (2003) Monolithically-integrated MicroChemLab for gas-phase chemical analysis. Proc.1-TAS 03, Transducers Research Foundation, San Diego, CA, USA, $1247-1250$.

Manini P, Andreoli R, Dall'Asta C, Galaverna G, Mutti A, Niessen WMA (2010) Evaluation of Alternate Isotope-Coded Derivatization Assay (AIDA) in the LCMS/MS analysis of aldehydes in exhaled breath condensate. $J$ Chromatogr $B, 878$ : $2616-2622$. 
Martin AN, Farquar GR, Jones AD, Frank M (2010) Human breath analysis: methods for sample collection and reduction of localized background effects. Anal Bioanal Chem, 396: 739 - 750 .

Mazzone PJ, Hammel J, Dweik R, Na J, Czich C, Laskowski D, Mekhail T (2007) Diagnosis of lung cancer by the analysis of exhaled breath with a colorimetric sensor array. Thorax, 62: $565-568$.

Mazzone PJ, Wang X, Xu Y, Mekhail T, Beukemann MC, Na J, Kemling JW, Suslick KS, Sasidhar M (2012) Exhaled breath analysis with a colorimetric sensor array for the identification and characterization of lung cancer. J Thorac Oncol, 7: 137 -142 .

Miekisch W, Kischkel S, Sawacki A, Liebau T, Mieth M, Schubert JK (2008) Impact of sampling procedures on the results of breath analysis. J Breath Res, 2: 026007.

Mieth M, Schubert JK, Groeger T, Sabel B, Kischkel S, Fuchs P, Hein D, Zimmermann R, Miekisch W (2010) Automated needle trap heart-cut GC/MS and needle trap comprehensive two-dimensional GC/TOF-MS for breath gas analysis in the clinical environment. Anal Chem, 82: 2541 - 2551.

Montuschi P, Kharitonov SA, Barnes PJ (2001) Exhaled carbon monoxide and nitric oxide in COPD. Chest 120: 496 - 501.

Pauling L, Robinson AB, Teranishi R, Cary P (1971) Quantitative analysis of urine vapor and breath by gas-liquid partition chromatography. Proc Natl Acad Sci USA 68: $2374-2376$.

Pawliszyn J and Arthur CL (1990) Solid-phase microextraction with thermal desorption using fused silica optical fibers. Anal Chem, 62: $2145-2148$.

Peng G, Hakim M, Broza YY, Billan S, Abdah-Bortnyak R, Kuten A, Tisch U, Haick H (2010) Detection of lung, breast, colorectal, and prostate cancers from exhaled breath using a single array of nanosensors. Br J Cancer, 103: 542 - 551

Peng G, Tisch U, Adams U, Hakim M, Shehada N, Broza YY, Billan S, Abdah-Bortnyak R, Kuten A, Haick H (2009) Diagnosing lung cancer in exhaled breath using gold nanoparticles. Nature Nanotechnol, 4: 669 - 673.

Phillips M, Altorki N, Austin JHM, Cameron RB, Cataneo RN, Kloss R, Wai J (2008) Detection of lung cancer using weighted digital analysis of breath biomarkers. Clin Chim Acta, 393: 76 - 84.

Phillips M, Cataneo RN, Condos R, Erickson GAR, Greenberg J, La Bomdardi V, Munawar MI, Tietje Olaf (2007) Volatile biomarkers of pulmonary tuberculosis in the breath. Tuberculosis, 87: $44-52$. 
Phillips M, Gleeson K, Hughes JMB, Greenberg J, Cataneo RN, Baker L, McVay P (1999) Volatile organic compounds in breath as markers of lung cancer: A crosssectional study, The Lancet 353: 1930 - 1933.

Plebani C, Tranfo G, Salerno A, Panebianco A, Marcelloni AM (1999) An optimized sampling and GC-MS analysis method for benzene in exhaled breath, as a biomarker for occupational exposure. Talanta 50: 409 - 412 .

Poli D, Carbognani P, Corradi M, Goldoni M, Acampa O, Balbi B, Bianchi L, Rusca M, Mutti A (2005) Exhaled volatile organic compounds in patients with non-small cell lung cancer: cross sectional and nested short-term follow-up study. Respir Res, 6: $71-81$.

Poli D, Goldoni M, Corradi M, Acampa O, Carbognani P, Internullo E, Casalini A, Mutti A (2010) Determination of aldehydes in exhaled breath of patients with lung cancer by means of on-fiber-derivatisation SPME-GC/MS. J Chromatogr B: Anal Technol Biomed Life Sci, 878: 2643 - 2651.

Preti GLJ, Kostelc JG, Aldinger S, Daniele R (1988) Analysis of lung air from patients with bronchogenic carcinoma and controls using gas chromatography-mass spectrometry. J Chromatogr, 432: 1 - 11 .

Pryor WA, Das B, Church DF (1991) The ozonation of unsaturated fatty-acids aldehydes and hydrogen-peroxide as products and possible mediators of ozone toxicity. Chem Res Toxicol, 4: $391-407$.

Psathakis K, Papatheodorou G, Plataki M, Panagou P, Loukides S, Siafakas NM, Bouros D (2004) 8-Isoprostane, a marker of oxidative stress, is increased in the expired breath condensate of patients with pulmonary sarcoidosis. Chest 125: 1005 - 1011.

Pysanenko A, Spanel P, Smith D (2008) A study of sulfur-containing compounds in mouth- and nose-exhaled breath and in the oral cavity using selected ion flow tube mass spectrometry. J Breath Res, 2: 046004.

Riahi Y, Cohen G, Shamni O, Sasson S (2010) Signaling and cytotoxic functions of 4hydroxyalkenals Am J Physiol Endocrinol Metab, 299: E879 - E886.

Riemer DD, Pos W, Milne P, Farmer C, Zika R, Apel EC, Olszyna K, Kliendienst T, Lonneman W, Bertman S, Shepson P, Starn T (1998) Observations of nonmethane hydrocarbons and oxygenated volatile organic compounds at a rural site in the southeastern United States. J Geophys Res, 103: $28111-28128$.

Risby TH and Solga SF (2006) Current status of clinical breath analysis. Appl Phys B, 85: $421-426$.

Roeck F, Sarsan N, Weimar U (2008) Electronic nose: Current status and future trends. Chem Rev, 108: 705 - 725 . 
Savage N, (2011) EARLY DETECTION: Spotting the first signs. Nature, 471: S14 - S15.

Savelev SU, Perry JD, Bourke SJ, Jary H, Taylor, Fisher AJ, Corris PA, Petrie M, De Soyza A (2011) Volatile biomarkers of Pseudomonas aeruginosa in cystic fibrosis and noncystic fibrosis bronchiectasis. Lett Appl Microbiol, 52: 610 - 613.

Schauer JJ, Kleeman MJ, Cass GR, Simoneit BRT (1999) Measurement of emissions from air pollution sources. 2. C-1 through C-30 organic compounds from medium duty diesel trucks. Environ Sci Technol, 33: 1578 - 1587.

Schauer JJ, Kleeman MJ, Cass GR, Simoneit BRT (2001) Measurement of emissions from air pollution sources. 3. C-1-C-29 organic compounds from fireplace combustion of wood. Environ Sci Technol, 35: 1716 - 1728.

Schumann C, Triantafilou K, Krueger S, Hombach V, Triantafilou M, Becher G, Lepper PM (2006) Detection of erythropoietin in exhaled breath condensate of nonhypoxic subjects using a multiplex bead array. Mediat Inflamm, 2006: $1-5$.

Schwarz K, Filipiak W, Amann A (2009) Determining concentration patterns of volatile compounds in exhaled breath by PTR-MS. J Breath Res, 3: $1-15$.

Scotter JM, Langford VS, Wilson PF, McEwan MJ, Chambers ST (2005) Real-time detection of common microbial volatile organic compounds from medically important fungi by Selected Ion Flow Tube-Mass Spectrometry (SIFT-MS). $J$ Microbiol Meth, 63: 127 - 134.

Sive BC, Zhou Y, Troop D, Wang Y, Little WC, Wingenter, OW, Russo RS, Varner RK, Talbot R (2005) Development of a cryogen-free concentration system for measurements of volatile organic compounds. Anal Chem, 77: 6989-6998.

Snell N and Newbold P (2008) The clinical utility of biomarkers in asthma and COPD. Curr Opin Pharmacol, 8: 222-235.

Spanel P, Dryahina K, Smith D (2006) A general method for the calculation of absolute trace gas concentrations in air and breath from selected ion flow tube mass spectrometry data. Int J Mass Spectrom, 249: 230 - 239.

Svensson S, Larstad M, Broo K, Olin AC (2007) Determination of aldehydes in human breath by on-fibre derivatization, solid-phase microextraction and GC-MS, $J$ Chromatogr B: Anal Technol Biomed Life Sci, 860: 86 - 91.

Tian WC, Chan HKL, Lu CJ, Pang SW, Zellers ET (2005) Multiple-Stage Microfabricated Preconcentrator-Focuser for Micro Gas Chromatography System. J Microelectromech Syst, 14: 498 - 506.

Uchiyama S, Ando M, Aoyagi S (2003) Isomerization of aldehyde-2,4dinitrophenylhydrazone derivatives and validation of high-performance liquid chromatographic analysis. J Chromatogr A, 996: 95 - 102. 
Ueta I, Saito Y, Hosoe M, Okamoto M, Ohkita H, Shirai S, Tamura H, Jinno K (2009) Breath acetone analysis with miniaturized sample preparation device: In-needle preconcentration and subsequent determination by gas chromatography-mass spectroscopy, J Chromatogr B: Anal Technol Biomed Life Sci, 877: 2551 - 2556.

Uebori M and Imamura K (2004) Analysis of aliphatic and aromatic carbonyl compounds in ambient air by LC/MS/MS. Anal Sci, 20: $1459-1462$.

Voiculescu I, Zaghloul M, Harasimhan N (2008) Microfabricated chemical preconcentrators for gas-phase microanalytical detection systems. Trends Anal Chem, 27: $327-343$.

Wang B, Lee SC, Ho KF (2007) Characteristics of carbonyls: Concentrations and source strengths for indoor and outdoor residential microenvironments in China. Atmos Environ, 41: 2851 - 2861.

Wang Y, Hu Y, Wang D, Yu K, Wang L, Zou Y, Zhao C, Zhang X, Wang P, Ying K (2012) The analysis of volatile organic compounds biomarkers for lung cancer in exhaled breath, tissues and cell lines. Cancer Biomarkers, 11: 129 - 137.

Wehinger A, Schmid A, Mechtcheriakov S, Ledochowski M, Grabmer C, Gastl GA, Amann A (2007) Lung cancer detection by proton transfer reaction massspectrometric analysis of human breath gas, International Journal of Mass Spectrometry, 265: 49 - 59 .

Xiong D, Cheng J, Li H, Deng W, Ye K (2010) Anodic bonding of glass-ceramics to stainless steel coated with intermediate $\mathrm{SiO}_{2}$ layer. Microelec Eng, 87: 1741 1746.

Yuan B, Chen W, Shao M, Wang M, Lu S, Wang B, Liu Y, Chang C, Wang B (2012) Measurements of ambient hydrocarbons and carbonyls in the Pearl River Delta (PRD), China. Atmos Res, 116: 93 - 104.

Zhao H, Ge Y, Hao C, Han X, Fu M, Yu L, Shah AN (2010) Carbonyl compound emissions from passenger cars fueled with methanol/gasoline blends. Sci Tot Envrion, 408: 3607 - 3613. 


\title{
CURRICULUM VITAE
}

\author{
NAME: $\quad$ Mingxiao Li \\ ADDRESS: $\quad 3400$ Fountain Dr. Apt. 3 \\ Louisville, KY, 40218 \\ EDUCATION: $\quad$ University of Louisville, Louisville, KY 2009-2013 \\ Doctor of Philosophy in Chemical Engineering \\ Thesis Title: "A Microreator Approach for Chemoselective \\ Capture and Analysis of Carbonyl Compounds in Air and Exhaled \\ Breath" \\ Tsinghua University, Beijing, China 2004-2008 \\ Bachelor of Science in Chemical Engineering \\ Thesis Title: "Fabrication of Encapsulated Phase-Change Materials \\ with Emulsifier-free Emulsion" \\ EXPERIMENTAL \\ SKIILS: \\ Microfabrication: Mask design and write, Photolithography, \\ Front and back optical alignment, Wet etching, RIE, DRIE, E- \\ beam evaporator, PECVD, ALD, Sputtering, Oxidation, Diffusion, \\ Anodic bonding. \\ Metrology: EDAX, XRD, XPS, AFM, STM, Dektak surface \\ profilermeter, Thin film stress measurement, Raman spectrum, \\ SEM. \\ Chemical Analysis Techniques: GC-MS, FTICR-MS, DSC, \\ FTIR. \\ Statistics Software: Matlab, MathCAD, Maple, JMP. \\ Modeling \& Design Software: COMSOL, CoventorWare, L-edit. \\ PUBLICATIONS: $\quad$ M. Li, S. Biswas, M. H. Nantz, R. M. Higashi and X. Fu, "A \\ microfabricated preconcentration device for breath analysis", \\ Sensors and Actuators B: Chemical, 2013, 180, 130-136.
}


K. Miller, M. Li, K. M. Walsh and X. Fu, "The effects of DRIE operational parameters on vertically aligned micropillar arrays", Journal of Micromechanics and Microengineering, 2013, 23, 35-39.

M. Li, S. Biswas, M. H. Nantz, R. M. Higashi and X. Fu, "Preconcentration and Analysis of Trace Volatile Carbonyl Compounds", Analytical Chemistry, 2012, 84, 1288-1293.

X. Fu, M. Li, S. Biswas, M. H. Nantz and R. M. Higashi, "A novel microreactor approach for analysis of ketones and aldehydes in breath", Analyst, 2011, 136, 4662-4666. 